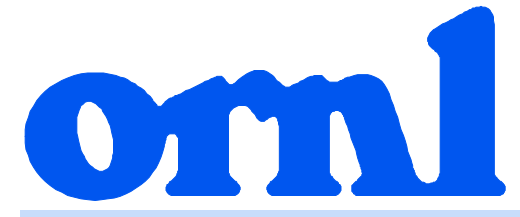

OAK RIDGE NATIONAL LABORATORY

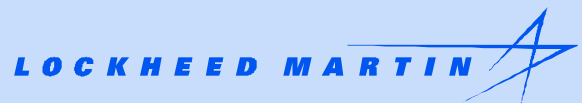

MANAGED AND OPERATED BY

LOCKHEED MARTIN ENERGY RESEARCH CORPORATION FOR THE UNITED STATES

DEPARTMENT OF ENERGY

\section{Simulation of Low-Enriched Uranium (LEU) Burnup in Russian VVER Reactors with the HELIOS Code Package}

\author{
B. D. Murphy ${ }^{*}$ \\ J. Kravchenko* \\ A. Lazarenko* \\ A. Pavlovitchev ${ }^{\star *}$ \\ V. Sidorenko ${ }^{* *}$ \\ A. Chetverikov ${ }^{\dagger}$
}

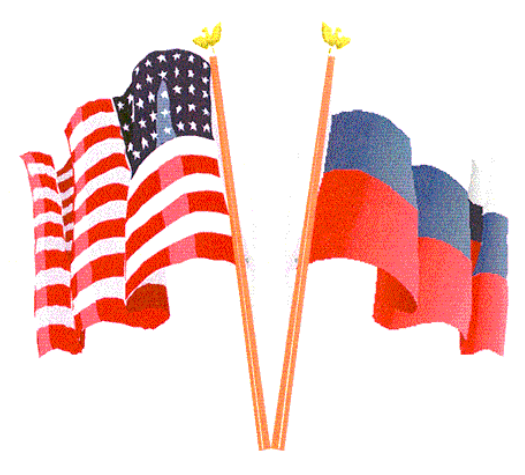

Fissile Materials Disposition Program

${ }^{*}$ Oak Ridge National Laboratory

${ }^{* *}$ Russian Research Center (Kurchatov Institute)

'State Scientific Center Research Institute of Atomic Reactors, Moscow 
This report has been reproduced directly from the best available copy.

Available to DOE and DOE contractors form the Office of Scientific and Technical Information, P.O. Box 62, Oak Ridge, TN 37831; prices available from (615) 576-8401.

Available to the public from the National Technical Information Service, U.S. Department of Commerce, 5285 Port Royal Rd., Springfield, VA 22161.

This report was prepared as an account of work sponsored by an agency of the United States Government. Neither the United States nor any agency thereof, nor any of their employees, makes any warranty, express or implied, or assumes any legal liability or responsibility for the accuracy, completeness, or usefulness of any information, apparatus, product, or process disclosed, or represents that its use would not infringe privately owned rights. Reference herein to any specific commercial product, process, or service by trade name, trademark, manufacturer, or otherwise, does not necessarily constitute or imply its endorsement, recommendation, or favoring by the United States Government or any agency thereof. The views and opinions of authors expressed herein do not necessarily state or reflect those of the United States Government or any agency thereof. 
Computational Physics and Engineering Division

\section{Simulation of Low-Enriched Uranium (LEU) Burnup in Russian VVER Reactors with the HELIOS Code Package}

B. D. Murphy*

J. Kravchenko**

A. Lazarenko**

A. Pavlovitchev ***

V. Sidorenko**

A. Chetverikov ${ }^{\mathrm{H}}$

Date Published: March 2000

*Oak Ridge National Laboratory

${ }^{* *}$ Russian Research Center (Kurchatov Institute)

HState Scientific Center Research Institute of Atomic Reactors, Moscow

Prepared by the

OAK RIDGE NATIONAL LABORATORY

P.O. Box 2008

Oak Ridge, Tennessee 37831-6370

managed by

LOCKHEED MARTIN ENERGY RESEARCH CORP.

for the

U.S. DEPARTMENT OF ENERGY

under contract DE-AC05-96OR22464 



\section{CONTENTS}

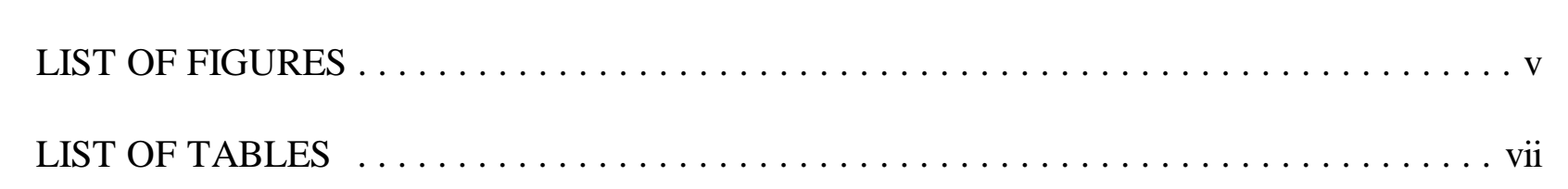

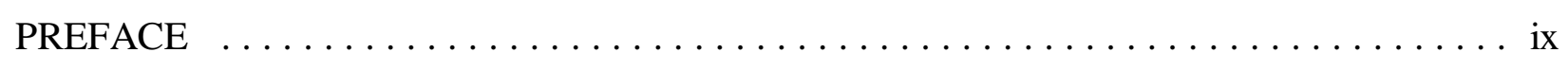

ACKNOWLEDGMENTS $\ldots \ldots \ldots \ldots \ldots \ldots \ldots \ldots \ldots \ldots \ldots \ldots \ldots \ldots \ldots \ldots$

ABSTRACT $\ldots \ldots \ldots \ldots \ldots \ldots \ldots \ldots \ldots \ldots \ldots \ldots \ldots \ldots \ldots \ldots \ldots \ldots \ldots \ldots \ldots$

1. INTRODUCTION . . . . . . . . . . . . . . . . . . . . . .

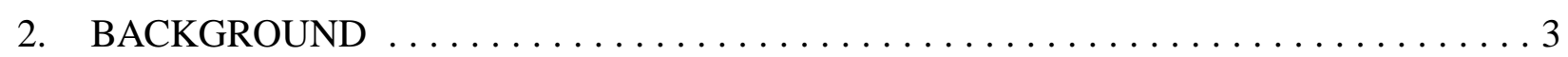

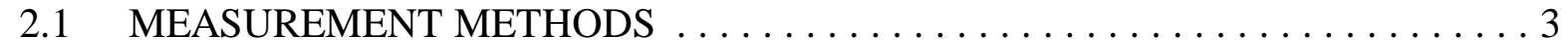

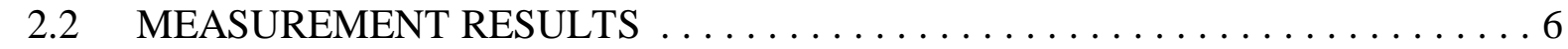

2.3 SIMULATIONS $\ldots \ldots \ldots \ldots \ldots \ldots \ldots \ldots \ldots \ldots \ldots \ldots \ldots \ldots$

$2.4 \quad$ BURNUP AND IRRADIATION HISTORY $\ldots \ldots \ldots \ldots \ldots \ldots \ldots \ldots \ldots \ldots$

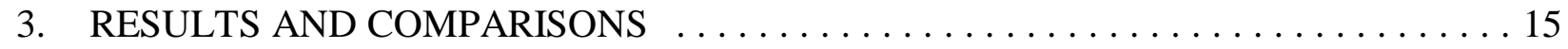

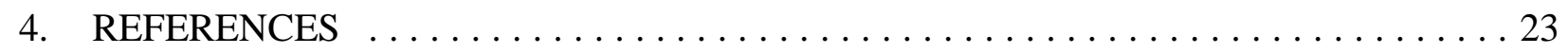

APPENDIX A C DESCRIPTIONS AND DATA TRANSMITTED FROM THE
KURCHATOV INSTITUTE TO OAK RIDGE NATIONAL LABORATORY $\ldots \ldots . .25$

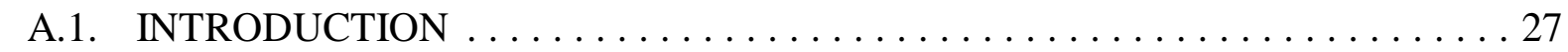

A.2. FUEL CHARACTERISTICS AND IRRADIATION HISTORY . . . . . . . . . 27

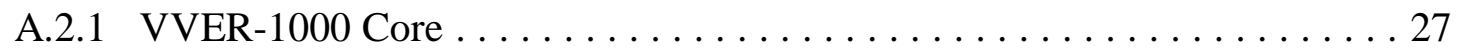

A.2.2 Fuel Assemblies Investigated . . . . . . . . . . . . . . . . . . 27

A.2.2.1 Fuel assembly ED-0623 (Kalinin-1. cycle 5) . . . . . . . . . . . . . . 29

A.2.2.2 Fuel assembly ED-1476 (Balakovo-2, cycles 3-5) . . . . . . . . . 30

A.2.2.3 Fuel assembly E-1591 (Balakovo-3, cycles 2-4) . . . . . . . . 32

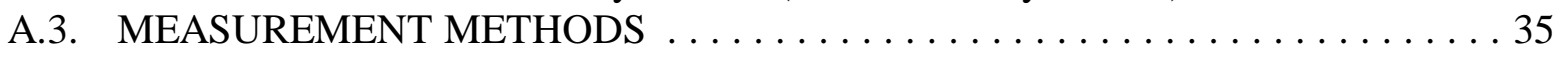

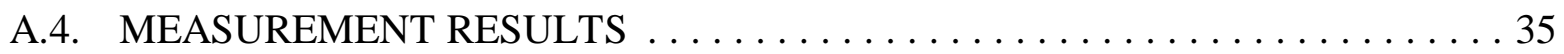

A.5. BENCHMARK PROBLEM FORMULATION . . . . . . . . . . . . . . . 35

A.5.1 Influence of Various Operational Parameters on Nuclide Content . . . . . 35

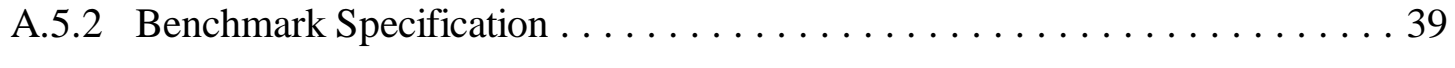


APPENDIX B C HELIOS INPUT INSTRUCTIONS USED IN SIMULATIONS _ . . . . . . 43

B.1. HELIOS INPUT FOR SIX LEU SAMPLES . . . . . . . . . . . . . . . . . . 45

LISTING No. 1; THE HELIOS INPUT FOR SAMPLE 33 IN KALININ-1: . . . . 46

LISTING No. 2; THE HELIOS INPUT FOR SAMPLE 448 IN KALININ-1: . . . . 51

LISTING No. 3; THE HELIOS INPUT FOR SAMPLE 6 IN BALAKOVO-2: . . . . 56

LISTING No. 4; THE HELIOS INPUT FOR SAMPLE 15 IN BALAKOVO-2: . . 61

LISTING No. 5; THE HELIOS INPUT FOR SAMPLE 912 IN BALAKOVO-3: 66

LISTING No. 6; THE HELIOS INPUT FOR SAMPLE 581 IN BALAKOVO-3: . 71 


\section{LIST OF FIGURES}

Figure

Page

1. Simplified design of the fuel assemblies ED-0623 and ED-1476 showing the locations of

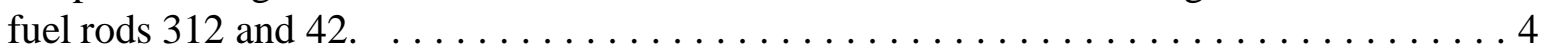

2. Simplified design of the fuel assembly E-1591 showing the locations of fuel rod 23. . . . 5

3. The triangular section of a VVER assembly that was modeled with HELIOS. . . . . . . 9

4. Calculated-to-experiment ratios for Sample 33 from Rod 312 exposed in Kalinin-1. The burnup used in the simulation was $13,660 \mathrm{MWd} / \mathrm{t} . \ldots \ldots \ldots \ldots \ldots$

\$. Calculated-to-experiment ratios for Sample 448 from Rod 312 exposed in Kalinin-1. The burnup used in the simulation was $15,632 \mathrm{MWd} / \mathrm{t} . \ldots \ldots \ldots \ldots \ldots \ldots$

6. Calculated-to-experiment ratios for Sample 6, Rod 42 exposed in Balakovo-2. The burnup for the simulation was $46,200 \mathrm{MWd} / \mathrm{t}$. . . . . . . . . . . . . . . . . . . . 19

7. Calculated-to-experiment ratios for Sample 15, Rod 42 exposed in Balakovo-2.

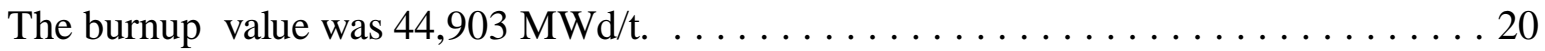

8. Calculated-to-experiment ratios for Sample 912, Rod 23 exposed in Balakovo-3. Burnup for the simulation was $45,600 \mathrm{MWd} / \mathrm{t} . \ldots \ldots \ldots \ldots \ldots \ldots \ldots \ldots \ldots \ldots$

9. Calculated-to-experiment ratios for Sample 581, Rod 23 exposed in Balakovo-3. Burnup for the simulation was 47,318 MWd/t.

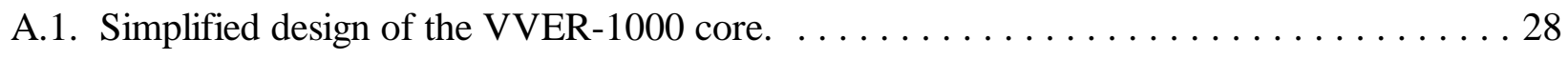

A.2. Kalinin-1 core loading pattern, cycle 5 (60E symmetry sector). Burnup distribution

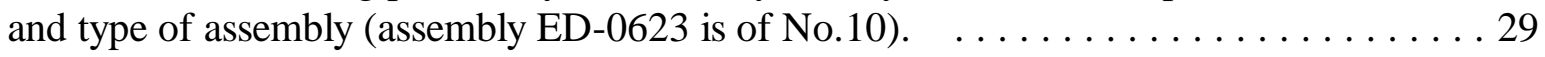

A.3. Balakovo-2 core loading pattern, cycle 3 (60E symmetry sector). Burnup distribution and type of assembly (assembly ED-1476 is of No. 24) . . . . . . . . . 31

A.4. Balakova-2 core loading pattern, cycle 4 (60E symmetry sector). Burnup distribution and type of assembly (assembly ED-1476 is of No. 19) . . . . . . . . . 31 


\section{LIST OF FIGURES (continued)}

A.5. Balakovo-2 core loading pattern, cycle 5 ( $60 \mathrm{E}$ symmetry sector). Burnup distribution and type of assembly (assembly ED-1476 is of No. 14) . . . . . . . . 32

A.6. Balakovo-3 core loading pattern, cycle 2 (60E symmetry sector). Burnup distribution and type of assembly (assembly E-1591 is of No. 27). . . . . . . . 33

A.7. Balakovo-3 core loading pattern, cycle 3 (60E symmetry sector). Burnup distribution and type of assembly (assembly E-1591 is of No. 12). . . . . . . . . 34

A.8. Balakovo-3 core loading pattern, cycle 4 (60E symmetry sector). Burnup distribution and type of assembly (assembly E-1591 is of No. 19). 


\section{LIST OF TABLES}

Table

Page

1. Nuclide concentrations in spent fuel $(\mathrm{kg} / \mathrm{t}$ initial uranium $) \ldots \ldots \ldots \ldots \ldots \ldots \ldots$

2. Dimensions of VVER-1000 reactor components $\ldots \ldots \ldots \ldots \ldots \ldots \ldots \ldots \ldots$

3. Composition of materials in a VVER-1000 fuel assembly $\ldots \ldots \ldots \ldots \ldots \ldots \ldots \ldots$

4. Irradiation histories for the VVER samples $\ldots \ldots \ldots \ldots \ldots \ldots \ldots \ldots \ldots$

5. $\quad$ Other relevant irradiation parameters for VVER samples $\ldots \ldots \ldots \ldots \ldots \ldots \ldots \ldots$

6. Summary of $\mathrm{C} / \mathrm{E}$ values for VVER LEU samples $\ldots \ldots \ldots \ldots \ldots \ldots \ldots \ldots$

A.1. The irradiation history of the fuel assembly ED-0623 $\ldots \ldots \ldots \ldots \ldots \ldots \ldots$

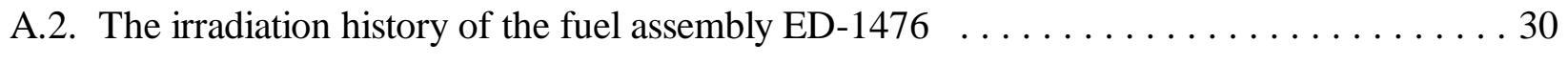

A.3. The irradiation history of the fuel assembly E-1591 $\ldots \ldots \ldots \ldots \ldots \ldots \ldots \ldots \ldots$

A.4. Peak and average fuel burnups (MWd/kg initial $\mathrm{U})$ and axial pin ${ }^{137} \mathrm{Cs}$ peaking

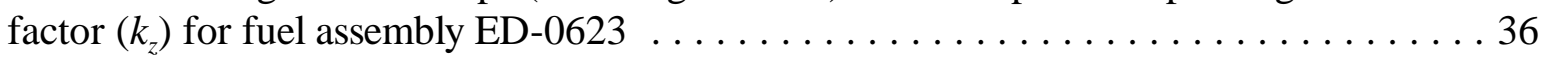

A.5. Peak and average fuel burnups (MWd/kg initial $\mathrm{U})$ and axial pin ${ }^{13 /} \mathrm{Cs}$ peaking

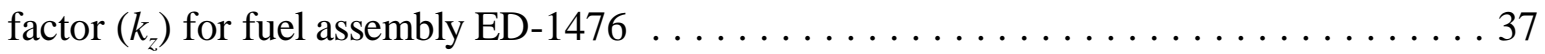

A.6. Peak and average fuel burnups (MWd/kg initial $\mathrm{U})$ and axial pin ${ }^{137} \mathrm{Cs}$ peaking

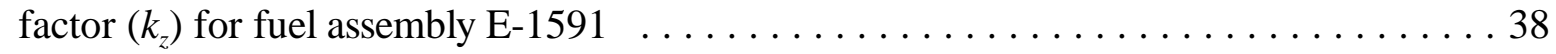

A.7. Nominal operating parameters of VVER-1000 fuel assembly $\ldots \ldots \ldots \ldots \ldots \ldots$. . . . 40

A.8. Sensitivity of nuclide content to irradiation conditions . $\ldots \ldots \ldots \ldots \ldots \ldots \ldots \ldots$

A.9. Irradiation conditions of investigated fuel assemblies $\ldots \ldots \ldots \ldots \ldots \ldots \ldots \ldots \ldots \ldots$ 



\section{PREFACE}

The work reported here was sponsored under the Fissile Materials Disposition Program in the U.S. Department of Energy. Program data were supplied to the Oak Ridge National Laboratory (ORNL) by the Russian Research Center, Kurchatov Institute. The transfer of these data to ORNL was facilitated by the efforts of Dr. A. Lazarenko at the Kurchatov Institute. This report has as its primary objective the documentation of the results of simulations performed at ORNL and their comparison with the results of chemical analyses carried out in Russia. In doing this, the main body of this document explains how ORNL made use of the information that was supplied. For completeness, the description that accompanied the data obtained from Russia is included in an appendix. As a result, the reader may notice a small amount of repetition between the main body of the report and the appendix. 



\section{ACKNOWLEDGMENTS}

This work was sponsored by the Fissile Materials Disposition Program, Office of Fissile Materials Disposition, United States Department of Energy.

While carrying out these studies the author benefitted from technical discussions on reactor

physics issues with R. Trent Primm III and technical discussions related to the HELIOS code system with Jess Gehin. 



\section{ABSTRACT}

The HELIOS reactor-physics computer program system was used to simulate the burnup of $\mathrm{UO}_{2}$ fuel in three VVER reactors. The manner in which HELIOS was used in these simulations is described. Predictions of concentrations for actinides up to ${ }^{244} \mathrm{Cm}$ and for isotopes of neodymium were compared with laboratory-measured values. Reasonable agreement between calculated and measured values was seen for experimental samples from a fuel rod in the interior of an assembly. Agreements were poorer for rods on the outside edge of an assembly 



\section{INTRODUCTION}

Post-irradiation data are available for three assemblies discharged from three Russian VVER-1000 reactors. These data were transmitted to the Oak Ridge National Laboratory (ORNL) by staff at the Russian Research Center, Kurchatov Institute. The three reactors are

1. Kalinin-1, located at Udamlya, Tver;

2. Balakovo-2, located at Balakovo, Saratov; and

3. Balakovo-3, also located at Balakovo, Saratov.

For each of the three assemblies (one from each of the three reactors), ORNL received analysis results for two samples. In the case of each assembly, both samples were located in the same fuel rod but at different heights (each one of the two samples would experience a different burnup). For all samples, measured concentration values were transmitted to ORNL for actinides from ${ }^{235} \mathrm{U}$ to ${ }^{244} \mathrm{Cm}$, as well as for neodymium isotopes with mass numbers 142 through 146 . All measured concentration values were taken at the end of irradiation.

These post-irradiation data offered an opportunity for ORNL to compare predictions of spent fuel composition with actual measurements. These comparisons are part of an ongoing effort at ORNL. In this particular instance, the opportunity to do comparison studies for VVER reactors was of special interest because plans are to dispose of weapons-useable plutonium in the Balakovo reactors. Work is being done at the Kurchatov Institute that compares the spent fuel measurements with simulations performed using Russian codes. The work to be reported below involves comparisons with the HELIOS ${ }^{1}$ code that has been in use at ORNL for about three years.

The main part of this report describes how the Russian data were employed and interpreted for burnup simulation and were compared with experimentally measured concentrations. For completeness, all data obtained from the Kurchatov Institute, together with the accompanying descriptive information, are reproduced in Appendix A. 



\section{BACKGROUND}

Among the six irradiated samples, the burnup conditions varied slightly with differences in fuel composition, location in the VVER assembly, and burnup amount.

The VVER-1000 reactor is a pressurized-light-water-moderated and cooled reactor with a power of $3000 \mathrm{MWth}$ (1000 MWe). The VVER-1000 standard core consists of 163 hexagonal fuel assemblies arranged in the hexagonal lattice with a lattice pitch of $23.6 \mathrm{~cm}$. A diagram of a VVER-1000 assembly is shown in Fig. 1. Each assembly contains $312 \mathrm{UO}_{2}$ fuel pins, 18 guide thimbles for control rods or burnable poisons and a central guide/instrumentation tube Ball arranged in a hexagonal lattice with a pitch of $1.275 \mathrm{~cm}$. The fuel rods are annular $\mathrm{UO}_{2}$ pellets with zirconium alloy cladding. In the Balakovo-3 assembly the fuel was of uniform composition, but in the other two assemblies the fuel enrichment was non-uniform. Uniform fuel assemblies are composed of 312 fuel pins of the appropriate enrichment. The non-uniform assemblies contained 246 pins with $4.4 \%{ }^{235} \mathrm{U}$ and 66 pins with $3.6 \%{ }^{235} \mathrm{U}$. Figure 1 hhows the locations of the 4.4-wt $\%{ }^{235} \mathrm{U}$ and the $3.6 \mathrm{wt} \%{ }^{235} \mathrm{U}$ for the cases of Kalinin-1 and Balakovo-2. Figure 2 is a diagram of the Balakovo-3 assembly, where all of the fuel rods contained 4.4-wt $\%{ }^{235} \mathrm{U}$. The captions for Figs. 1 and 2 also contain the reference numbers for the experimental assemblies to which they refer.

In the Kalinin-1 case, the sample rod was exposed for one reactor cycle and the sample burnups were estimated to be 13.7 and $15.6 \mathrm{GWd} / \mathrm{t}$. The Kalinin-1 fuel assembly is designated as ED-0623. The samples studied in the Kalinin-1 case are from one of the $3.6-\mathrm{wt} \%{ }^{235} \mathrm{U}$ rods on the periphery.

In the case of both Balakovo-2 and Balakovo-3, the samples were irradiated for three reactor cycles and all burnup values were estimated to be in the range of 44.9 and $47.3 \mathrm{GWd} / \mathrm{t}$. The Balakovo-2 fuel assembly is designated as ED-1476. The sample rod from this assembly is a 4.4wt $\%{ }^{235} \mathrm{U}$ rod from the interior region. The sample rod in the Balakovo-3 assembly (E-1591) was located at the periphery. The positions of the three rods that contained the samples are also shown in Figs. 1 and 2.

\subsection{MEASUREMENT METHODS}

Measurements were carried out using nondestructive and destructive methods. Axial ${ }^{137} \mathrm{Cs}$ distributions in fuel rods of the fuel assemblies investigated were measured by gamma scanning using a slit collimator and a gamma spectrometer. Nondestructive fuel burnup estimates were obtained by comparison of ${ }^{137} \mathrm{Cs}$ gamma count rates in fuel rods investigated and in a standard. Fission-product concentrations in the standard were measured by destructive methods. 


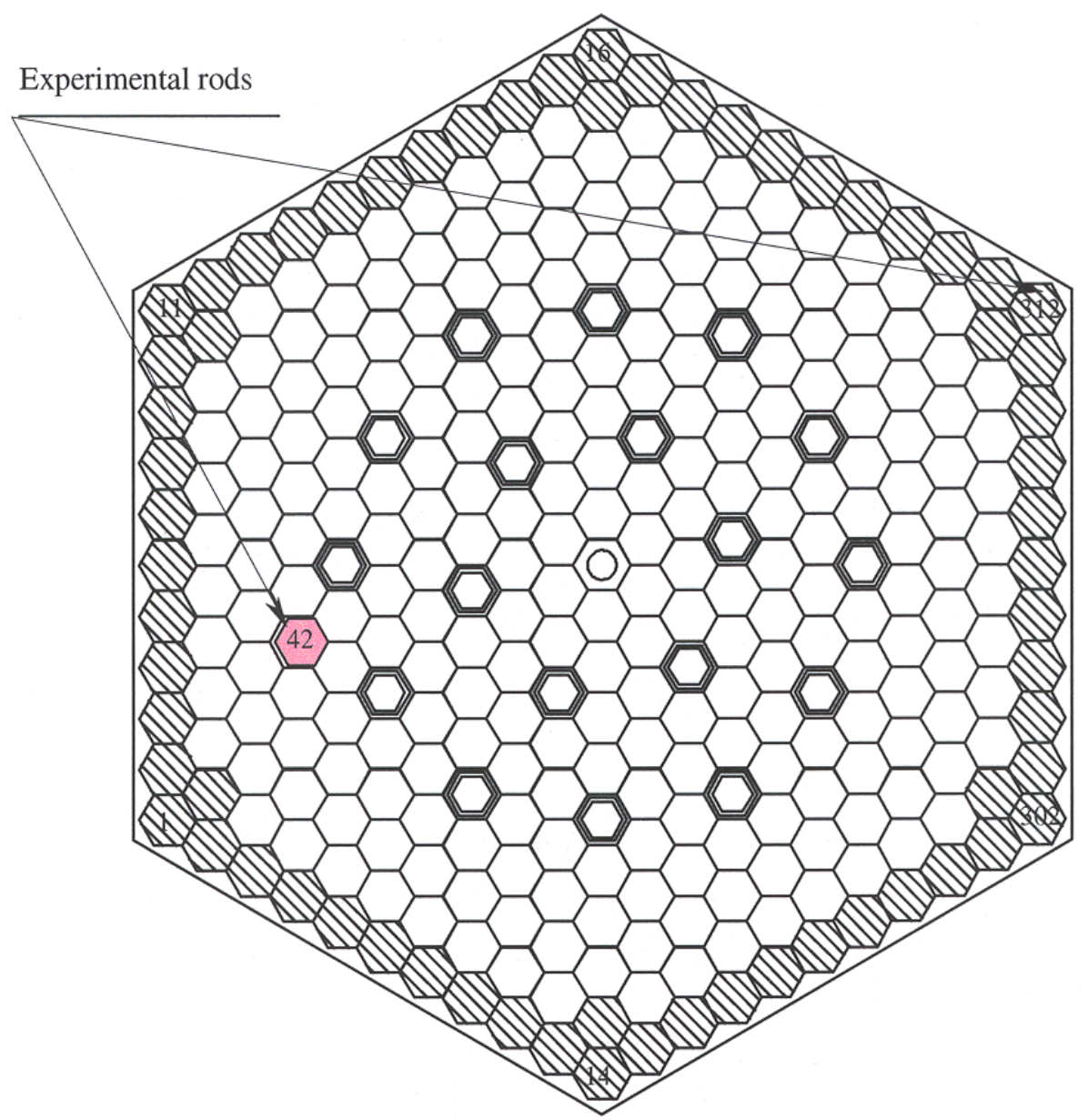

Fuel element, 3.6 w. $\%{ }^{235} \mathrm{U}$

Fuel element, 4.4 w.\% ${ }^{235} \mathrm{U}$

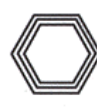

Guide tube with or without burnable absorbers

(O) Central tube

Fig. 1. Simplified design of the fuel assemblies ED-0623 and ED-1476 showing the locations of fuel rods 312 and 42. 


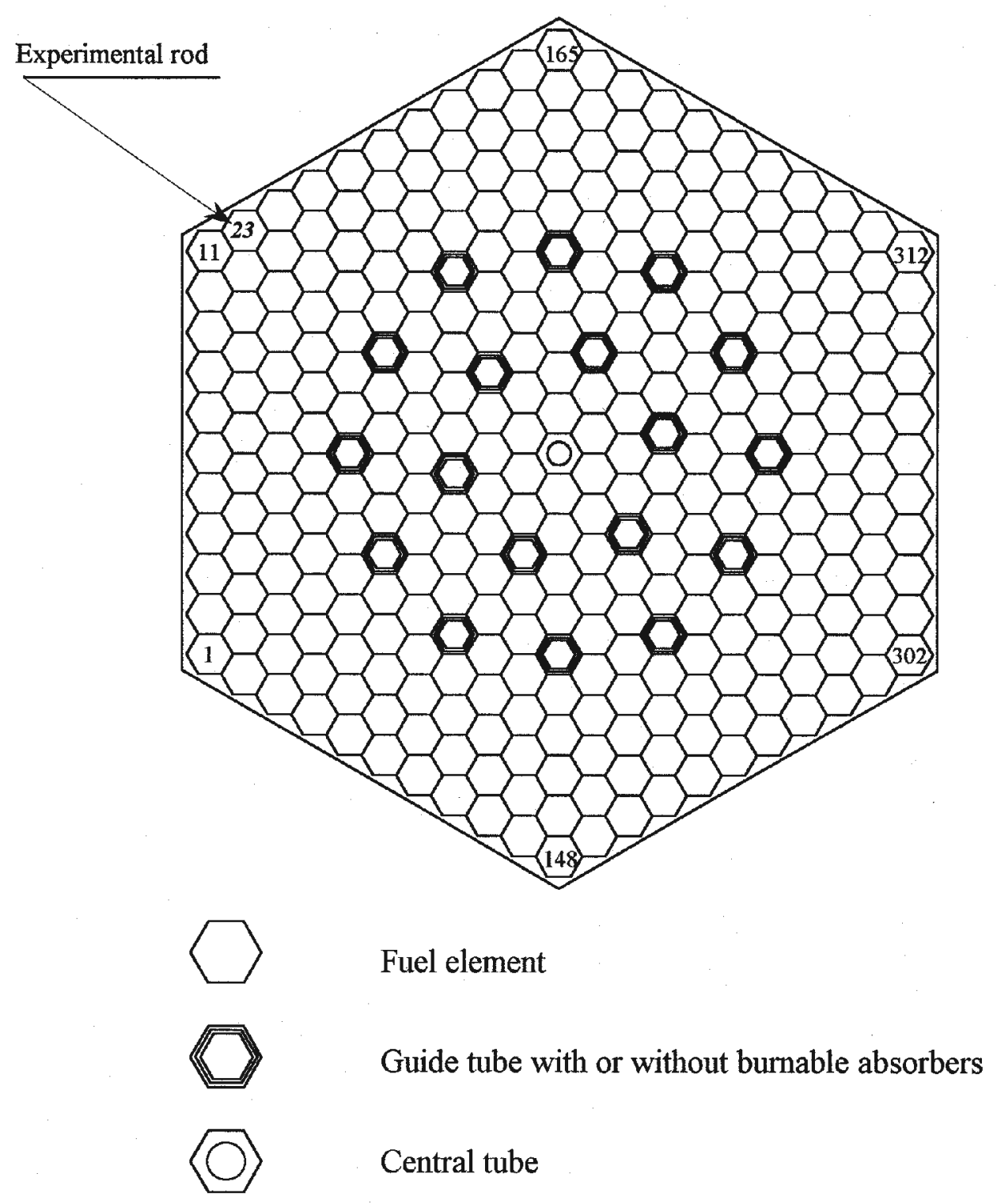

Fig. 2. Simplified design of the fuel assembly E-1591 showing the locations of fuel rod 23 . 
Fuel rods for destructive examination were selected on the basis of gamma-scanning (i.e., rods and sections of rod were identified that had roughly experienced the desired burnup). The 10-mmthick pellet samples were taken at different distances above the bottom of the fuel rods. The pellet samples were dissolved in $8 M$ nitric acid, and the separation of uranium, plutonium, americium, curium and neodymium was carried out using ion-exchange chromatography and extraction chromatography. Uranium, plutonium, americium and neodymium concentrations were measured by an isotope dilution technique in combination with mass-spectrometric analysis. Concentrations for

${ }^{238} \mathrm{Pu}$ and the curium isotopes were measured by a combination of alpha-spectrometry and massspectrometry. Fuel burnups were also estimated as part of the measurement program by examination of the build-up of ${ }^{145} \mathrm{Nd}+{ }^{146} \mathrm{Nd}$. The burnup values that were estimated in this manner are shown in Table 1. These burnup values (estimated from the measured concentrations) are slightly different from the burnup estimates used in the simulations. Furthermore, the former are given $\mathrm{kg} / \mathrm{t}$ initial uranium (in Table 1), whereas the latter are in $\mathrm{MWd} / \mathrm{t}$ initial heavy metal (see later discussions on HELIOS simulations).

\subsection{MEASUREMENT RESULTS}

In summary, actinide and neodymium concentration measurements were reported by the Kurchatov Institute for the six samples. The nuclides for which measurements were reported are the following:

Uranium: $\quad{ }^{235} \mathrm{U},{ }^{236} \mathrm{U},{ }^{238} \mathrm{U}$

Plutonium: $\quad{ }^{238} \mathrm{Pu},{ }^{239} \mathrm{Pu},{ }^{240} \mathrm{Pu},{ }^{241} \mathrm{Pu},{ }^{242} \mathrm{Pu}$

Americium: $\quad{ }^{241} \mathrm{Am},{ }^{243} \mathrm{Am}$

Curium: $\quad{ }^{242} \mathrm{Cm},{ }^{244} \mathrm{Cm}$

Neodymium: $\quad{ }^{142} \mathrm{Nd},{ }^{143} \mathrm{Nd},{ }^{144} \mathrm{Nd},{ }^{145} \mathrm{Nd},{ }^{146} \mathrm{Nd}$

In the case of the Kalinin-1 samples, no concentrations were reported for ${ }^{242} \mathrm{Cm}$.

Concentration values were reported as $\mathrm{kg} /$ tonne of initial uranium. The reported values are shown in Table 1. Nuclide concentrations in Table 1 refer to end of irradiation. Presumably, the measurements were carried out at some time after the end of irradiation and the end-of-irradiation values were estimated from these measurements. The reported uncertainties that are also shown in Table 1 refer to the $95 \%$ confidence limit. Extensive details of the measurement techniques were not reported. 
Table 1. Nuclide concentrations in spent fuel (kg/t initial uranium)

\begin{tabular}{|c|c|c|c|c|c|c|}
\hline Reactor & Kalinin-1 & Kalinin-1 & Balakovo-2 & Balakovo-2 & Balakovo-3 & Balakovo-3 \\
\hline assembly & ED-0623 & ED-0623 & ED-1476 & ED-1476 & E-1591 & E-1591 \\
\hline rod & 312 & 312 & 42 & 42 & 23 & 23 \\
\hline sample & 33 & 448 & 6 & 15 & 912 & 581 \\
\hline${ }^{235} \mathrm{U}$ & $23.42 \pm 0.09$ & $20.97 \pm 0.09$ & $10.27 \pm 0.07$ & $10.64 \pm 0.07$ & $10.18 \pm 0.07$ & $8.18 \pm 0.06$ \\
\hline${ }^{236} \mathrm{U}$ & $2.90 \pm 0.02$ & $3.20 \pm 0.02$ & $6.11 \pm 0.05$ & $6.17 \pm 0.04$ & $6.15 \pm 0.04$ & $6.34 \pm 0.05$ \\
\hline${ }^{238} \mathrm{U}$ & $962.98 \pm 0.08$ & $952.69 \pm 0.09$ & $925.18 \pm 0.08$ & $926.55 \pm 0.09$ & $925.48 \pm 0.09$ & $925.66 \pm 0.08$ \\
\hline${ }^{238} \mathrm{Pu}$ & $0.016 \pm 0.001$ & $0.022 \pm 0.001$ & $0.31 \pm 0.02$ & $0.30 \pm 0.01$ & $0.32 \pm 0.01$ & $0.33 \pm 0.02$ \\
\hline${ }^{239} \mathrm{Pu}$ & $4.75 \pm 0.03$ & $4.87 \pm 0.04$ & $6.10 \pm 0.05$ & $6.07 \pm 0.04$ & $6.26 \pm 0.05$ & $6.08 \pm 0.05$ \\
\hline${ }^{240} \mathrm{Pu}$ & $0.88 \pm 0.01$ & $1.05 \pm 0.01$ & $2.67 \pm 0.02$ & $2.58 \pm 0.02$ & $2.62 \pm 0.02$ & $2.68 \pm 0.02$ \\
\hline${ }^{241} \mathrm{Pu}$ & $0.42 \pm 0.01$ & $0.52 \pm 0.01$ & $1.76 \pm 0.02$ & $1.70 \pm 0.01$ & $1.76 \pm 0.02$ & $1.76 \pm 0.01$ \\
\hline${ }^{242} \mathrm{Pu}$ & $0.044 \pm 0.001$ & $0.068 \pm 0.001$ & $0.72 \pm 0.02$ & $0.69 \pm 0.01$ & $0.75 \pm 0.01$ & $0.88 \pm 0.01$ \\
\hline${ }^{241} \mathrm{Am}$ & $0.018 \pm 0.001$ & $0.025 \pm 0.001$ & $0.066 \pm 0.002$ & $0.048 \pm 0.002$ & $0.054 \pm 0.002$ & $0.071 \pm 0.002$ \\
\hline${ }^{243} \mathrm{Am}$ & $0.0027 \pm 0.0001$ & $0.0050 \pm 0.0001$ & $0.157 \pm 0.004$ & $0.141 \pm 0.004$ & $0.151 \pm 0.004$ & $0.192 \pm 0.005$ \\
\hline${ }^{242} \mathrm{Cm}$ & $--^{a}$ & $--^{a}$ & $0.024 \pm 0.002$ & $0.021 \pm 0.002$ & $0.021 \pm 0.002$ & $0.023 \pm 0.002$ \\
\hline${ }^{244} \mathrm{Cm}$ & $0.00039 \pm 0.00004$ & $0.00044 \pm 0.00004$ & $0.059 \pm 0.005$ & $0.055 \pm 0.006$ & $0.059 \pm 0.005$ & $0.079 \pm 0.007$ \\
\hline${ }^{142} \mathrm{Nd}$ & $0.0033 \pm 0.0001$ & $0.0043 \pm 0.0001$ & $0.034 \pm 0.001$ & $0.033 \pm 0.001$ & $0.034 \pm 0.001$ & $0.037 \pm 0.001$ \\
\hline${ }^{143} \mathrm{Nd}$ & $0.433 \pm 0.004$ & $0.482 \pm 0.004$ & $1.070 \pm 0.008$ & $1.053 \pm 0.008$ & $1.056 \pm 0.008$ & $1.099 \pm 0.009$ \\
\hline${ }^{144} \mathrm{Nd}$ & $0.483 \pm 0.005$ & $0.561 \pm 0.005$ & $1.821 \pm 0.012$ & $1.761 \pm 0.011$ & $1.797 \pm 0.010$ & $1.938 \pm 0.010$ \\
\hline${ }^{145} \mathrm{Nd}$ & $0.312 \pm 0.003$ & $0.351 \pm 0.003$ & $0.912 \pm 0.008$ & $0.889 \pm 0.006$ & $0.899 \pm 0.007$ & $0.922 \pm 0.007$ \\
\hline${ }^{146} \mathrm{Nd}$ & $0.271 \pm 0.003$ & $0.308 \pm 0.003$ & $0.975 \pm 0.008$ & $0.948 \pm 0.006$ & $0.961 \pm 0.008$ & $1.007 \pm 0.008$ \\
\hline Burnup & $14.3 \pm 0.2$ & $16.3 \pm 0.3$ & $46.7 \pm 0.7$ & $45.1 \pm 0.7$ & $46.2 \pm 0.7$ & $47.9 \pm 0.7$ \\
\hline
\end{tabular}

\footnotetext{
${ }^{a}$ Values were not reported.
} 


\subsection{SIMULATIONS}

The simulation results reported here were performed at ORNL using the code system HELIOS 1 This is a two-dimensional (2-D), current-coupling, collision-probability code. The version of HELIOS used in this work was HELIOS-1.4 and its associated nuclear data library based on ENDF-B/VI. HELIOS allows the user to define the components of a reactor assembly (or a whole reactor core) with varying degrees of complexity. Typically, the defining components in a HELIOS assembly will be the pin cells composed of fuel, clad and surrounding moderator. The fuel or the clad can be subdivided into zones, and the moderator region can be subdivided in numerous ways.

The VVER assemblies described here were modeled in the following manner: the fuel pellet was annular (i.e., it contained an inner void). The fuel itself was surrounded by a gap, and the gap was surrounded with cladding material. Thus, a fuel rod is defined by four zones: void, fuel, gap, and clad. The VVER pin cell is hexagonal and, therefore, the water moderator was divided into six regions surrounding the fuel pin.

Three types of pin cells are located in each VVER: the fuel pin cell, the burnable absorber pin cell, and a central water hole. Each of these was modeled with a central cylindrical section surrounded radially by six water regions. For the burnable absorber cell, the central cylindrical portion consists of absorber material followed by a gap, cladding, water, and a cylindrical guide tube. The circular part of the central water hole consists of water surrounded by a cylindrical guide tube.

Because of the symmetry of an assembly, the simulations can be carried out on a triangular section equal to one-sixth of the assembly, with the appropriate boundary conditions. Figure 3 is a diagram of a triangular section of a VVER-1000 assembly (one-sixth of the assembly) that was modeled with the HELIOS system. The locations of the fuel samples are shown as rods of a lighter shade. One of these fuel samples is in the bottom corner and is therefore shared by two adjacent triangular sections; as a result, half of it is shown in each bottom corner. Four burnable absorber pins are shown: two of these are in the interior, and two are on the edge of the triangular section. The ones on the edge are shared with adjacent triangular sections. In modeling this triangular section, only half of each pin on a border with another section is treated, and boundary conditions are imposed that match the edges that are connected to other similar triangular sections. The left-hand side of the triangular section shown lies along the right-hand side of a similar triangular section, and vice versa. The boundary conditions employed were to match the right-hand and left-hand boundaries (periodic) and to impose a white boundary condition on the third side that is to the outside of the assembly. The burnable absorber material consists of pellets containing natural boron in a matrix that is primarily composed of aluminum (as reported in Appendix A for the case of Balakovo-2, burnable absorber rods were present for only one cycle and the HELIOS model for Balakovo-2 reflected this fact). The dimensions of various VVER-1000 components are shown in Table 2. The material-composition data are shown in Table 3. 
The data in Tables 2 and 3 were used as input data for the HELIOS simulations. These data were transmitted to ORNL by the staff at the Kurchatov Institute. As regards Table 3, it is unlikely that the compositions of the various material are known with the precision implied by some of the weight percentages that are quoted. We surmise, rather, that because of the small percentages quoted for some of the minor elements, the unrealistic precision for the dominant elements is for purposes of producing a total of $100 \%$ (but note that, for the burnable-absorber material, the total is not quite 100).

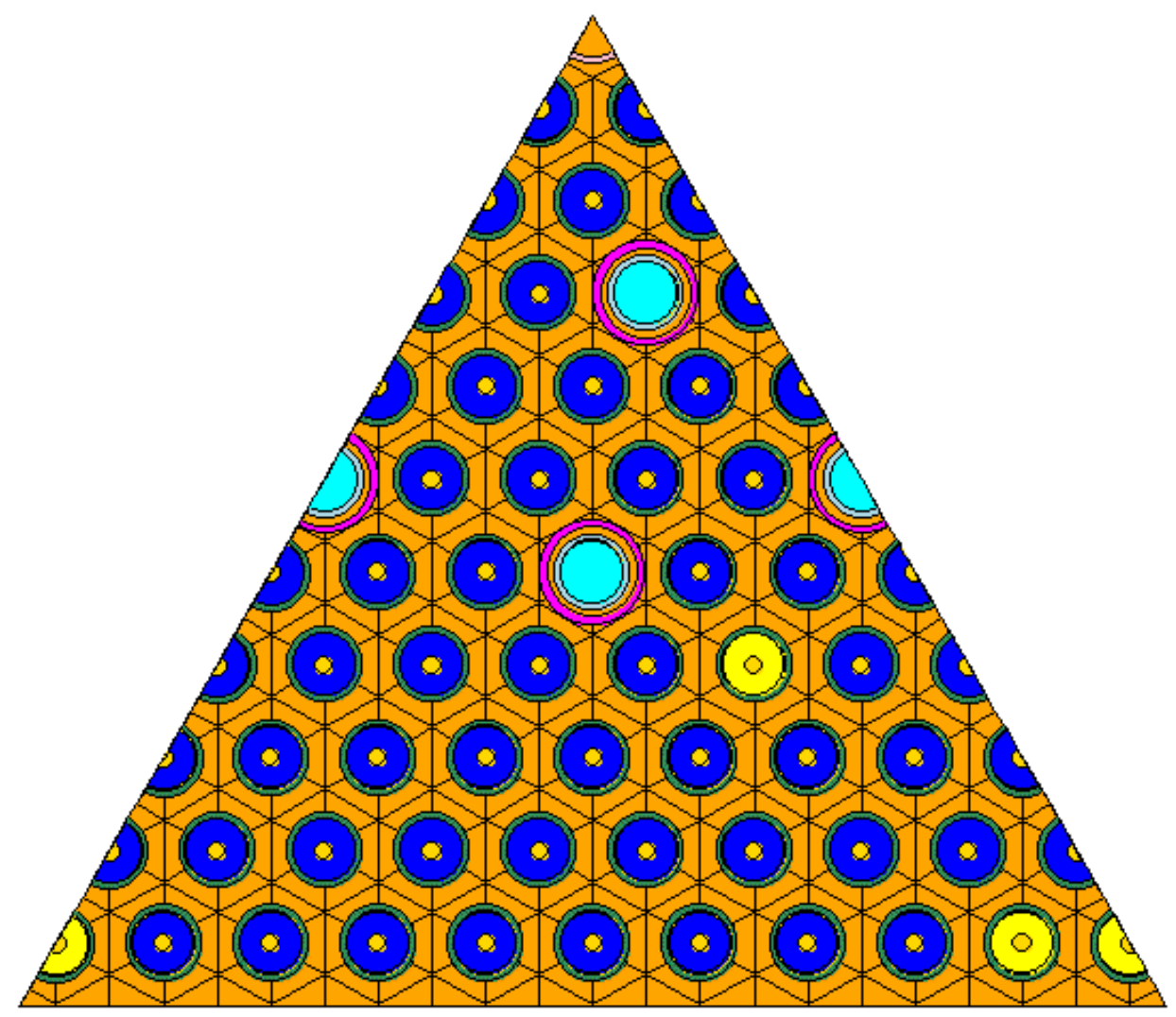

Fig. 3. The triangular section of a VVER assembly that was modeled with HELIOS. 
Table 2. Dimensions of VVER-1000 reactor components

\begin{tabular}{|c|c|c|}
\hline & Parameter & Value $(\mathrm{cm})$ \\
\hline \multirow[t]{8}{*}{1 . } & Fuel assembly: & \\
\hline & Distance across assembly (between flats) & 23.4 \\
\hline & Distance between fuel assembly centers & 23.6 \\
\hline & Fuel pin lattice pitch & 1.275 \\
\hline & Inner diameter of guide thimbles & 1.09 \\
\hline & Thickness of guide thimbles & 0.08732 \\
\hline & Central instrumentation tube inner diameter & 0.96 \\
\hline & Thickness of central instrumentation tube & 0.0826 \\
\hline \multirow[t]{6}{*}{2.} & Fuel rod: & \\
\hline & Inner clad diameter & 0.772 \\
\hline & Clad thickness & 0.07220 \\
\hline & Fuel pellet diameter & 0.755 \\
\hline & Central hole diameter & 0.23 \\
\hline & Height of fuel column & 355 (hot) \\
\hline \multirow[t]{4}{*}{3.} & Burnable absorber pin: & \\
\hline & Absorber diameter & 0.758 \\
\hline & Clad inner diameter & 0.772 \\
\hline & Clad thickness & 0.069 \\
\hline
\end{tabular}


Table 3. Composition of materials in a VVER-1000 fuel assembly

\begin{tabular}{|c|c|c|c|}
\hline & Isotope & $\begin{array}{l}\text { Weight } \\
\%\end{array}$ & $\begin{array}{l}\text { Concentration } \\
(\text { per barn } \mathrm{cm})\end{array}$ \\
\hline \multirow[t]{4}{*}{1.} & Fuel rod pellet: & & \\
\hline & ${ }^{235} \mathrm{U}$ & $4.4 / 3.6$ & $1.0068 \mathrm{E} ! 3 / 8.2378 \mathrm{E} ! 4$ \\
\hline & ${ }^{238} \mathrm{U}$ & $95.6 / 96.4$ & 2.1600E! 2/2.1781E! 2 \\
\hline & ${ }^{16} \mathrm{O}$ & $\mathrm{NA}^{a}$ & 4.5214E! 2/4.5210E! 2 \\
\hline \multirow[t]{9}{*}{2.} & Fuel rod cladding: & & \\
\hline & $\mathrm{Zr}$ & 94.21849 & $4.095 \mathrm{E} ! 2$ \\
\hline & $\mathrm{Nb}$ & 0.95199 & $4.062 \mathrm{E} ! 4$ \\
\hline & $\mathrm{Hf}$ & 0.02856 & $6.343 \mathrm{E} ! 6$ \\
\hline & $\mathrm{Fe}$ & 3.35491 & $2.382 \mathrm{E} ! 3$ \\
\hline & $\mathrm{Ni}$ & 0.50410 & $3.403 \mathrm{E} ! 4$ \\
\hline & $\mathrm{Cr}$ & 0.88818 & $6.772 \mathrm{E} ! 4$ \\
\hline & $\mathrm{Ti}$ & 0.04801 & $3.976 \mathrm{E} ! 5$ \\
\hline & $\mathrm{C}$ & 0.00576 & $1.902 \mathrm{E} ! 5$ \\
\hline \multirow[t]{8}{*}{3.} & Burnable absorber pellet: & & \\
\hline & B10 & 0.226 & $3.943 \mathrm{E} ! 4$ \\
\hline & B11 & 1.015 & $1.610 \mathrm{E} ! 3$ \\
\hline & $\mathrm{Al}$ & 91.742 & $5.933 \mathrm{E} ! 2$ \\
\hline & $\mathrm{Fe}$ & 0.192 & $5.999 \mathrm{E} ! 5$ \\
\hline & $\mathrm{Ni}$ & 1.915 & $5.689 \mathrm{E} ! 4$ \\
\hline & $\mathrm{Cr}$ & 2.992 & $1.004 \mathrm{E} ! 3$ \\
\hline & $\mathrm{Zr}$ & 1.915 & $3.663 \mathrm{E} ! 4$ \\
\hline \multirow[t]{4}{*}{4.} & Burnable absorber cladding: & & \\
\hline & $\mathrm{Zr}$ & 98.97 & 4.259E! 2 \\
\hline & $\mathrm{Nb}$ & 1.00 & $4.225 \mathrm{E} ! 4$ \\
\hline & Hf & 0.03 & $6.597 \mathrm{E} ! 6$ \\
\hline \multirow[t]{9}{*}{5 . } & Central instrumental tube: & & \\
\hline & $\mathrm{Zr}$ & 95.60715 & $4.143 \mathrm{E} ! 2$ \\
\hline & $\mathrm{Nb}$ & 0.96602 & $4.110 \mathrm{E} ! 4$ \\
\hline & Hf & 0.02898 & $6.418 \mathrm{E} ! 6$ \\
\hline & $\mathrm{Fe}$ & 2.37441 & $1.681 \mathrm{E} ! 3$ \\
\hline & $\mathrm{Ni}$ & 0.35677 & $2.402 \mathrm{E} ! 4$ \\
\hline & $\mathrm{Cr}$ & 0.62860 & 4.779E! 4 \\
\hline & $\mathrm{Ti}$ & 0.03398 & $2.806 \mathrm{E} ! 5$ \\
\hline & $\mathrm{C}$ & 0.00408 & $1.342 \mathrm{E} ! 5$ \\
\hline \multirow[t]{6}{*}{6 . } & Guide tube: & & \\
\hline & $\mathrm{Fe}$ & 69.88 & $5.933 \mathrm{E} ! 2$ \\
\hline & $\mathrm{Ni}$ & 10.5 & $8.477 \mathrm{E} ! 3$ \\
\hline & $\mathrm{Cr}$ & 18.5 & $1.687 \mathrm{E} ! 2$ \\
\hline & $\mathrm{Ti}$ & 1.0 & $9.904 \mathrm{E} ! 4$ \\
\hline & $\mathrm{C}$ & 0.12 & 4.737E! 4 \\
\hline
\end{tabular}

${ }^{a}$ Not applicable. For the fuel, weight percentages refer only to the uranium isotopes. 


\subsection{BURNUP AND IRRADIATION HISTORY}

Data were obtained for each cycle for which each sample was irradiated. This method allowed the determination of the total burnup of a sample and how that burnup was apportioned among cycles. The amount of burnup experienced by the samples is of prime importance in the prediction of final nuclide concentrations. Determining each sample's burnup can be difficult, and uncertainties in burnup are a serious hindrance when assessing the validity of a particular simulation approach because the process is reasonably sensitive to variations in burnup. $2^{2}$ The nuclide ${ }^{148} \mathrm{Nd}$ is

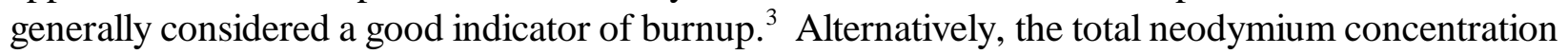
has been suggested as a burnup indicator 4 Burnup values were quoted for the samples; however, no ${ }^{148} \mathrm{Nd}$ concentrations were quoted. The ${ }^{145} \mathrm{Nd}$ and ${ }^{146} \mathrm{Nd}$ concentrations were reasonably well predicted when the reported burnup values were used. The ${ }^{142} \mathrm{Nd},{ }^{143} \mathrm{Nd}$, and ${ }^{144} \mathrm{Nd}$ concentrations, however, were not as well predicted. In the case of both Kalinin-1 samples, ${ }^{142} \mathrm{Nd}$ and ${ }^{144} \mathrm{Nd}$ were poorly predicted. On this basis it was decided to use the ${ }^{145} \mathrm{Nd}$ and ${ }^{146} \mathrm{Nd}$ concentrations as burnup indicators. The practical manner in which this was employed was to use a burnup value in each instance that produced a calculated-to-measured (experimental) value that was on average unity for ${ }^{145} \mathrm{Nd}$ and ${ }^{146} \mathrm{Nd}$.

The Kalinin-1 samples (assembly ED-0623) were irradiated for one reactor cycle C a cycle of 250 days duration. Consequently, the simulations employed a constant burnup, over 250 days that yielded the reported ${ }^{145} \mathrm{Nd}$ and ${ }^{146} \mathrm{Nd}$ concentrations. No doubt, the reactor power level varied during this cycle. However, in the absence of any data about such variations, a constant power level assumption is appropriate. Only in the case of extreme power variations and with short-lived nuclides might such an approach be inappropriate.

For Balakovo-2 and Balakovo-3 (assemblies ED-1476 and E-1591), irradiation was over three reactor cycles in all cases. An average power density was reported for each sample location and for each cycle for these irradiations. The length of each cycle was also reported. Thus, the irradiation histories for the Balakovo samples were constructed by requiring that (1) the ${ }^{145} \mathrm{Nd}$ and ${ }^{146} \mathrm{Nd}$ concentrations be used as indicators of total burnup, (2) each cycle be of the appropriate duration (and with the reported downtime between cycles), and (3) the power levels for the three cycles for any one sample be in the same ratios as the power densities reported.

Table 4 hows details of the irradiation history used in the HELIOS simulations. The sample burnup values shown in Table 4 are those that are based on the three criteria above. In all cases the cumulative burnup at the end of the relevant cycle is indicated. Burnups are shown in units of megawatt days per tonne of heavy metal. These units must be used when exercising HELIOS (the burnup values obtained from staff at the Kurchatov Institute were in units of $\mathrm{kg} /$ tonne of initial uranium). Furthermore, when executing HELIOS, the burnup values that are input to the model are those for the structure that is being simulated. These structure burnup values are also shown in Table 4. The burnup at the sample location is obtained as part of the HELIOS output. Because the structure being modeled refers to the axial position of the sample, the structure burnup values for two samples on the same rod will be different. Note that for the internal rod (42), structure burnup values are greater than sample burnup values and for rods on the periphery; structure burnup values are less. This situation is what one might expect. The cycle lengths are shown in days, and the downtime shown with each cycle is the downtime at the end of that particular cycle before the next cycle begins. Thus, no downtime is shown for the final cycle of each irradiation (the reported concentrations refer 
to the end of irradiation, and no information was available as to when the actual measurements were carried out). The cycle numbers are those used by the reactor operators.

Table 4. Irradiation histories for the VVER samples

\begin{tabular}{cccccccc}
\hline Reactor & Unit & Rod & Sample & Cycle & $\begin{array}{c}\text { Cycle length/ } \\
\text { downtime } \\
\text { (days) }\end{array}$ & $\begin{array}{c}\text { Cumulative } \\
\text { sample } \\
\text { burnup } \\
\text { (MWd/t) }\end{array}$ & $\begin{array}{c}\text { Cumulative } \\
\text { structure } \\
\text { burnup } \\
\text { (MWd/t) }\end{array}$ \\
\hline Kalinin & 1 & 312 & 33 & 5 & $250 / \mathrm{NA}$ & 13,660 & 12,955 \\
\hline \hline Kalinin & 1 & 312 & 448 & 5 & $250 / \mathrm{NA}$ & 15,632 & 14,839 \\
\hline \hline Balakovo & 2 & 42 & 6 & 3 & $283 / 189$ & 16,506 & 16,633 \\
Balakovo & 2 & 42 & 6 & 4 & $322 / 76$ & 32,604 & 32,855 \\
Balakovo & 2 & 42 & 6 & 5 & $359 / \mathrm{NA}$ & 46,200 & 46,556 \\
\hline \hline Balakovo & 2 & 42 & 15 & 3 & $283 / 189$ & 15,579 & 15,705 \\
Balakovo & 2 & 42 & 15 & 4 & $322 / 76$ & 31,681 & 31,938 \\
Balakovo & 2 & 42 & 15 & 5 & $359 / \mathrm{NA}$ & 44,903 & 45,267 \\
\hline \hline Balakovo & 3 & 23 & 912 & 2 & $297 / 94$ & 11,373 & 10,488 \\
Balakovo & 3 & 23 & 912 & 3 & $350 / 78$ & 28,541 & 26,321 \\
Balakovo & 3 & 23 & 912 & 4 & $413 / \mathrm{NA}$ & 45,600 & 42,053 \\
\hline \hline Balakovo & 3 & 23 & 581 & 2 & $297 / 94$ & 13,527 & 12,490 \\
Balakovo & 3 & 23 & 581 & 3 & $350 / 78$ & 30,046 & 27,744 \\
\hline Balakovo & 3 & 23 & 581 & 4 & $413 / \mathrm{NA}$ & 47,318 & 43,692 \\
\hline
\end{tabular}


Table 5 contains other data pertinent to the simulations (i.e., moderator densities, fuel temperatures and boron concentrations). The boron concentration is given as boric acid concentration per kilogram of moderator water. These values were converted to atom densities for use in HELIOS. For these simulations, a moderator temperature of $575 \mathrm{~K}$ was assumed. In executing HELIOS, the burnup and power levels input to the model are "assembly-average " values, rather than actual values for the location of the samples. However, the code provides the burnup at a particular location as part of the output. Therefore, the procedure adopted in these simulations was to use an assembly-average burnup that resulted in the measured ${ }^{145} \mathrm{Nd}$ and ${ }^{146} \mathrm{Nd}$ concentrations, and the actual burnup at the sample location is obtained as part of the simulation results. Furthermore, because HELIOS is a 2-D code, the term "assembly-average burnup" is a misnomer. Rather than dealing with the whole assembly, HELIOS models a 2-D cross section of the assembly using power levels and conditions at the actual height of the sample. Thus, burnup and power levels are for that axial position rather than for the assembly as a whole.

Table 5. Other relevant irradiation parameters for VVER samples

\begin{tabular}{lccccccc}
\hline Reactor & Unit & Rod & Sample & Cycle & $\begin{array}{c}\text { Moderator } \\
\text { density } \\
(\mathrm{g} / \mathrm{ml})\end{array}$ & $\begin{array}{c}\text { Fuel } \\
\text { temperature } \\
(\mathrm{K})\end{array}$ & $\begin{array}{c}\text { Boric acid } \\
\text { content } \\
(\mathrm{g} / \mathrm{kg})\end{array}$ \\
\hline Kalinin & 1 & 312 & 33 & 5 & 0.68 & 963 & 4.01 \\
\hline Kalinin & 1 & 312 & 448 & 5 & 0.74 & 988 & 4.01 \\
\hline Balakovo & 2 & 42 & 6 & 3 & 0.72 & 1002 & 2.52 \\
Balakovo & 2 & 42 & 6 & 4 & 0.72 & 877 & 2.45 \\
Balakovo & 2 & 42 & 6 & 5 & 0.73 & 809 & 2.72 \\
\hline \hline Balakovo & 2 & 42 & 15 & 3 & 0.69 & 966 & 2.52 \\
Balakovo & 2 & 42 & 15 & 4 & 0.69 & 874 & 2.45 \\
Balakovo & 2 & 42 & 15 & 5 & 0.71 & 811 & 2.72 \\
\hline \hline Balakovo & 3 & 23 & 912 & 2 & 0.70 & 853 & 2.10 \\
Balakovo & 3 & 23 & 912 & 3 & 0.69 & 881 & 2.35 \\
Balakovo & 3 & 23 & 912 & 4 & 0.70 & 824 & 2.62 \\
\hline \hline Balakovo & 3 & 23 & 581 & 2 & 0.74 & 891 & 2.10 \\
Balakovo & 3 & 23 & 581 & 3 & 0.74 & 892 & 2.35 \\
Balakovo & 3 & 23 & 581 & 4 & 0.74 & 822 & 2.62 \\
\hline
\end{tabular}




\section{RESULTS AND COMPARISONS}

In reporting these results we show ratios of calculated values to experimental values (C/E). "Calculated" means that the values are determined from the simulations, and the words experiment or experimental refer to the results obtained by laboratory experimental measurements. The word measured is sometimes used interchangeably with experimental.

Calculated-to-experimental ratios for the various samples are listed in Table 6, and they are plotted in Figs. 4 hrough 9. In the figures, actinide and neodymium results are shown together for each sample. The experimental results were reported as $\mathrm{kg} / \mathrm{t}$ of initial uranium. The values calculated by HELIOS are atom densities. For comparison purposes, both calculated and experimental values have been converted to $\mathrm{mg} / \mathrm{g}$ of ${ }^{238} \mathrm{U}$ in the spent fuel. Strictly speaking, this removes one degree of freedom from the comparison process, and it automatically results in a C/E ratio of unity for ${ }^{238} \mathrm{U}$. However, this is not of great practical concern. Because ${ }^{238} \mathrm{U}$ is so dominant, its final concentration is always well predicted. By the same token, a good prediction for the final concentration of ${ }^{238} \mathrm{U}$ is not meaningful. (What is of interest in the case of ${ }^{238} \mathrm{U}$ is the amount that is removed by neutron capture and this may, in fact, be difficult to measure because it involves the small difference between the amount present in the fresh and spent fuel.) For these reasons, the ${ }^{238} \mathrm{U}$ concentrations are not included in Figs. 4 hrough 9 or in Table 6.

From Figs. 4 through 9 one can see that the results for Rod 312 are noticeably poorer than for the other two rods. The predictions for Rod 42 are superior to the others. It is noteworthy that Rod 42 is an internal fuel rod, so perhaps, the other two rods could be better simulated by including adjacent assemblies in the HELIOS models. In general, ${ }^{238} \mathrm{Pu}$ and the higher actinides (starting with

${ }^{241} \mathrm{Pu}$ ) tend to be underpredicted. However, the predictions for most of the actinides are reasonable in the case of Rod 42.

We have indicated earlier that the concentrations of both ${ }^{145} \mathrm{Nd}$ and ${ }^{146} \mathrm{Nd}$ were well predicted. The ${ }^{144} \mathrm{Nd}$ concentration is consistently underpredicted. Predictions for ${ }^{142} \mathrm{Nd}$ and ${ }^{143} \mathrm{Nd}$ are poor for Rod 312. The ${ }^{142} \mathrm{Nd}$ and ${ }^{143} \mathrm{Nd}$ values are slightly underpredicted in all other cases, thus, for both actinides and fission products there is noticeably poorer agreement in the case of Rod 312. In the case of the fission products (neodymiun isotopes), the predictability is about equal for Rods 42 and 23. However, for the actinides, it might be argued that there is better predictability in the case of Rod 42 than in the case of Rod 23.

An objective of this work was to determine how well one can predict the nuclide concentrations in spent $\mathrm{UO}_{2}$ fuel with burnup codes commonly in use at ORNL, and, specifically, to do so for VVER fuel assemblies using the HELIOS code. Comparisons using the SAS2H sequence of the SCALE system ${ }^{5}$ would also be of interest, but resources did not permit such an effort to date. For many practical applications, such as burnup credit calculations, the SCALE system has proven to be effective. Furthermore, the SAS2H sequence in the SCALE system has been found to perform reasonably well when compared with HELIOS. 
Table 6. Summary of C/E values for VVER LEU samples

\begin{tabular}{|c|c|c|c|c|c|c|}
\hline $\begin{array}{l}\text { Reactor } \\
\text { assembly }\end{array}$ & $\begin{array}{l}\text { Kalinin-1 } \\
\text { ED-0623 }\end{array}$ & $\begin{array}{l}\text { Kalinin-1 } \\
\text { ED-0623 }\end{array}$ & $\begin{array}{c}\text { Balakovo-2 } \\
\text { ED-1476 }\end{array}$ & $\begin{array}{c}\text { Balakovo-2 } \\
\text { ED-1476 }\end{array}$ & $\begin{array}{c}\text { Balakovo-3 } \\
\text { E-1591 }\end{array}$ & Balakovo-3 \\
\hline $\operatorname{rod}$ & 312 & 312 & 42 & 42 & 23 & 23 \\
\hline sample & 33 & 448 & 6 & 15 & 912 & 581 \\
\hline${ }^{235} \mathrm{U}$ & 0.98 & 1.01 & 0.95 & 0.98 & 0.92 & 1.07 \\
\hline${ }^{236} \mathrm{U}$ & 0.83 & 0.83 & 0.96 & 0.94 & 0.94 & 0.92 \\
\hline${ }^{238} \mathrm{Pu}$ & 0.72 & 0.67 & 0.75 & 0.75 & 0.65 & 0.69 \\
\hline${ }^{239} \mathrm{Pu}$ & 0.93 & 0.91 & 0.95 & 0.99 & 0.88 & 0.91 \\
\hline${ }^{240} \mathrm{Pu}$ & 0.94 & 0.91 & 1.02 & 1.04 & 0.98 & 0.99 \\
\hline${ }^{241} \mathrm{Pu}$ & 0.87 & 0.84 & 0.89 & 0.93 & 0.85 & 0.88 \\
\hline${ }^{242} \mathrm{Pu}$ & 0.81 & 0.75 & 0.90 & 0.88 & 0.84 & 0.78 \\
\hline${ }^{241} \mathrm{Am}$ & 0.17 & 0.15 & 0.80 & 1.13 & 0.85 & 0.67 \\
\hline${ }^{243} \mathrm{Am}$ & 0.91 & 0.77 & 0.92 & 0.95 & 0.90 & 0.79 \\
\hline${ }^{242} \mathrm{Cm}$ & $--^{a}$ & $--^{a}$ & 0.84 & 0.92 & 0.86 & 0.86 \\
\hline${ }^{244} \mathrm{Cm}$ & 0.56 & 0.86 & 0.90 & 0.88 & 0.79 & 0.70 \\
\hline${ }^{142} \mathrm{Nd}$ & 0.62 & 0.61 & 0.91 & 0.88 & 0.90 & 0.90 \\
\hline${ }^{143} \mathrm{Nd}$ & 0.92 & 0.92 & 0.98 & 0.99 & 0.97 & 0.95 \\
\hline${ }^{144} \mathrm{Nd}$ & 0.33 & 0.33 & 0.79 & 0.78 & 0.79 & 0.77 \\
\hline${ }^{145} \mathrm{Nd}$ & 1.01 & 1.01 & 1.00 & 1.01 & 1.01 & 1.02 \\
\hline${ }^{146} \mathrm{Nd}$ & 1.00 & 1.00 & 1.00 & 0.99 & 0.99 & 0.99 \\
\hline
\end{tabular}

${ }^{a}$ Values were not reported. 


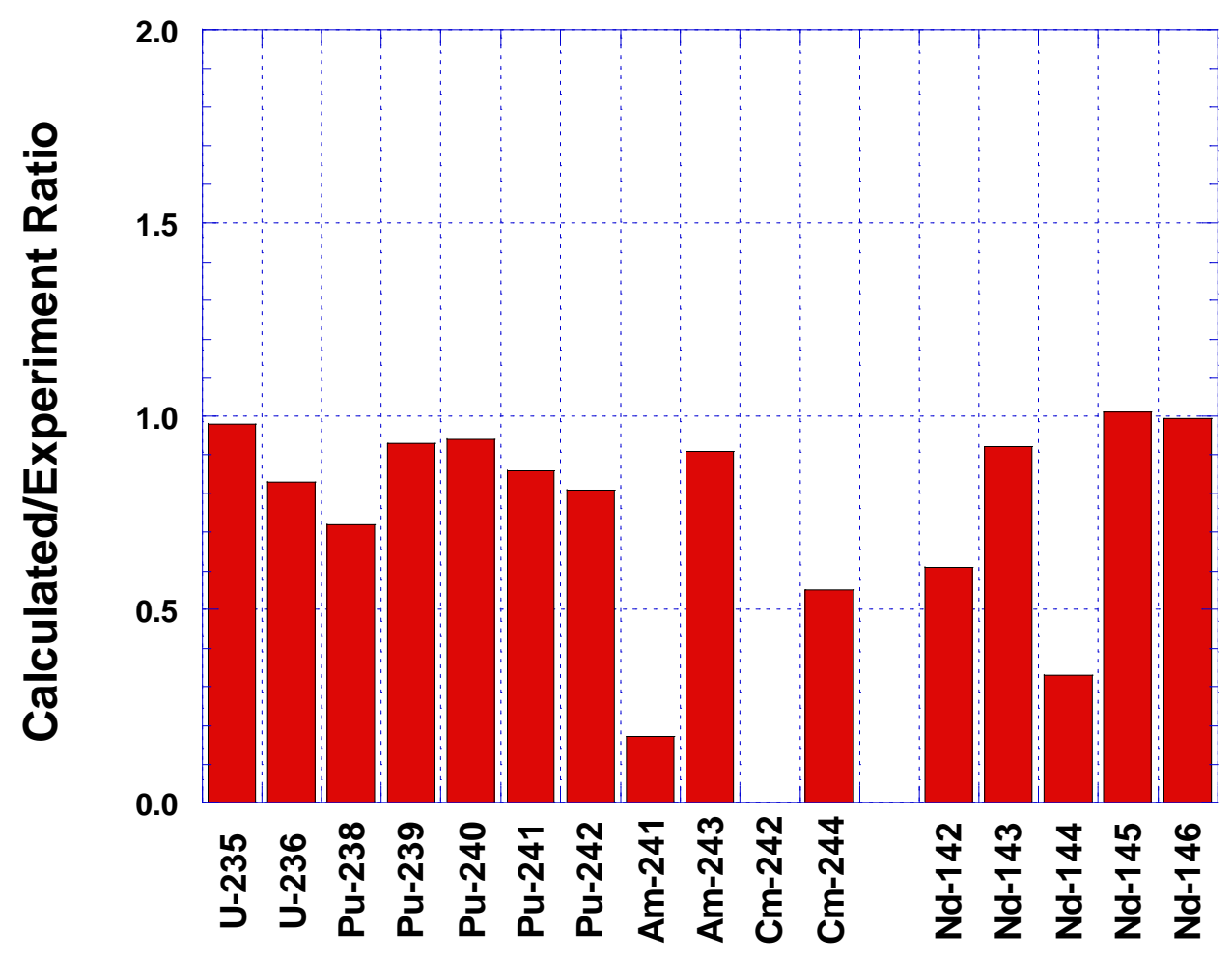

Fig. 4. Calculated-to-experiment ratios for Sample 33 from Rod 312 exposed in Kalinin-1. The burnup used in the simulation was 13,660 MWd/t. 


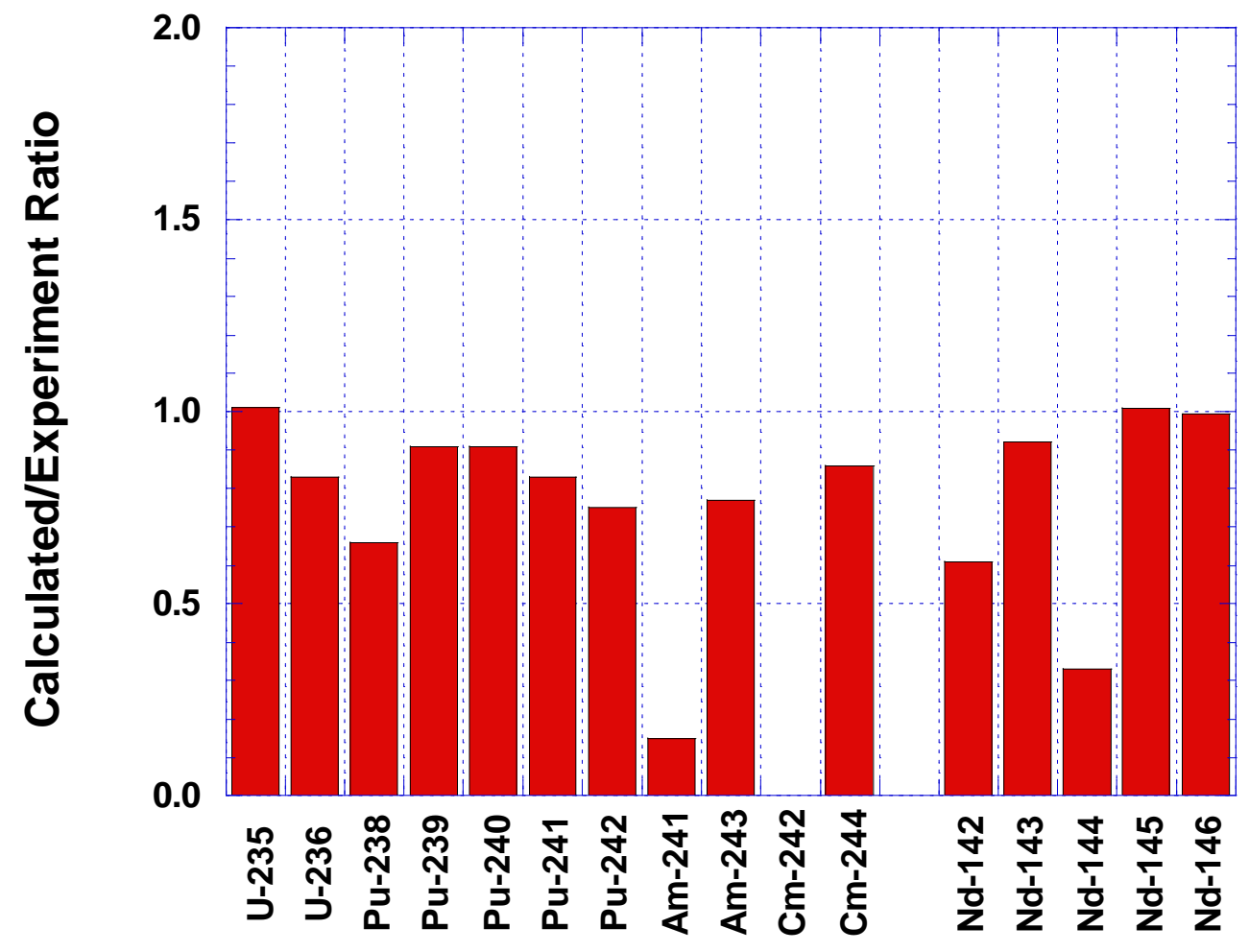

Fig. 5. Calculated-to-experiment ratios for Sample 448 from Rod 312 exposed in Kalinin-1. The burnup used in the simulation was $15,632 \mathrm{MWd} / \mathrm{t}$. 


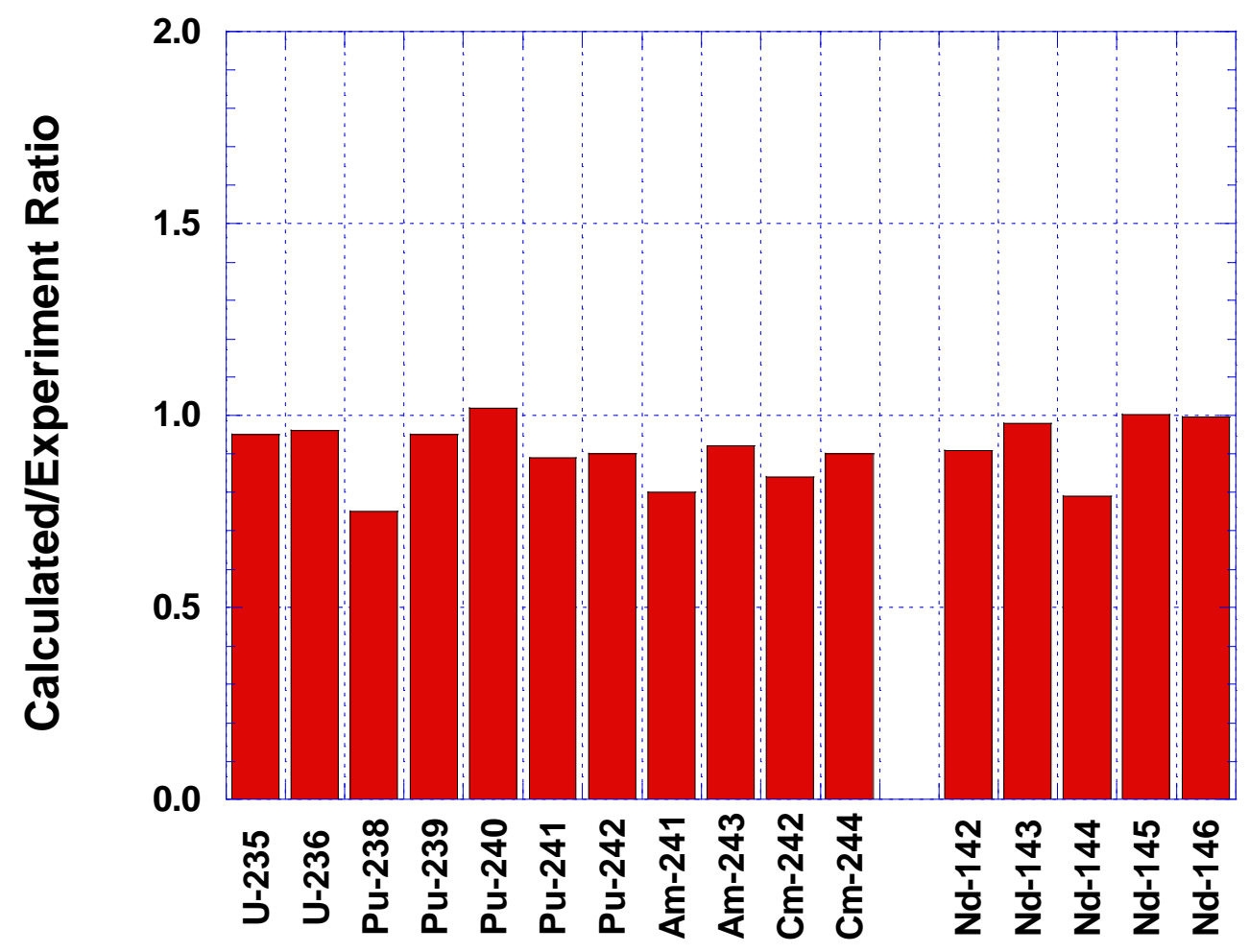

Fig. 6. Calculated-to-experiment ratios for Sample 6, Rod 42 exposed in Balakovo-2. The burnup for the simulation was 46,200 MWd/t. 


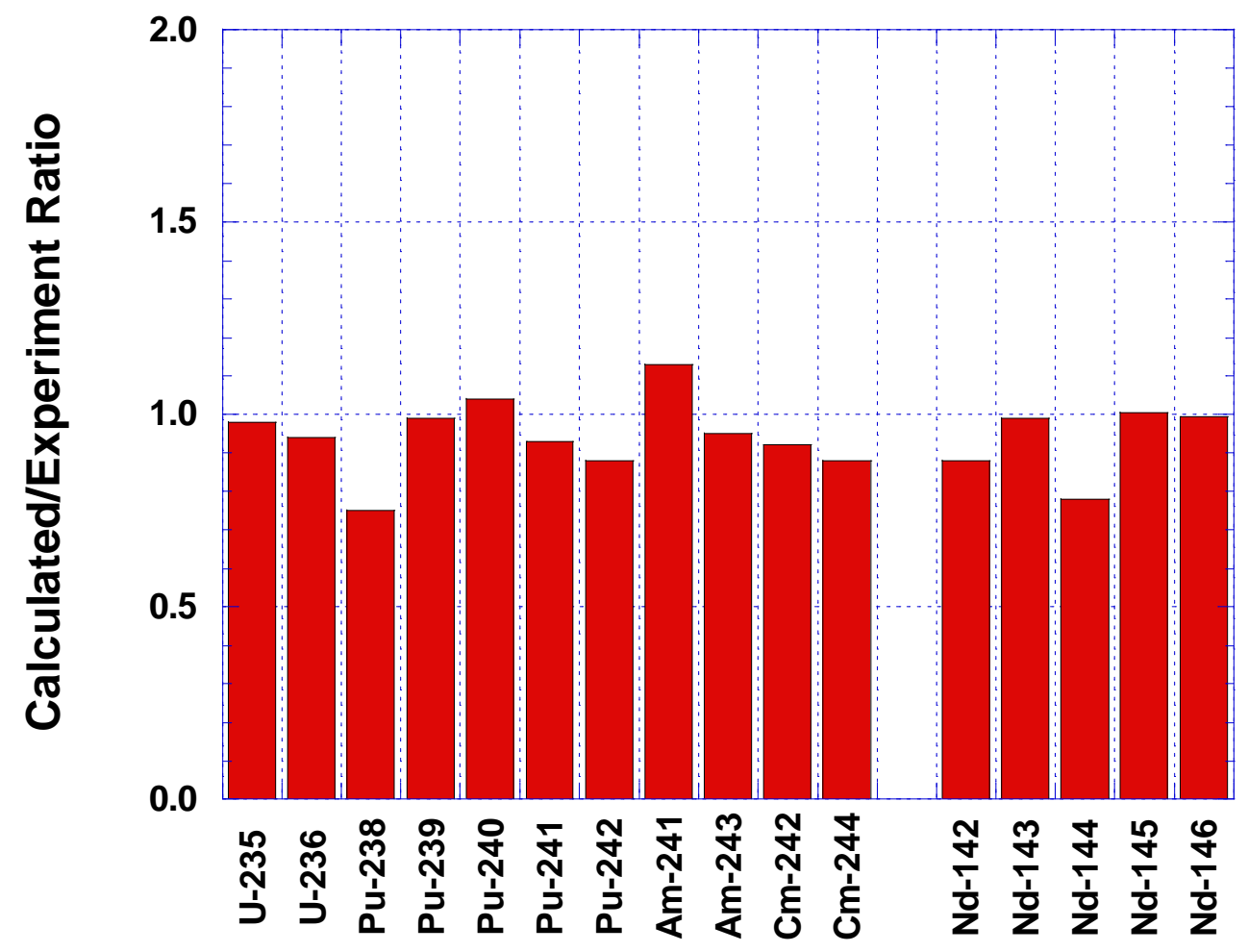

Fig. 7. Calculated-to-experiment ratios for Sample 15, Rod 42 exposed in Balakovo-2. The burnup value was 44,903 MWd/t. 


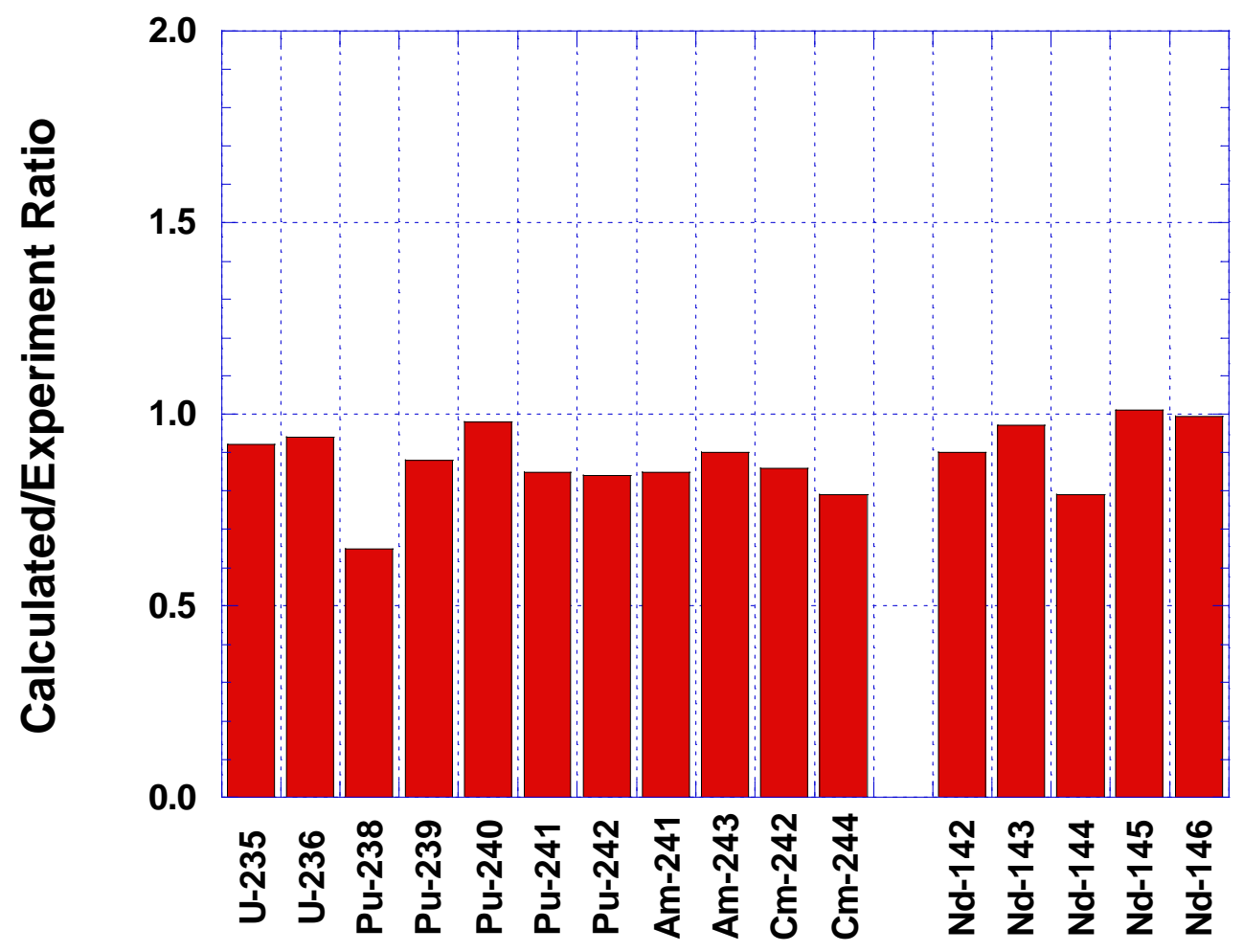

Fig. 8. Calculated-to-experiment ratios for Sample 912, Rod 23 exposed in Balakovo-3. Burnup for the simulation was $45,600 \mathrm{MWd} / \mathrm{t}$. 


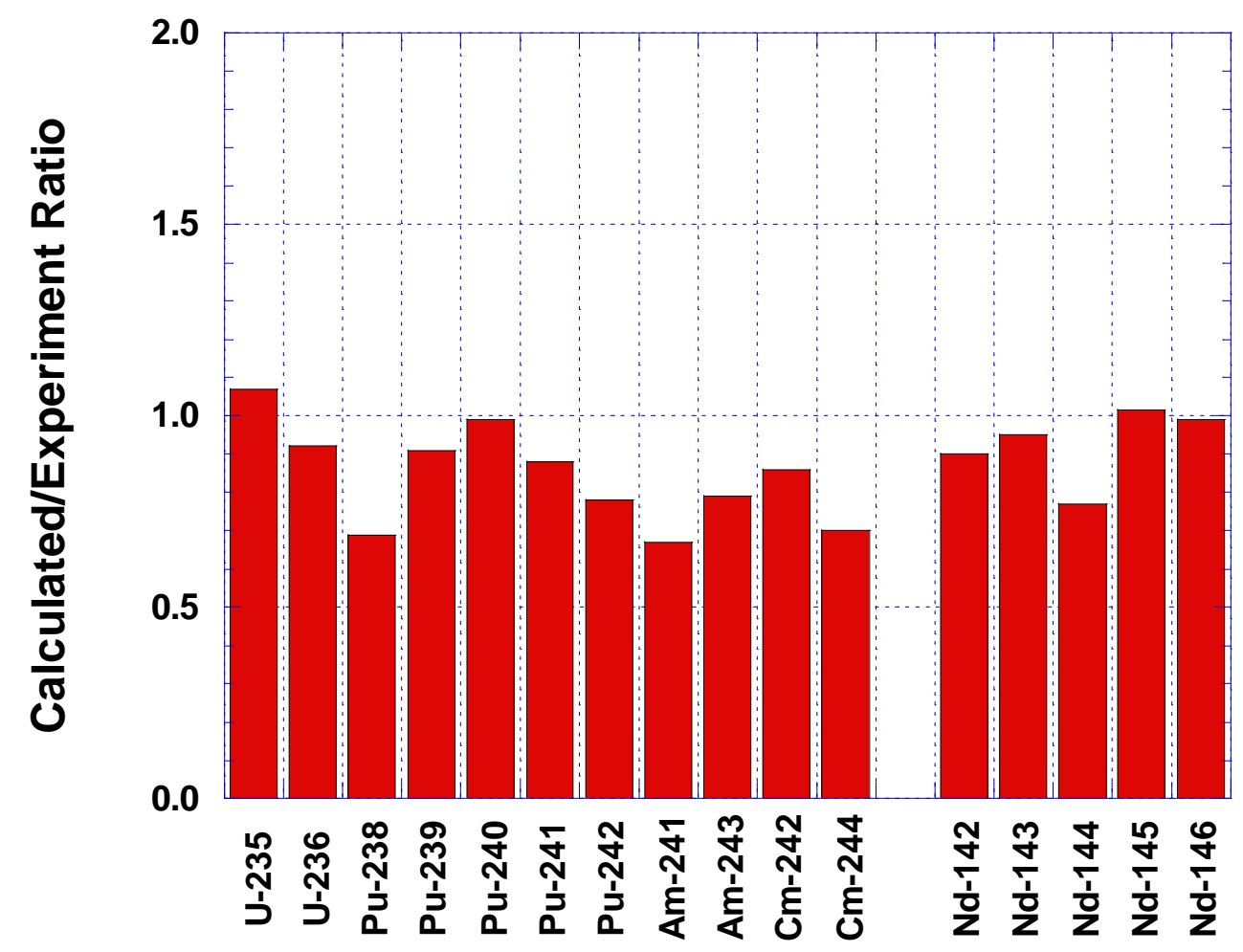

Fig. 9. Calculated-to-experiment ratios for Sample 581, Rod 23 exposed in Balakovo-3. Burnup for the simulation was $47,318 \mathrm{MWd} / \mathrm{t}$. 


\section{REFERENCES}

1. J. J. Casal, R. J. J. Stamm'ler, E. A. Villarino, and A. A. Ferri, "HELIOS: Geometric Capabilities of a New Fuel-Assembly Program," in Proc. International Topical Meeting on Advances in Mathematics, Computations, and Reactor Physics, April 28BMay 2, 1991, Pittsburgh, Pa. (1991).

2. B. D. Murphy, Prediction of the Isotopic Composition of $\mathrm{UO}_{2}$ Fuel from a BWR: Analysis of the DU1 Sample from the Dodewaard Reactor, ORNL/TM-13687, Lockheed Martin Energy Research Corp., Oak Ridge National Laboratory, October 1998.

3. ASTM, Annual Book of Standards, Vol. 12.01, E321, Standard Test Method for Atom Percent Fission in Uranium and Plutonium Fuel (Neodymium-148 Method), American Society for Testing Materials, 100 Barr Harbor Dr., West Conshohocken, Pa. 19428 (1996).

4. C. T. Walker, M. Coquerelle, W. Goll, and R. Manzel, "Irradiation Behaviour of MOX Fuel: Results of an EPMA Investigation," Nucl. Eng. and Design 131, 1 B16 (1991).

5. SCALE: A Modular Code System for Performing Standardized Computer Analyses for Licensing Evaluation, NUREG/CR-0200, Rev. 5 (ORNL/NUREG/CSD-2/R5), Vols. I, II, and III, March 1997. Available from Radiation Safety Information Computational Center at Oak Ridge National Laboratory as CCC-545.

6. Y. A. Styrin, Kurchatov Institute, Personal communication. Draft report issued as: Fuel Assembly and Core Model for Neutronics Calculations of VVER-1000. Russian Research Center, Kurchatov Institute, Moscow, 1998.

7. A. N. Novikov et al., Problems of VVER In-Core Fuel Management, IAEA-TECDOC-567, p. 325, International Atomic Energy Agency, Vienna, 1990.

8. ! . E. U , (: @ \% =. AD@, : 8@ ; , H@48" 4 B@N@ 8 \&ZRAF: , >4' 2" $24 F 4<@ H H$

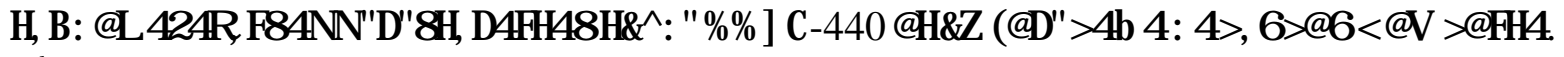
$7^{\text {th }}$ AER Symposium on VVER Reactor Physics and Reactor Safety, Sept. 23-26, 1997, Hornitz near Zittau, Germany, pp. 749B758 (1997). 



\section{APPENDIX A}

\section{DESCRIPTIONS AND DATA TRANSMITTED FROM THE KURCHATOV INSTITUTE TO OAK RIDGE NATIONAL LABORATORY}





\section{A.1. INTRODUCTION}

The comparison of calculated and measured isotopic composition of spent fuel is an important stage of the computer codes validation process. Such a comparison gives information about code accuracy in reference to conditions of real power operation.

However, data of nuclide composition measurements as a rule are rather difficult to interpret for many reasons: uncertainty of some parameters (fuel temperature for example), incomplete information about operation history, difficulties in accounting for the effect of nearby assemblies.

Destructive analyses of VVER-1000 spent fuel are not numerous because of their complexity and high cost. The selected experiments that are described below reflect the most typical situations of fuel sample's irradiation conditions. The following parameters were varied:

$\$$ fuel assembly type (uniform or profiled);

$\$$ location of investigated fuel rod (in central or peripheral assembly region);

$\$$ irradiation time (1 or 3 years);

The measurements were carried out in State Scientific Center Research Institute of Atomic Reactors (SSC RIAR).

\section{A.2. FUEL CHARACTERISTICS AND IRRADIATION HISTORY}

\section{A.2.1 VVER-1000 Core}

The VVER-1000 reactor is a pressurized-light-water-moderated and cooled reactor with the power $3000 \mathrm{MWth}$ (1000 MWe). The VVER-1000 standard core consists of 163 hexagonal fuel assemblies arranged in the hexagonal lattice with a lattice pitch of $236 \mathrm{~mm}$ (Fig. A.1). Each assembly contains $312 \mathrm{UO}_{2}$ fuel pins, 18 guide thimbles for control rods or burnabie poisons and a central guide/instrumentation tube arranged in a hexagonal lattice with a pitch of $12.75 \mathrm{~mm}$.

The fuel rods are annular $\mathrm{UO}_{2}$ pellets with zirconium alloy cladding. Uniform fuel assemblies are composed of 312 fuel pins of appropriate enrichment, as shown in Fig. 2 (in main text). The non-uniform assemblies are composed of $2464.4 \%$ pins and $663.6 \%$ pins, as shown in Fig. 1 (in main text).

The details of the VVER-1000 core and fuel assemblies with nominal parameter values are presented by Styrin. ${ }^{6}$

\section{A.2.2 Fuel Assemblies Investigated}

The fuel assembly designated ED-0623 with non-uniform fuel enrichment was selected for nuclide composition and burnup measurements of a VVER-1000 spent nuclear fuel assembly at low average burnup. The fuel assembly designated ED-1476 was selected for the analogous measurements (with non-uniform fuel enrichment inside the fuel assembly) at practically interesting high burnup. The fuel assembly designated E-1591 with uniform fuel enrichment was selected for measurement at high burnup. 


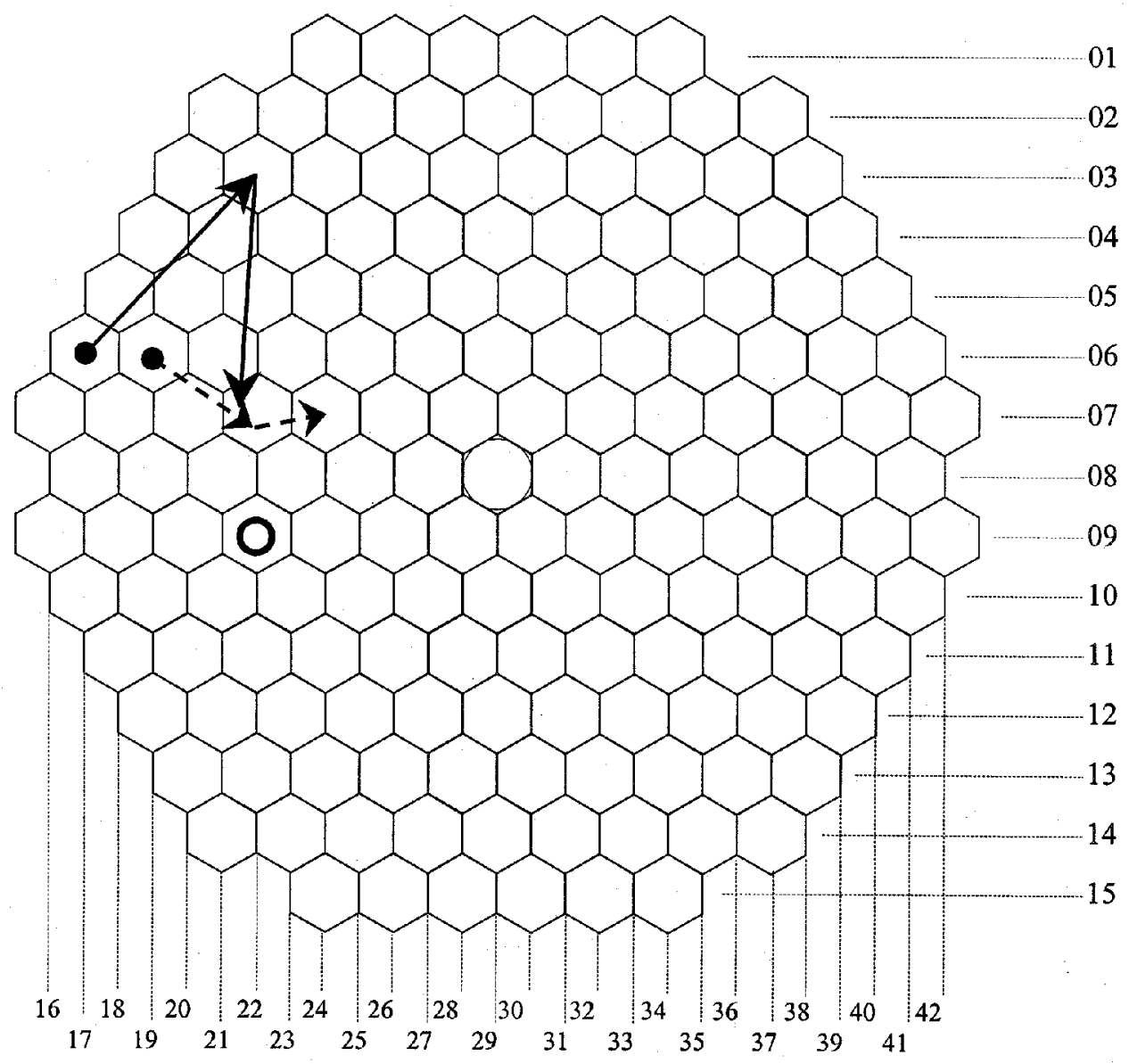

position of fuel assembly №0623 in the core

$----\rightarrow$ movement of fuel assembly №1476 in the core

$\rightarrow \quad$ movement of fuel assembly №1591 in the core

Fig. A.1. Simplified design of the VVER-1000 core. 


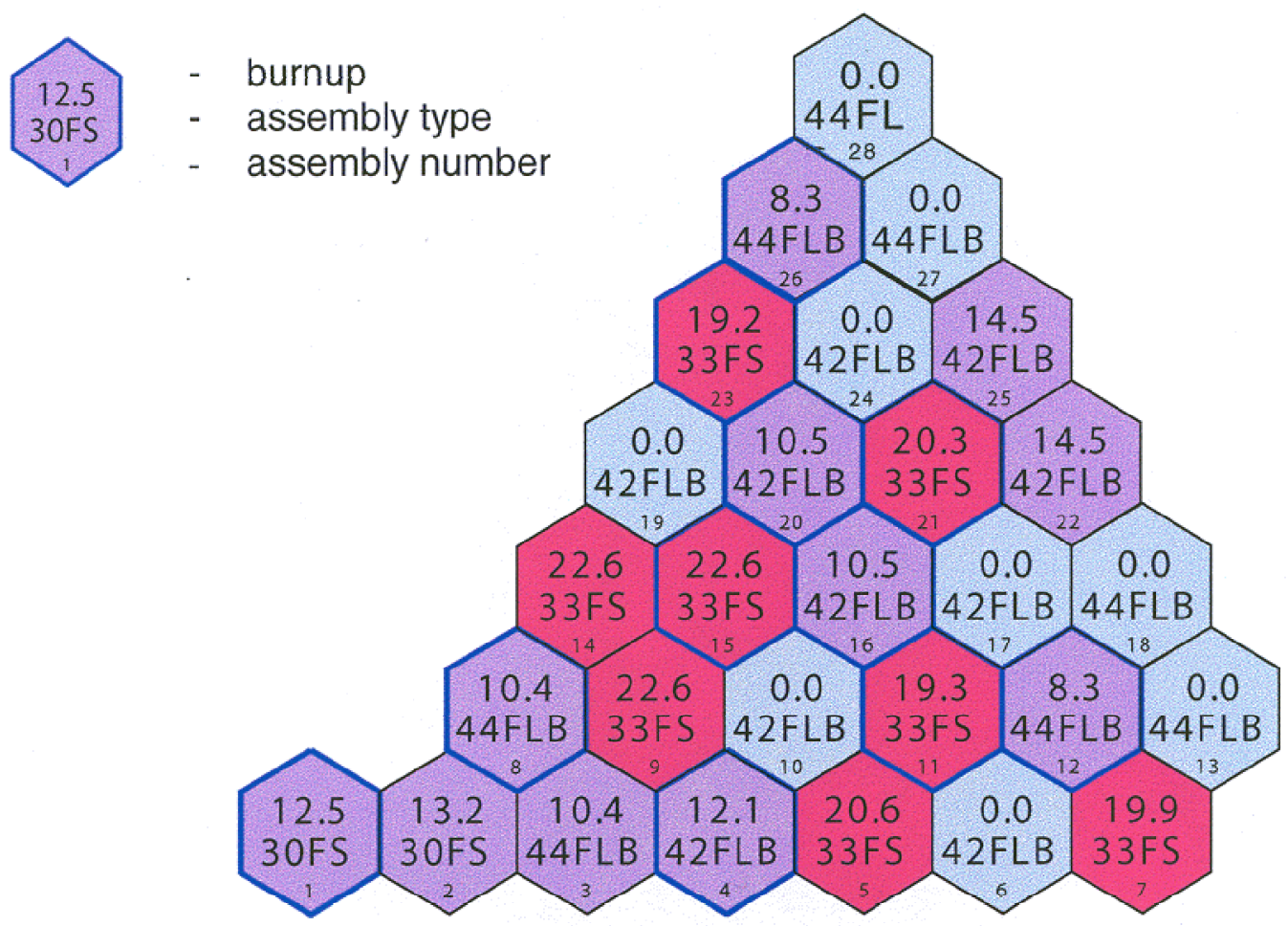

Fig. A.2. Kalinin-1 core loading pattern, cycle 5 (60E symmetry sector). Burnup distribution and type of assembly (assembly ED-0623 is of No. 10).

\section{A.2.2.1 Fuel assembly ED-0623 (Kalinin-1, cycle 5)}

The fuel assembly ED-0623 was irradiated for 236.8 effective days in the Kalinin-1 VVER-1000 during cycle 5 to an estimated average burnup of $13.5 \mathrm{MWd} / \mathrm{kg} \mathrm{U}$. The irradiation history of the fuel assembly is shown in Table A.1. Figure A.2 shows a 60-degree symmetry sector of the Kalinin-1 core loading pattern for cycle 5. The fuel assembly consisted of 66 fuel rods of 3.6-wt \% initial ${ }^{235} \mathrm{U}$ enrichment (all fuel rods in the peripheral row and 6 corner fuel rods in the second row), 246 fuel rods of 4.4 -wt $\%$ initial ${ }^{235} \mathrm{U}$ enrichment and 18 burnable absorber rods (Fig. 1 in main text). The assembly type sign "EECHB" presented in this figure has the following meaning: 
EE $B$ the average assembly enrichment multiplied by 10 ;

C B type of spacer grids and guide tubes material (F-stainless steel, Z-zirconium alloy);

$\mathrm{H} \quad$ B diameter of fuel pellet central hole $(\mathrm{L}=2.5 \mathrm{~mm}, \mathrm{~S}=1.5 \mathrm{~mm})$;

B B designates the amount of natural boron in burnable absorber (A B $0.02 \mathrm{~g} / \mathrm{cm}^{3}$, B B $0.036 \mathrm{~g} / \mathrm{cm}^{3}$, C B $0.05 \mathrm{~g} / \mathrm{cm}^{3}$, D B $0.065 \mathrm{~g} / \mathrm{cm}^{3}$ )

Table A.1. The irradiation history of the fuel assembly ED-0623

Cycle

Coordinates according to Figure A.1

Position in 60-degree symmetry sector

Date of loading/discharge

(day, month, year of $20^{\text {th }}$ century)

Burnup period:

Calendar days/Effective days

5

09B22

10

$10.10 .88 / 17.06 .89$

$250 / 236.8$

\section{A2.2.2 Fuel assembly ED-1476 (Balakovo-2, cycles 3-5)}

The fuel assembly ED-1476 was irradiated for 863.2 effective days in the Balakovo-2 VVER-1000 during cycles 3B5 to an estimated average burnup of $42.5 \mathrm{MWd} / \mathrm{kg}$ U. The irradiation history of the fuel assembly is shown in Table A.2. Figures A.3BA.5 show 60-degree symmetry sectors of the Balakovo- 2 core loading patterns for cycles $3 \mathrm{~B}$. The design of the assembly is the same as for assembly ED-0623, and it is illustrated in Fig. (in main text). Note that 18 burnable absorber rods were inserted during cycle 3 only.

Table A.2. The irradiation history of the fuel assembly ED-1476

\begin{tabular}{lccc}
\hline Cycle & 3 & 4 & 5 \\
Coordinates according to Fig. A.1 & $06 \mathrm{~B} 19$ & $07 \mathrm{~B} 22$ & $07 \mathrm{~B} 24$ \\
$\begin{array}{l}\text { Position in 60-degree symmetry } \\
\text { sector }\end{array}$ & 24 & 19 & 14 \\
$\begin{array}{l}\text { Date of loading/discharge } \\
\text { (day, month, year of 20 }\end{array}$ & $13.02 .90 / 23.11 .90$ & $31.05 .91 / 17.04 .92$ & $02.07 .92 / 26.06 .93$ \\
$\begin{array}{l}\text { Burnup period: } \\
\quad \text { Calendar days/effective days }\end{array}$ & & & \\
\hline
\end{tabular}




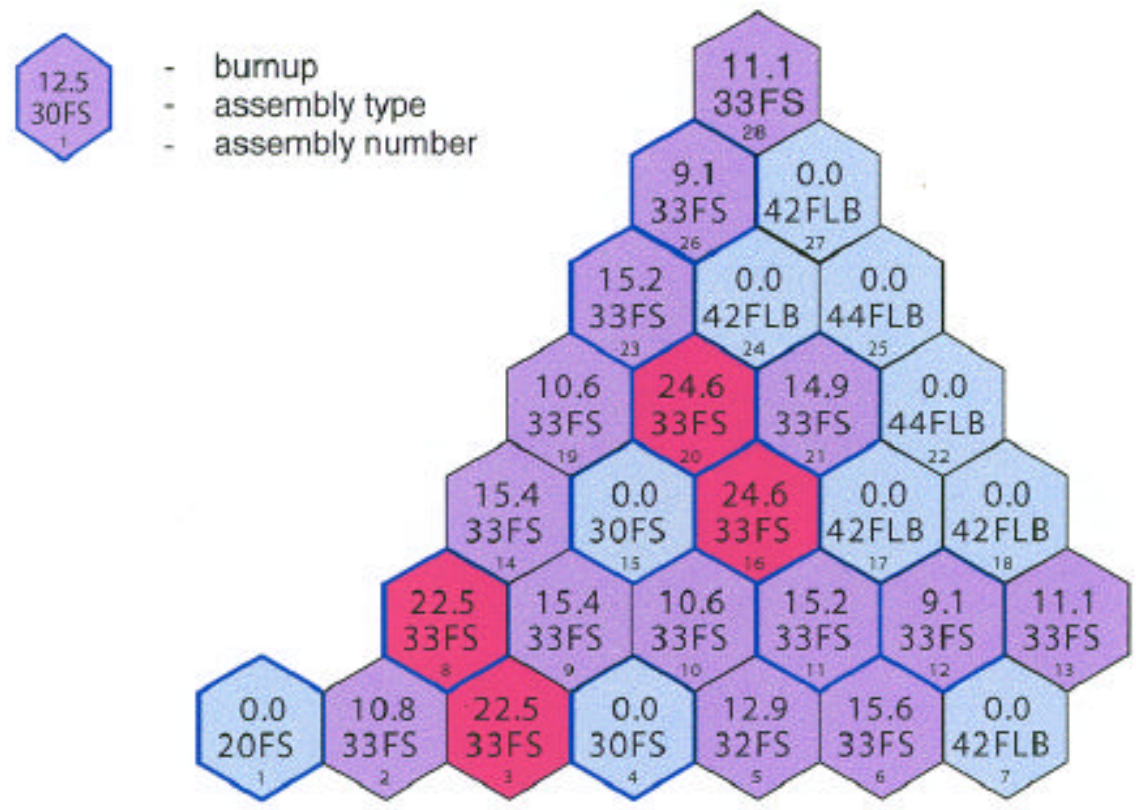

Fig. A.3. Balakovo-2 core loading pattern, cycle 3 (60Esymmetry sector). Burnup distribution and type of assembly (assembly ED-1476 is of No. 24).

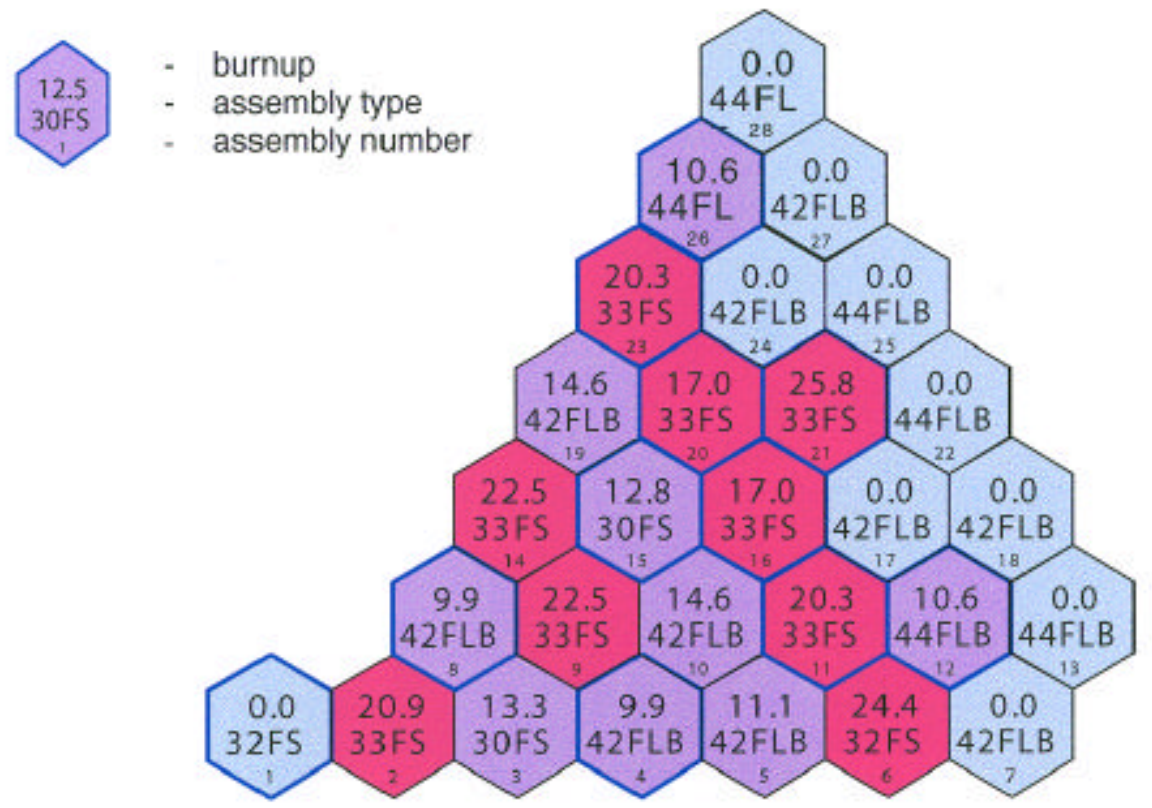

Fig. A.4. Balakova-2 core loading pattern, cycle 4 (60Esymmetry sector). Burnup distribution and type of assembly (assembly ED-1476 is of No. 19). 


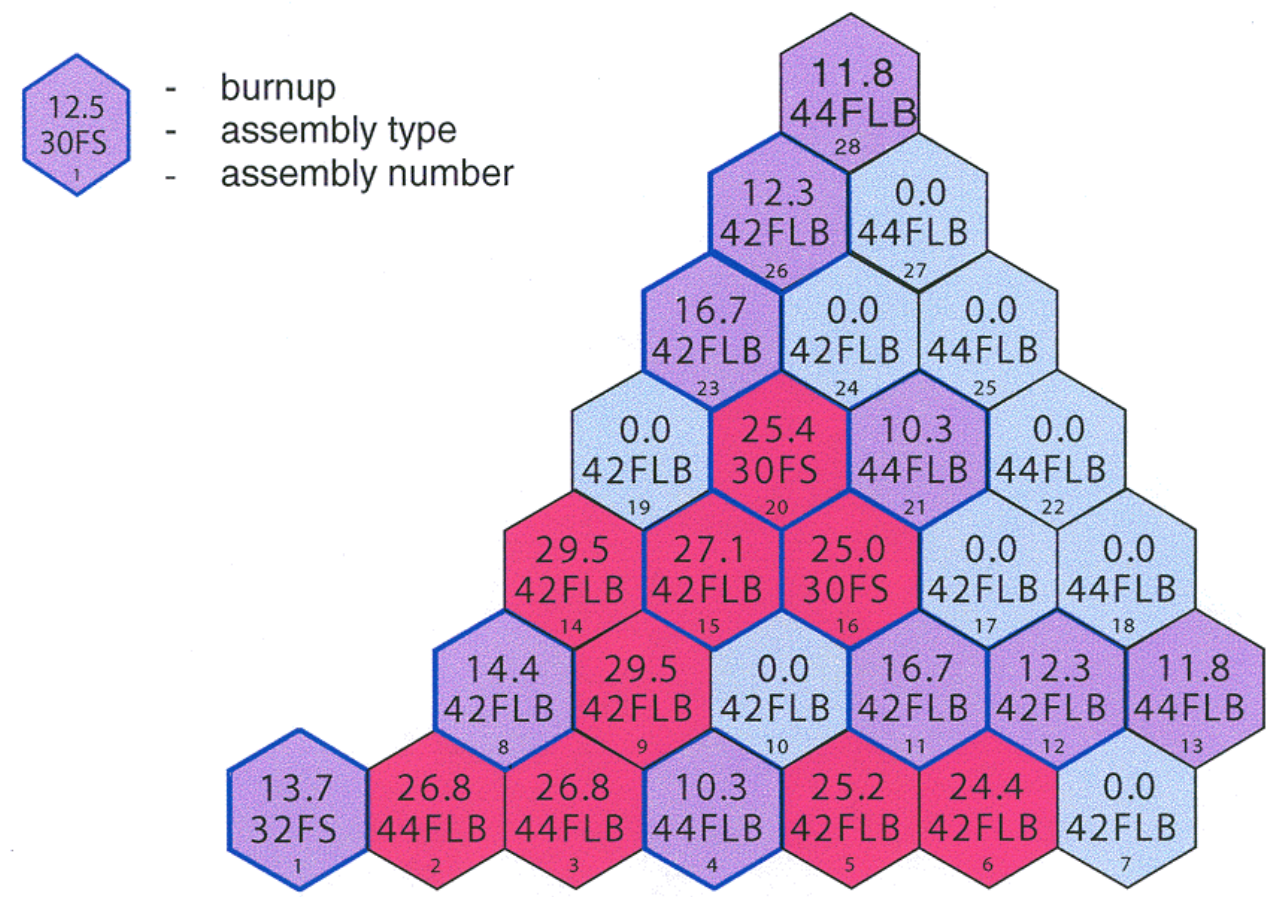

Fig. A.5. Balakovo-2 core loading pattern, cycle 5 (60E symmetry sector). Burnup distribution and type of assembly (assembly ED-1476 is of No. 14).

\section{A.2.2.3 Fuel assembly E-1591 (Balakovo-3, cycles 24)}

The fuel assembly E-1591 was irradiated for 895.1 effective days in the Balakovo-3 VVER-1000 during cycles 2B4 to an estimated average burnup $41.4 \mathrm{MWd} / \mathrm{kg} \mathrm{U}$. The irradiation history of the fuel assembly is shown in Table A.3. Figures A.6BA.8 show 60-degree symmetry sectors of the Balakovo-3 core loading patterns for cycles 2B4. The fuel assembly consisted of 312 fuel rods of 4.4-wt \% initial ${ }^{235} \mathrm{U}$ enrichment and 18 burnable absorber rods for the cycle 2 only (Fig. 2 in main text ). 
Table A.3. The irradiation history of the fuel assembly E-1591

\begin{tabular}{lccc}
\hline Cycle & 2 & 3 & 4 \\
Coordinates according to Fig. A.1 & $06 \mathrm{~B} 17$ & $03 \mathrm{~B} 22$ & $07 \mathrm{~B} 22$ \\
$\begin{array}{l}\text { Position in 60-degree symmetry } \\
\quad \text { sector }\end{array}$ & 27 & 12 & 19 \\
$\begin{array}{l}\text { Date of loading/discharge } \\
\text { (day, month, year of 20 }\end{array}$ & & & $07.08 .92 / 24.09 .93$ \\
$\begin{array}{l}\text { Burnup period: } \\
\quad \text { Calendar days/effective days }\end{array}$ & $11.05 .90 / 04.03 .91$ & $06.06 .91 / 21.05 .92$ & \\
\hline
\end{tabular}

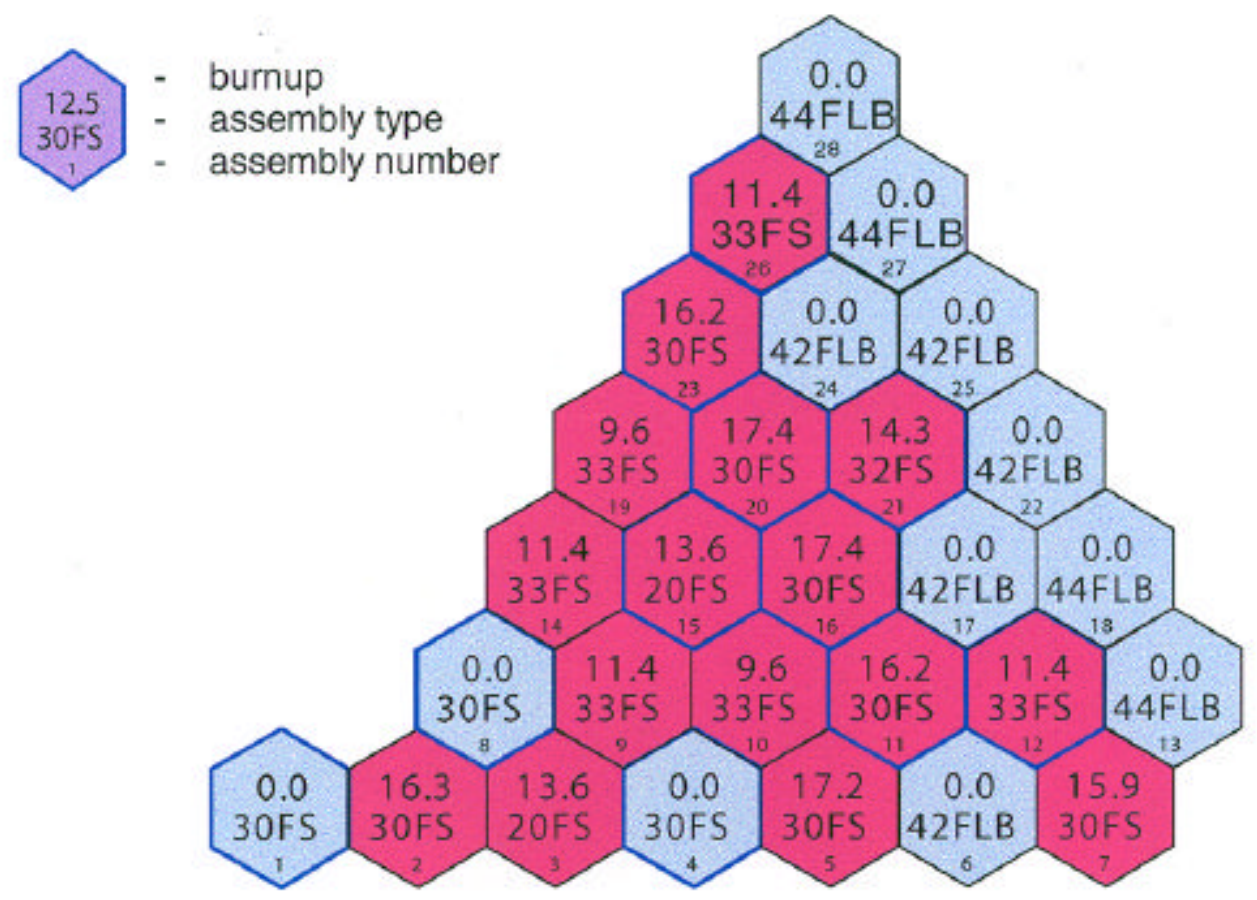

Fig. A.6. Balakovo-3 core loading pattern, cycle 2 (60E symmetry sector). Burnup distribution and type of assembly (assembly E-1591 is of No. 27). 


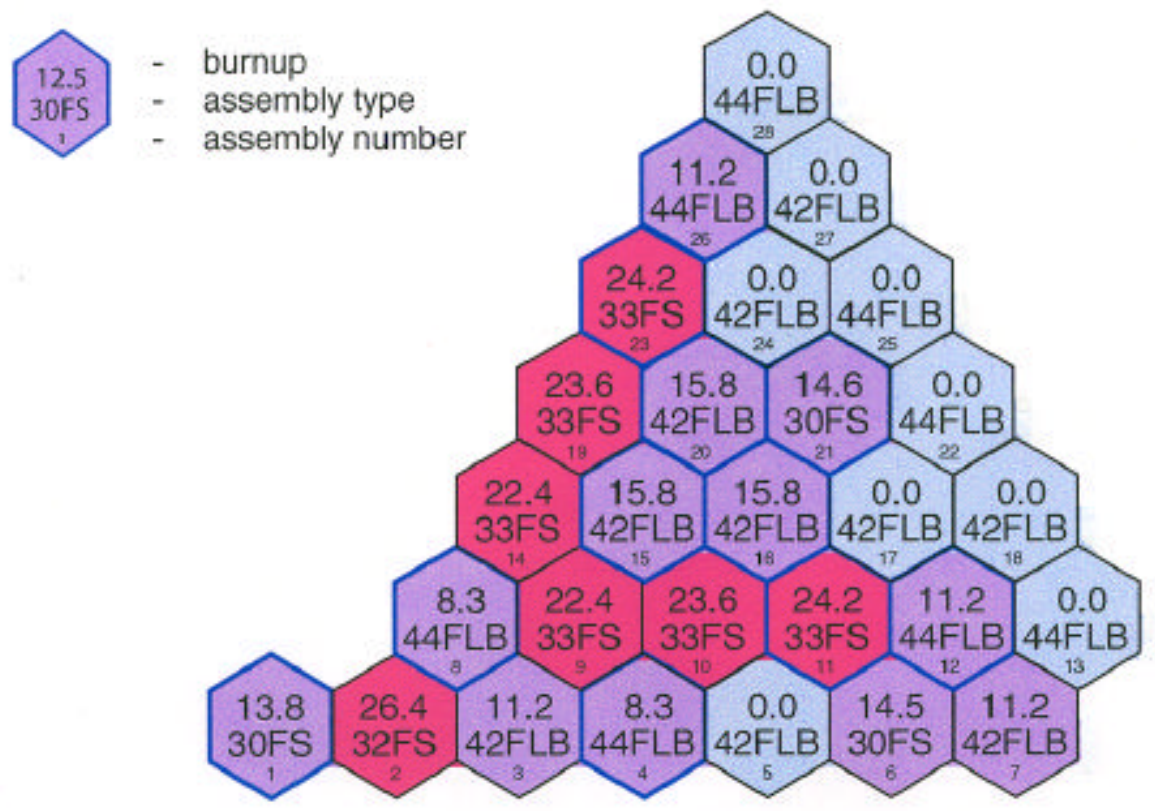

Fig. A.7. Balakovo-3 core loading pattern, cycle 3 (60E symmetry sector). Burnup distribution and type of assembly (assembly E-1591 is of No. 12).

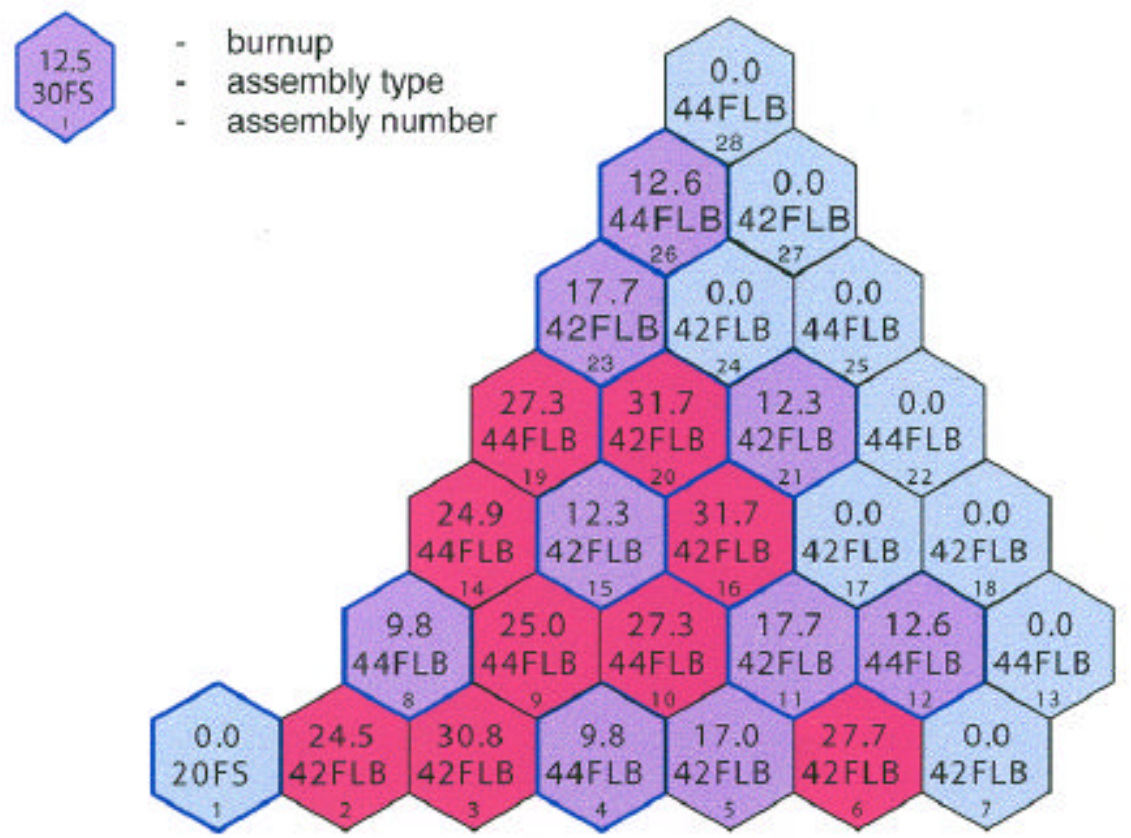

Fig. A.8. Balakovo-3 core loading pattern, cycle 4 (60E symmetry sector). Burnup distribution and type of assembly (assembly E-1591 is of No. 19. 


\section{A.3. MEASUREMENT METHODS}

Measurements were carried out using nondestructive and destructive methods. Axial ${ }^{137} \mathrm{Cs}$ distributions in fuel rods of the fuel assemblies investigated were measured by gamma scanning using a slit collimator and a gamma spectrometer. Nondestructive fuel burnup estimates were made by comparison of ${ }^{137} \mathrm{Cs}$ gamma count rates in the fuel rods investigated and in the standard. Fission-product concentrations in the standard were measured by a destructive method.

Fuel rods for destructive examination were selected on the basis of gamma-scanning. The 10mm-thick-pellet samples were taken at different distances above the bottom of the fuel rods.

The pellet samples were dissolved in $8 M$ nitric acid and the separation of uranium, plutonium, americium, curium and neodymium was carried out using ion-exchange chromatography and extraction chromatography. Uranium, plutonium, americium and neodymium concentrations were measured by an isotope dilution method in combination with mass-spectrometric analysis. The ${ }^{238} \mathrm{Pu}$ and curium isotopic concentrations were measured by alpha-spectrometry in combination with mass-spectrometric analysis.

Fuel burnups were measured by the ${ }^{145} \mathrm{Nd}+{ }^{146} \mathrm{Nd}$ buildup method.

\section{A.4. MEASUREMENT RESULTS}

The nuclide composition and burnup measurement results of VVER-1000 spent nuclear fuel at the end of irradiation are shown in Table 1 in the main text. Measurement errors correspond to a confidence probability $\mathrm{P}=0.95$.

In addition to destructive analysis, results of ( -scanning are presented. Peak and average fuel burnups of some fuel pins as well as axial pin ${ }^{137}$ Cs peaking factor $\left(k_{z}\right)$ for fuel assemblies ED-0623, ED-1476 and E-1591 are shown in Tables A.4 through A.6. Numeration of fuel pins are partially given in Figs. 1 and 2 in the main text.

\section{A.5. BENCHMARK PROBLEM FORMULATION}

\section{A.5.1 Influence of Various Operational Parameters on Nuclide Content}

Calculations of spent fuel isotopic composition are usually carried out for single-fuel-assembly configurations with operational parameters averaged over time $\left(T_{U_{2}}, \rho_{\mathrm{H}_{2} \mathrm{O}}\right.$, power density, boron content in moderator, and so on) under the supposition that taking accounting for their real time dependence does not practically influence the calculation. As a rule, the influence of nearby assemblies on nuclide composition is also neglected. In addition, note that experimental data for most of the lattice parameters (such as fuel temperature, local power density and so on) are absent and should be obtained from other calculations. This situation introduces additional uncertainty. 
Table A.4. Peak and average fuel burnups (MWD/kg initial U) and axial pin ${ }^{137} \mathrm{Cs}$ peaking factor $\left(k_{z}\right)$ for fuel assembly ED-0623

\begin{tabular}{cccc}
\hline Fuel rod & Peak burnup & Average burnup & $k_{z}$ \\
\hline 1 & 15.8 & 13.0 & 1.21 \\
11 & 15.8 & 12.9 & 1.22 \\
13 & 14.8 & 12.1 & 1.22 \\
22 & 14.9 & 12.2 & 1.22 \\
47 & 15.3 & 12.7 & 1.20 \\
55 & 15.3 & 12.5 & 1.22 \\
89 & 14.9 & 12.3 & 1.20 \\
119 & 14.9 & 12.6 & 1.18 \\
121 & 14.9 & 12.2 & 1.22 \\
148 & 16.3 & 13.4 & 1.21 \\
149 & 15.2 & 12.4 & 1.22 \\
152 & 15.2 & 12.4 & 1.22 \\
155 & 15.1 & 12.3 & 1.22 \\
158 & 14.9 & 12.2 & 1.22 \\
161 & 14.8 & 12.1 & 1.22 \\
164 & 14.3 & 11.7 & 1.22 \\
165 & 15.2 & 12.6 & 1.21 \\
175 & 15.5 & 13.0 & 1.19 \\
176 & 15.4 & 13.0 & 1.19 \\
209 & 15.0 & 12.6 & 1.20 \\
228 & 15.0 & 12.3 & 1.22 \\
266 & 16.0 & 13.4 & 1.19 \\
273 & 15.8 & 12.9 & 1.22 \\
291 & 15.6 & 12.8 & 1.22 \\
300 & 15.4 & 12.6 & 1.22 \\
302 & 17.0 & 14.0 & 1.21 \\
312 & 16.8 & 13.8 & 1.22 \\
\hline & & &
\end{tabular}


Table A.5. Peak and average fuel burnups (MWd/kg initial $U$ ) and axial pin ${ }^{137} \mathrm{Cs}$ peaking factor $\left(k_{z}\right)$ for fuel assembly ED-1476

\begin{tabular}{|c|c|c|c|}
\hline Fuel rod & Peak burnup & Average burnup & $k_{z}$ \\
\hline 1 & 41.7 & 37.5 & 1.11 \\
\hline 5 & 40.1 & 35.7 & 1.12 \\
\hline 11 & 41.1 & 37.4 & 1.10 \\
\hline 12 & 41.2 & 36.7 & 1.12 \\
\hline 26 & 42.6 & 38.3 & 1.11 \\
\hline 33 & 42.1 & 37.5 & 1.12 \\
\hline 34 & 42.4 & 38.0 & 1.12 \\
\hline 42 & 42.1 & 37.8 & 1.11 \\
\hline 58 & 42.8 & 38.2 & 1.12 \\
\hline 60 & 42.5 & 38.0 & 1.12 \\
\hline 79 & 41.1 & 36.6 & 1.12 \\
\hline 85 & 43.6 & 38.9 & 1.12 \\
\hline 104 & 43.7 & 39.0 & 1.12 \\
\hline 137 & 44.0 & 39.0 & 1.13 \\
\hline 138 & 44.0 & 39.0 & 1.13 \\
\hline 139 & 43.8 & 39.1 & 1.12 \\
\hline 148 & 42.4 & 38.0 & 1.12 \\
\hline 150 & 43.6 & 38.8 & 1.12 \\
\hline 151 & 43.5 & 38.9 & 1.12 \\
\hline 153 & 43.8 & 39.1 & 1.12 \\
\hline 156 & 44.1 & 39.2 & 1.13 \\
\hline 157 & 44.1 & 39.2 & 1.13 \\
\hline 160 & 43.9 & 39.1 & 1.12 \\
\hline 163 & 43.1 & 38.4 & 1.12 \\
\hline 165 & 41.5 & 37.6 & 1.10 \\
\hline 175 & 44.4 & 39.2 & 1.13 \\
\hline 176 & 44.6 & 39.4 & 1.13 \\
\hline 209 & 44.6 & 39.3 & 1.14 \\
\hline 210 & 44.8 & 39.9 & 1.12 \\
\hline 228 & 44.7 & 39.8 & 1.12 \\
\hline 236 & 44.7 & 39.8 & 1.12 \\
\hline 252 & 44.4 & 39.6 & 1.12 \\
\hline 253 & 44.3 & 39.3 & 1.13 \\
\hline 261 & 44.5 & 39.7 & 1.12 \\
\hline 279 & 44.9 & 39.6 & 1.13 \\
\hline 287 & 44.5 & 39.6 & 1.12 \\
\hline 296 & 45.0 & 40.1 & 1.12 \\
\hline 302 & 43.6 & 38.8 & 1.12 \\
\hline 312 & 43.6 & 38.7 & 1.13 \\
\hline
\end{tabular}


Table A.6. Peak and average fuel burnups (MWd/kg initial U) and axial pin ${ }^{137} \mathrm{Cs}$ peaking factor $\left(k_{z}\right)$ for fuel assembly E-1591

\begin{tabular}{|c|c|c|c|}
\hline Fuel rod & Peak burnup & Average burnup & $k_{z}$ \\
\hline 1 & 41.7 & 37.0 & 1.13 \\
\hline 10 & 45.2 & 40.1 & 1.13 \\
\hline 11 & 46.8 & 41.5 & 1.13 \\
\hline 13 & 39.3 & 34.9 & 1.13 \\
\hline 22 & 44.3 & 39.3 & 1.13 \\
\hline 26 & 39.4 & 34.9 & 1.13 \\
\hline 34 & 43.0 & 38.1 & 1.13 \\
\hline 55 & 40.3 & 35.7 & 1.13 \\
\hline 60 & 42.5 & 37.7 & 1.13 \\
\hline 102 & 41.1 & 36.4 & 1.13 \\
\hline 121 & 42.5 & 37.7 & 1.13 \\
\hline 137 & 42.3 & 37.5 & 1.13 \\
\hline 147 & 47.5 & 42.1 & 1.13 \\
\hline 148 & 39.5 & 35.0 & 1.13 \\
\hline 149 & 37.9 & 33.6 & 1.13 \\
\hline 150 & 37.5 & 33.2 & 1.13 \\
\hline 151 & 37.8 & 33.6 & 1.13 \\
\hline 152 & 38.8 & 34.4 & 1.13 \\
\hline 154 & 41.2 & 36.4 & 1.13 \\
\hline 156 & 42.4 & 37.5 & 1.13 \\
\hline 157 & 43.0 & 38.1 & 1.13 \\
\hline 159 & 42.7 & 38.2 & 1.12 \\
\hline 160 & 43.1 & 38.3 & 1.13 \\
\hline 161 & 43.2 & 38.4 & 1.13 \\
\hline 163 & 44.1 & 39.1 & 1.13 \\
\hline 164 & 45.4 & 40.2 & 1.13 \\
\hline 165 & 48.5 & 43.0 & 1.13 \\
\hline 174 & 41.8 & 37.1 & 1.13 \\
\hline 175 & 42.9 & 38.1 & 1.13 \\
\hline 176 & 42.9 & 38.1 & 1.13 \\
\hline 209 & 42.3 & 37.5 & 1.13 \\
\hline 224 & 41.8 & 37.0 & 1.13 \\
\hline 228 & 43.2 & 38.3 & 1.13 \\
\hline 253 & 41.1 & 36.5 & 1.13 \\
\hline 258 & 43.2 & 38.3 & 1.13 \\
\hline 263 & 41.0 & 36.3 & 1.13 \\
\hline 273 & 42.8 & 37.9 & 1.13 \\
\hline 276 & 46.0 & 40.8 & 1.13 \\
\hline 279 & 40.9 & 36.3 & 1.13 \\
\hline 287 & 43.6 & 38.7 & 1.13 \\
\hline 290 & 42.3 & 37.5 & 1.13 \\
\hline 291 & 41.9 & 37.2 & 1.13 \\
\hline 300 & 45.2 & 40.1 & 1.13 \\
\hline 302 & 44.4 & 39.4 & 1.13 \\
\hline 312 & 48.2 & 42.7 & 1.13 \\
\hline
\end{tabular}


To estimate the sensitivity of the calculated results to the uncertainties mentioned above, a series of fuel assembly burnup calculations were performed with the use of TVS-M code. As a reference variant a serial VVER-1000 assembly of 4.4\% enrichment with nominal parameter values (given in Table A.7) was chosen. Other variants differ from the reference variant in:

\$ fuel temperature;

\$ moderator density;

$\$$ time-averaged value of boron;

\$ accounting for the time dependence of boron concentration;

\$ removing the burnable absorbers (BA) from the assembly (in reference variant BAs were inserted during first year Bup to $12 \mathrm{MWd} / \mathrm{kg}$ );

$\$$ accounting for the exposure time between reloadings (at burnups of 12 and $35 \mathrm{MWd} / \mathrm{kg}$ exposure time is equal to 60 and 90 days, respectively);

Averaged over the assembly, nuclide contents of spent fuel corresponding to burnup value of $40 \mathrm{MWd} / \mathrm{kg}$ are compared with the reference variant. Results of the comparisons are presented in Table A.8. As is seen from the table, the spent fuel isotopic composition is sensitive to disturbances of moderator density (considerable), fuel temperature and to the presence of BA rods in the assembly. Accounting for fuel exposure time affects only unstable nuclides.

\section{A.5.2 Benchmark Specification}

A proposed benchmark specification was formulated within the approach of an isolated fuel assembly with a zero-current boundary condition and averaged operational characteristics. These characteristics (such as local power density, moderator density and temperature, boron acid concentration) were obtained from NPP operational data and from calculations simulating the whole core operation. These calculations were performed with the use of BIPR-7 code ${ }^{7}$ The fuel temperature was estimated using the TOPRA-S code. ${ }^{8}$

Geometric and material characteristics of a VVER-1000 fuel assembly are given in Tables 2 and 3 in the main text. Data for these tables were taken from the report by Styrin 6 Note that spacer grids are effectively taken into account by changing the width and content of the fuel pin cladding and of the central and guide tubes.

Table A.9 contains data on local (for given level) irradiation conditions of the investigated fuel assemblies. 
Table A.7. Nominal operating parameters of VVER-1000 fuel assembly

\begin{tabular}{ccccc}
\hline$T_{f}, \mathrm{~K}$ & $T_{m}, \mathrm{~K}$ & $\mathrm{D}_{m}, \mathrm{~g} / \mathrm{cm}^{3}$ & $\mathrm{~N}_{\mathrm{th}}, \mathrm{MW} / \mathrm{m}^{3}$ & $\mathrm{C}_{\mathrm{B}}, \mathrm{g} / \mathrm{kg}$ \\
\hline 1027 & 575 & 0.72348 & 108.0 & 0.6 \\
\hline
\end{tabular}

Table A.8. Sensitivity of nuclide content to irradiation conditions

\begin{tabular}{lccccccccccccccc}
\hline & \multicolumn{10}{c}{ Difference from reference variant, \% } \\
\cline { 2 - 11 } & ${ }^{235} \mathrm{U}$ & ${ }^{236} \mathrm{U}$ & ${ }^{238} \mathrm{U}$ & ${ }^{237} \mathrm{~Np}$ & ${ }^{238} \mathrm{Pu}$ & ${ }^{239} \mathrm{Pu}$ & ${ }^{240} \mathrm{Pu}$ & ${ }^{241} \mathrm{Pu}$ & ${ }^{242} \mathrm{Pu}$ & ${ }^{241} \mathrm{Am}$ & ${ }^{242 \mathrm{~m}} \mathrm{Am}$ & ${ }^{243} \mathrm{Am}$ \\
\hline $\mathrm{T}_{\mathrm{f}}=900 \mathrm{~K}$ & $! 0.78$ & 0.30 & 0.03 & $! 0.53$ & $! 0.14$ & $! 1.81$ & $! 0.44$ & $! 1.55$ & $! 0.46$ & $! 1.97$ & $! 2.05$ & $! 0.66$ \\
$\mathrm{D}_{\mathrm{m}}=\mathrm{D}_{\mathrm{m}}{ }^{0} \times 0.95$ & 1.94 & $! 0.06$ & $! 0.06$ & 2.69 & 4.43 & 4.57 & 1.37 & 3.97 & 0.36 & 4.28 & 6.52 & 3.30 \\
$\mathrm{C}_{\mathrm{B}}=0.5 \mathrm{~g} / \mathrm{kg}$ & $! 0.39$ & 0.04 & 0.01 & $! 0.54$ & $! 0.83$ & $! 0.75$ & $! 0.12$ & $! 0.77$ & $! 0.22$ & $! 0.84$ & $! 1.29$ & $! 0.77$ \\
$\mathrm{C}_{\mathrm{B}}=\mathrm{C}_{\mathrm{B}}(\mathrm{t})$ & 0.16 & 0.06 & 0.00 & $! 0.03$ & 0.01 & $! 0.02$ & 0.08 & 0.21 & 0.12 & 0.01 & 0.59 & 0.28 \\
$\mathrm{~W}_{\text {Without BA }}$ & $! 1.48$ & $! 0.15$ & 0.03 & $! 0.60$ & $! 1.19$ & $! 0.87$ & $! 1.13$ & $! 1.41$ & $! 1.35$ & $! 2.73$ & $! 3.10$ & $! 1.88$ \\
$\mathrm{t}_{\text {storage }}$ & 0.00 & 0.00 & 0.00 & 0.00 & 1.63 & $! 0.02$ & $! 0.04$ & $! 0.63$ & $! 0.22$ & 28.31 & 31.13 & $! 0.09$ \\
\hline
\end{tabular}




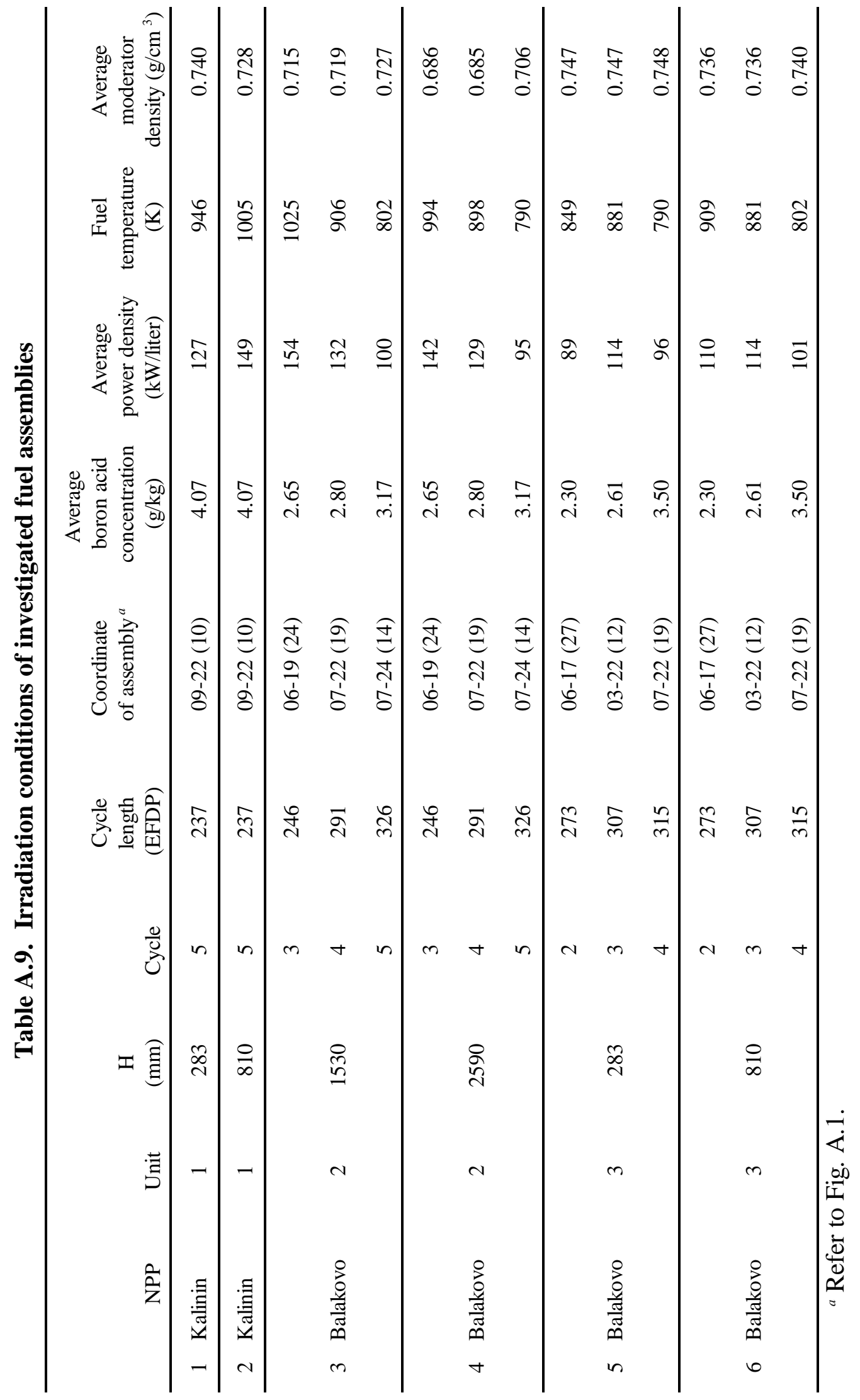





\section{APPENDIX B}

\section{HELIOS INPUT INSTRUCTIONS USED IN SIMULATIONS}





\section{B.1. HELIOS INPUT FOR SIX LEU SAMPLES}

Input data used in the HELIOS simulations are listed below. Six separate input streams are listed $C$ one for each of the six LEU samples studied. Each of the input streams is identified and comment cards are used to explain the function of the various parts of the input instructions. When studying these input streams, the reader should keep Fig. 3 (in the main text) in mind. The overall structure of the assembly sector modeled was the same in all instances. Most of the differences in the input streams that follow are related to fuel composition, location of the sample pin, moderator density, temperature, boron concentration, and irradiation history. 
LISTING NO. 1; THE HELIOS INPUT FOR SAMPLE 33 IN KALININ-1:

+ THEL

vverkal133 = CASE('library.bin'/'vverkal133.hrf'/'VVER- Kalinin-1; Sample 33')

!

!

\$AssemblyPitch

\$PinPitch

$!$

\$FuelHoleRadius

$\$$ FuelRadius

\$FuelinnerClad

\$CladRadius

\$GuideTubeInnerRadius

Simulating $1 / 6$ of Kalinin-1 Assembly

This one is for sample 33

\$GuideTubeOuterRadius

\$CentralTubeInnerRadius
\$CentralTubeOuterRadius

\$AbsorberRadius $\quad=\operatorname{PAR}(" 0.379 ")$

$=\operatorname{PAR}(" 23.6 ")$

Global

$=\operatorname{PAR}(" 1.275 ")$

$=\operatorname{PAR}(" 0.115 ")$

$=\operatorname{PAR}(" 0.3775 ")$

$=\operatorname{PAR}(" 0.386 ")$

$=\operatorname{PAR}(" 0.4582 ")$

$=\operatorname{PAR}(" 0.545 ")$

Guide tube !

$=\operatorname{PAR}(" 0.6323 ")$

$=\operatorname{PAR}(" 0.48 ")$

Central tube !

\$AbsorberInnerClad $\quad=\operatorname{PAR}(" 0.386 ")$

\$AbsorberCladRadius $\quad=$ PAR ("0.455")

\$rhole = PAR ("\$FuelHoleRadius")

Defining CCS structures

\$rfuel = PAR ("\$FuelRadius")

\$rcladi = PAR ("\$FuelInnerClad")

\$rclad = PAR ("\$CladRadius")

\$rcti = PAR ("\$CentralTubeInnerRadius")

\$rcto = PAR ("\$CentralTubeOuterRadius")

\$rbpa = PAR ("\$AbsorberRadius")

\$rbpb = PAR ("\$AbsorberInnerClad")

\$rbpc = PAR ("\$AbsorberCladRadius")

\$rgti = PAR("\$GuideTubeInnerRadius")

\$rgto = PAR ("\$GuideTubeOuterRadius")

! Pellet hole radius

! Pellet radius

! Clad inner radius

! Clad outer radius

! Central Tube inner rad !

! Central Tube outer rad

! absorber radius

! clad inner radius

! clad outer radius

! guide tube inner radius !

! guide tube outer radius !

Fpin = CCS (\$rhole, \$rfuel, \$rcladi, \$rclad //gap, fuel, gap, clad)

Cpin = CCS (\$rcti, \$rcto//cool, cclad)

Gpin = CCS (\$rbpa, \$rbpb, \$rbpc, \$rgti, \$rgto//abs, gap, aclad, cool, gclad)

! -------------- Coupling order, power density, temps ------------------ ! ! Some of this may be needed, some may not

$\$ \mathrm{k} \quad=\operatorname{PAR}(4) \quad$ ! Internal coupling order

$\$ \mathrm{~kb}=\operatorname{PAR}(4)$

white $=\operatorname{ALB}(1 / 1 / 1)$

\$PowerDensity $\quad=\operatorname{PAR}(52.40)$

\$FuelTemp1 $=\operatorname{PAR}(963)$

\$FuelTemp2 $=\operatorname{PAR}(579)$

\$FuelTemp3 $\quad=\operatorname{PAR}(300)$

\$CoolTemp1 $=\operatorname{PAR}(575)$

\$CoolTemp2 $=\operatorname{PAR}(300)$

\$Buckling

! Boundary coupling order

! Diagonal, equal elements

! Power density (W/gU)

! Kalinin-1 Hot fuel (K)

! Warm fuel (K)

! Cold fuel $(K)$

! Hot coolant (K)

! Cold coolant (K)

! Axial buckling ( $\mathrm{cm}-2)$

$\$ \mathrm{p} \quad=\operatorname{PAR}(" \$ P i n P i t c h ")$

! pin pitch

$\$ a$

$=\operatorname{PAR}(" \$ p / 2 ")$ 


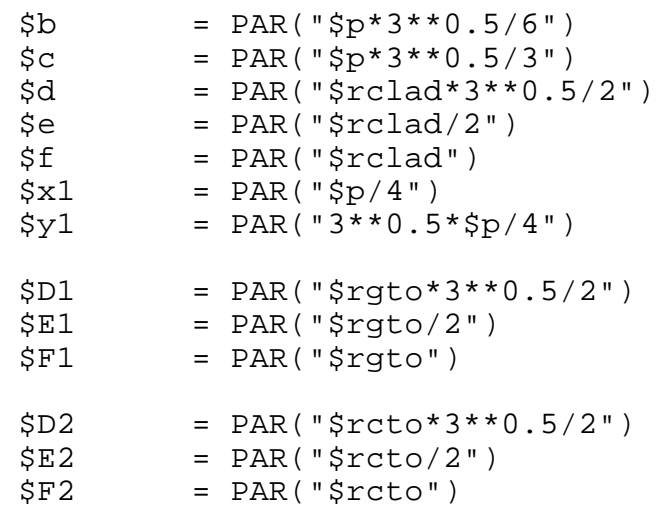




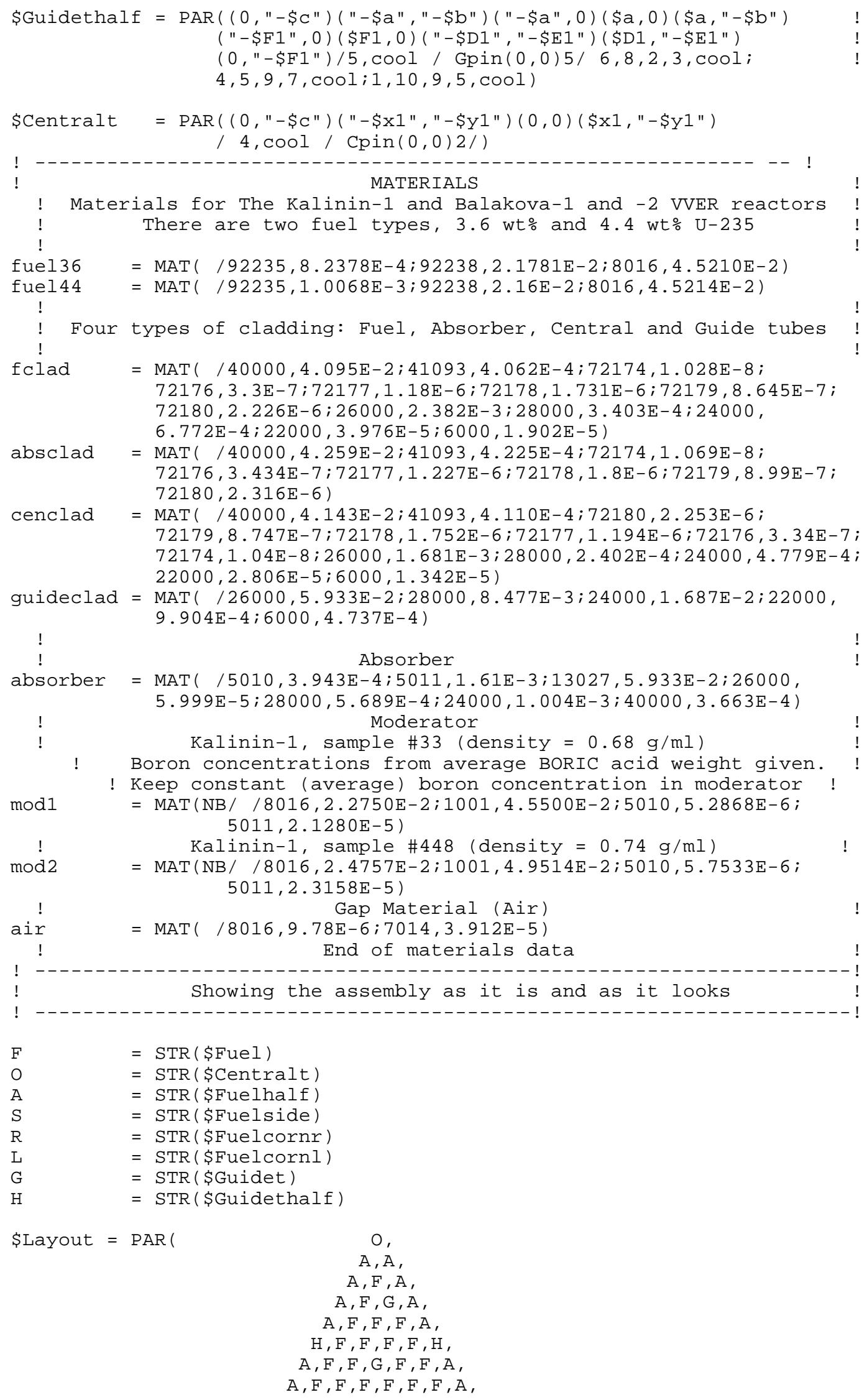




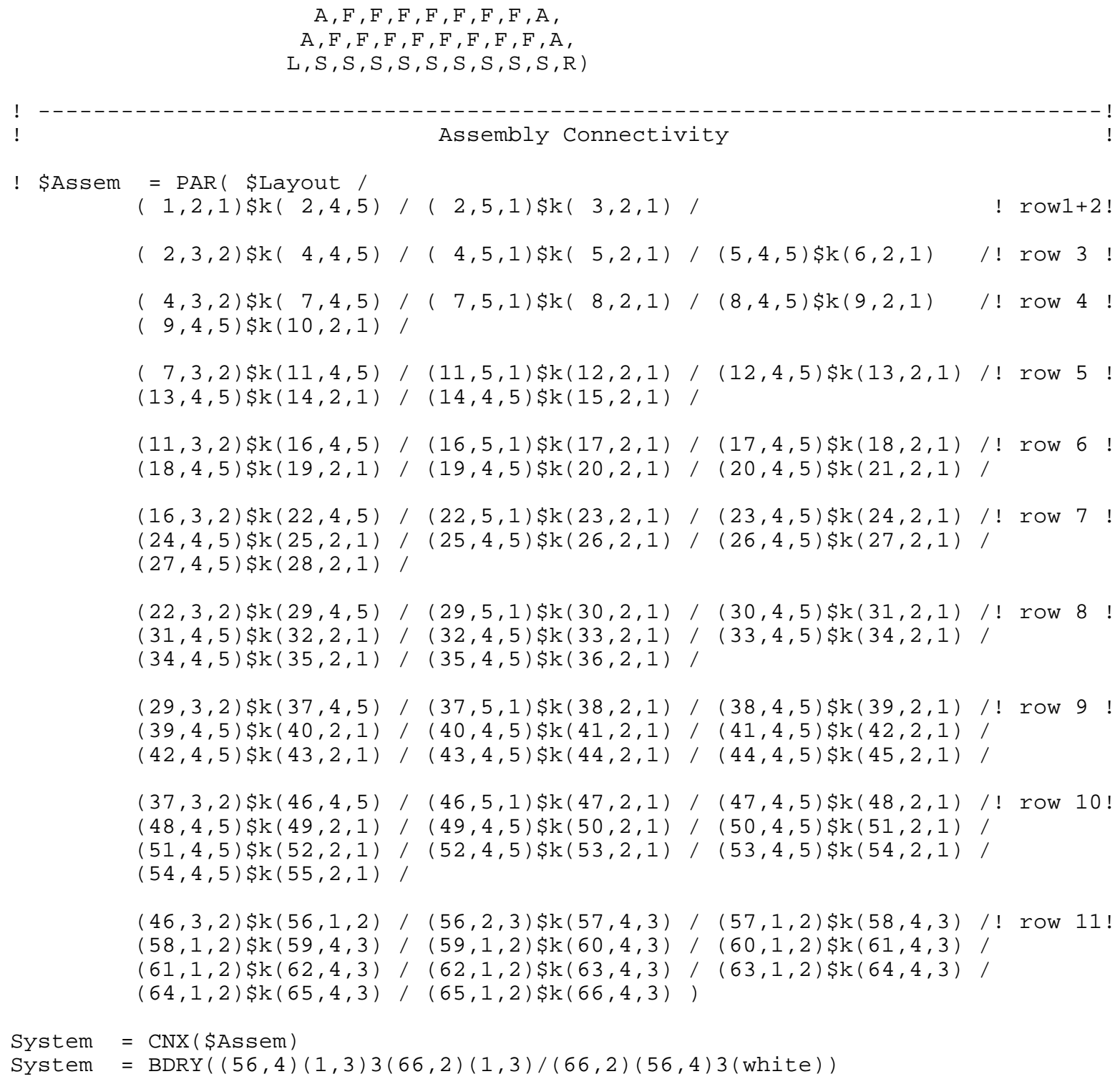




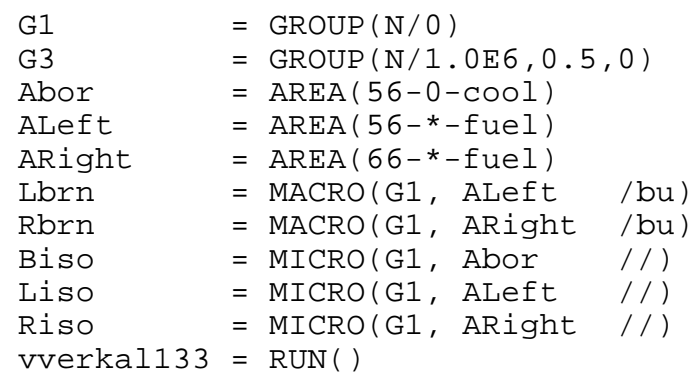


LISTING NO. 2; THE HELIOS INPUT FOR SAMPLE 448 IN KALININ-1:

+ THEI

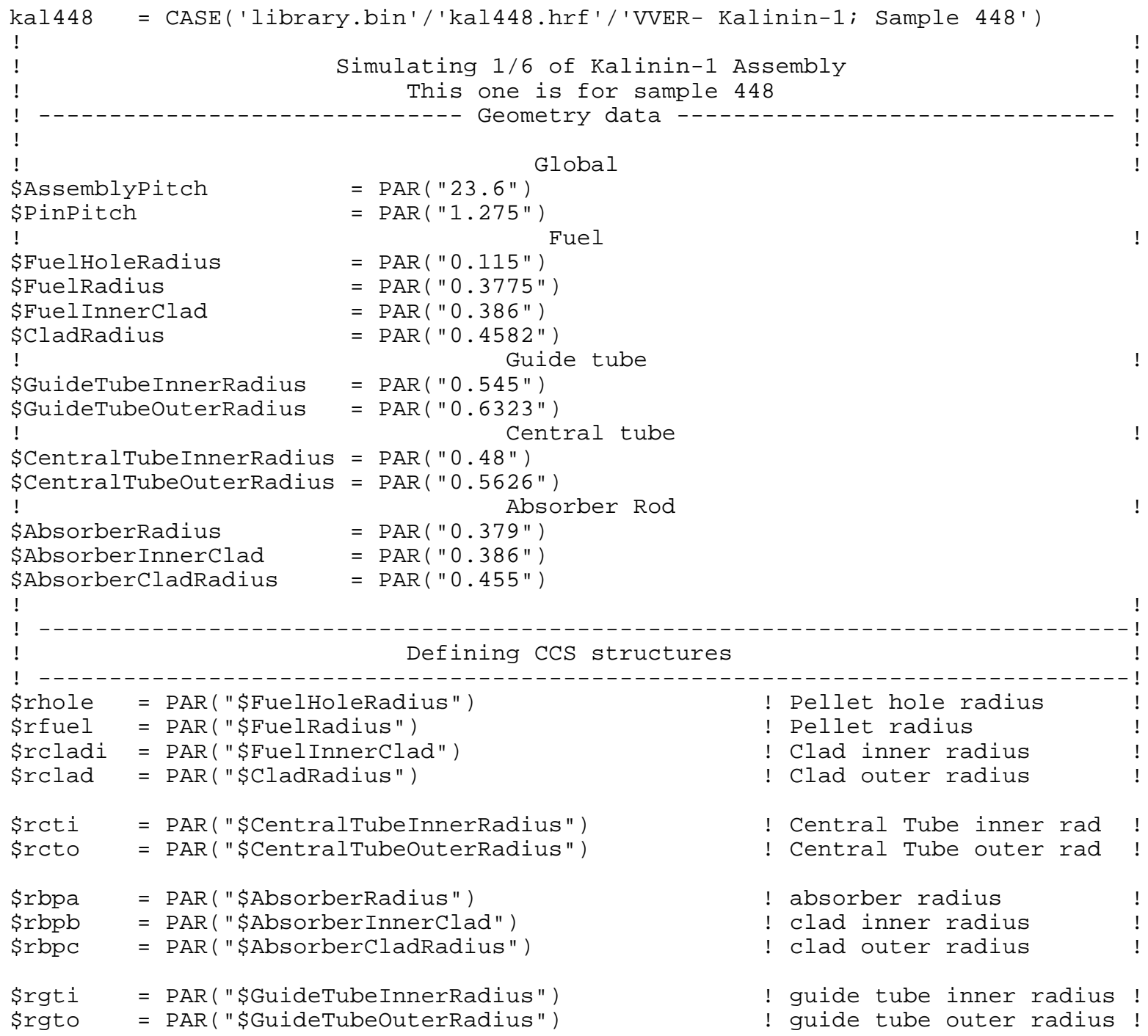

Fpin = CCS (\$rhole, \$rfuel, \$rcladi, \$rclad //gap, fuel, gap, clad)

Cpin= CCS (\$rcti, \$rcto//cool, cclad)

Gpin = CCS (\$rbpa, \$rbpb, \$rbpc, \$rgti, \$rgto//abs, gap, aclad, cool, gclad)

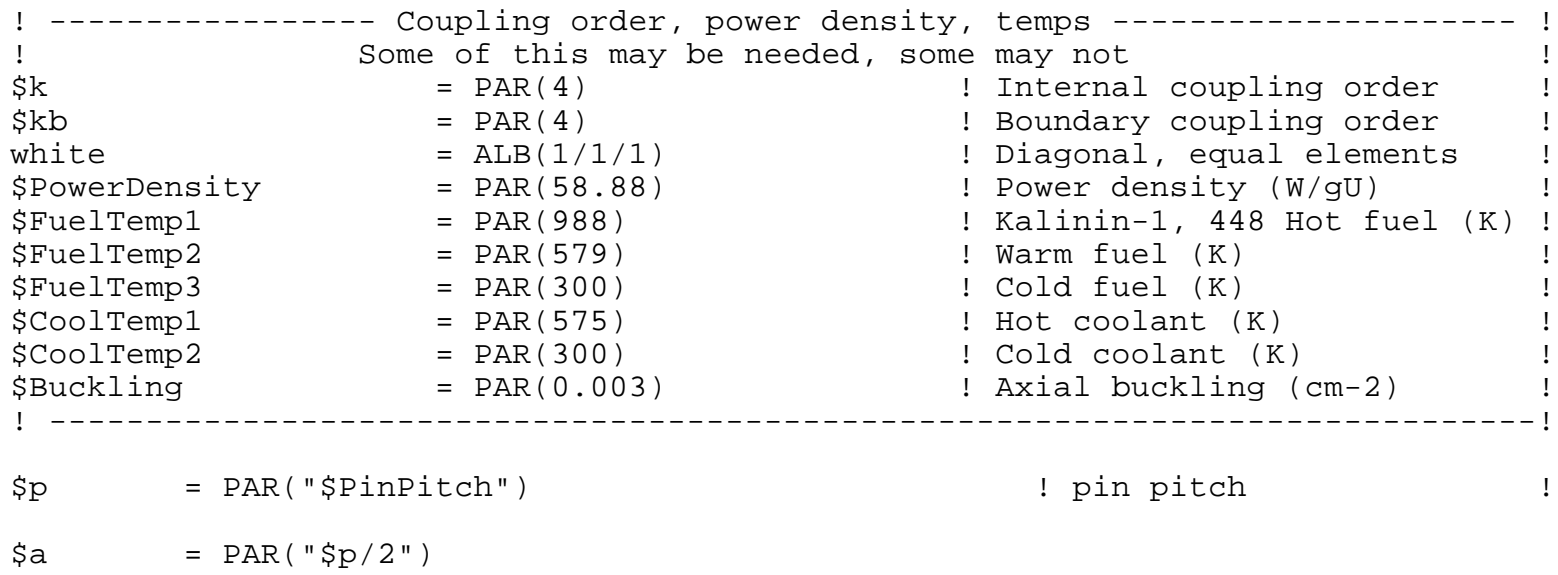




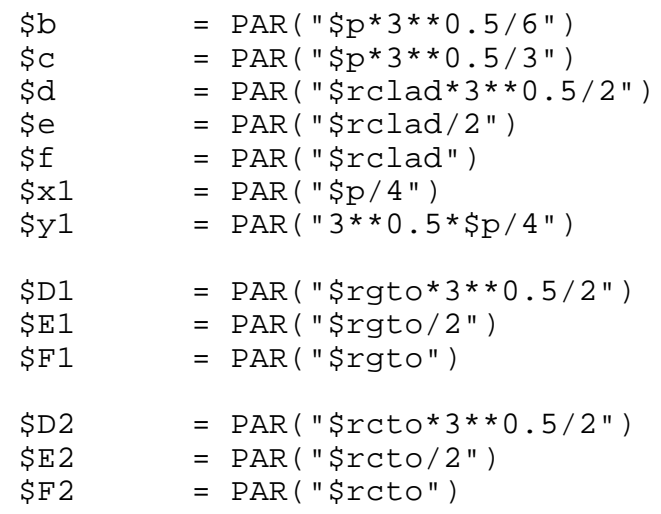

\$Guidet

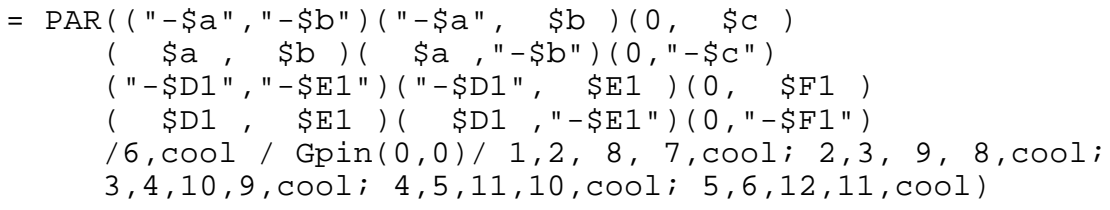
S




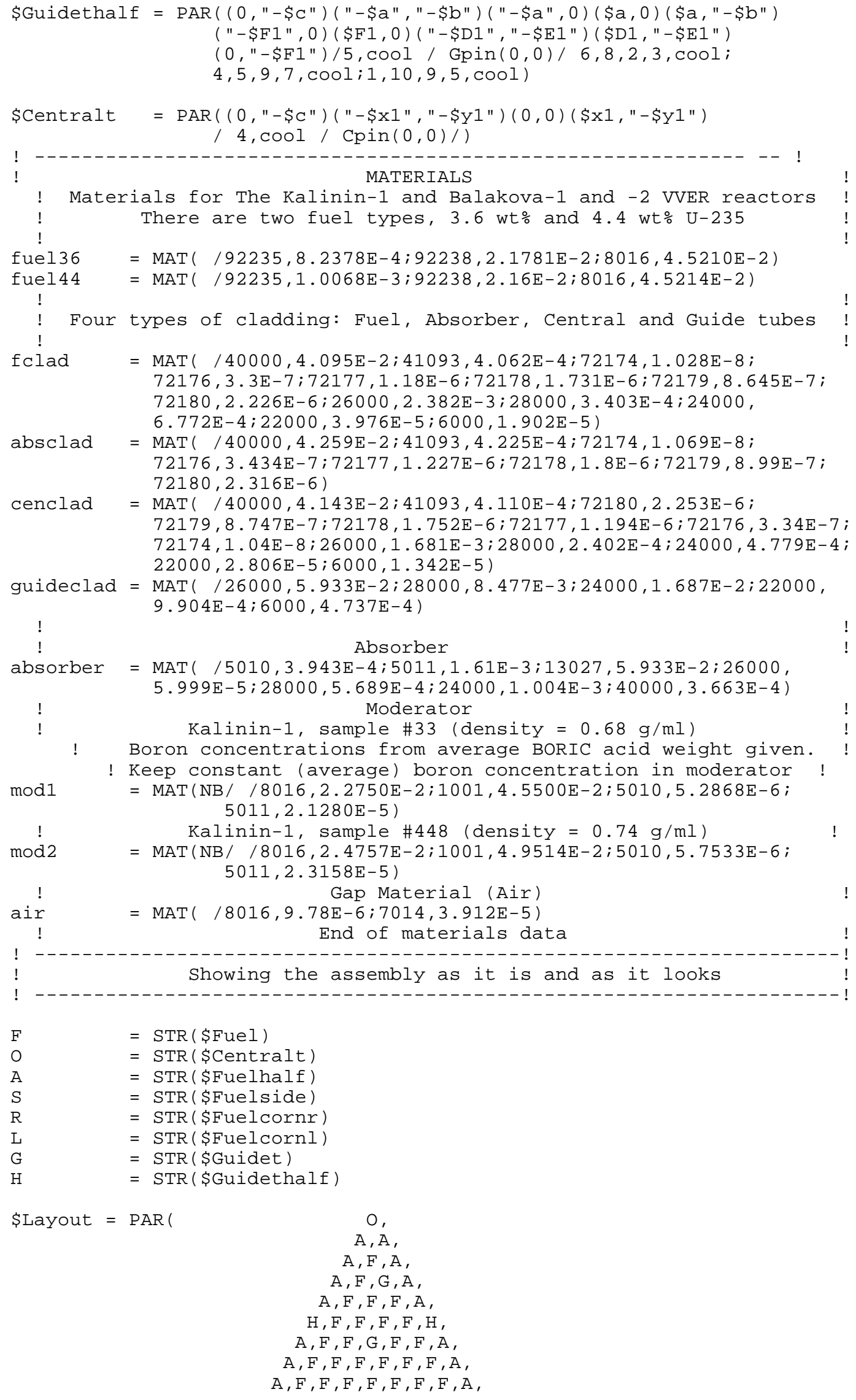




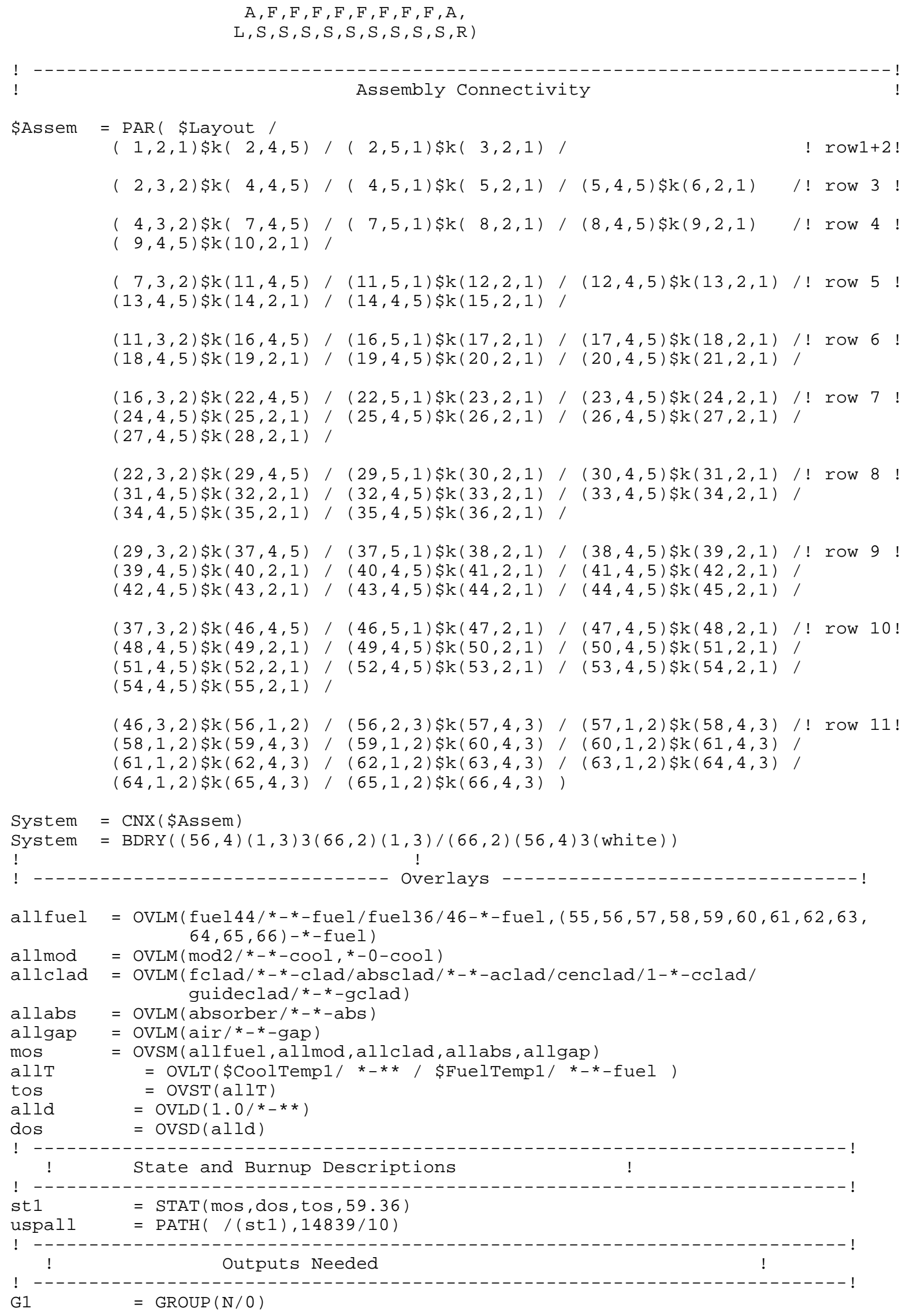




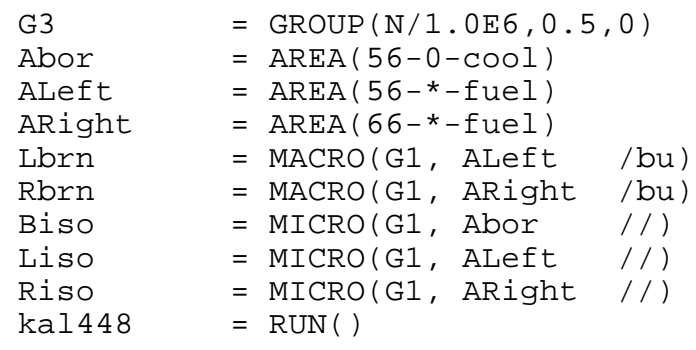


LISTING NO. 3; THE HELIOS INPUT FOR SAMPLE 6 IN BALAKOVO-2:

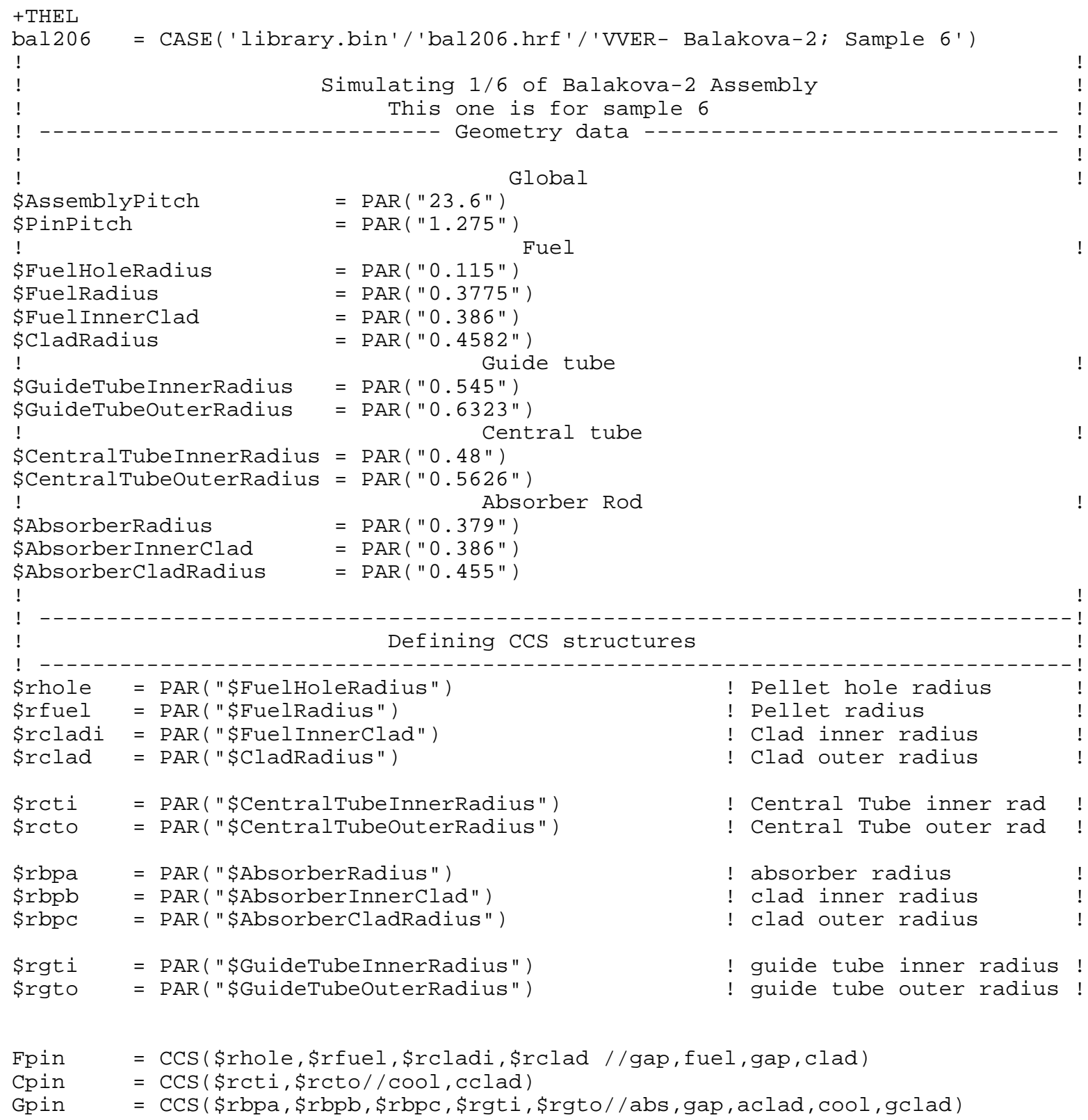




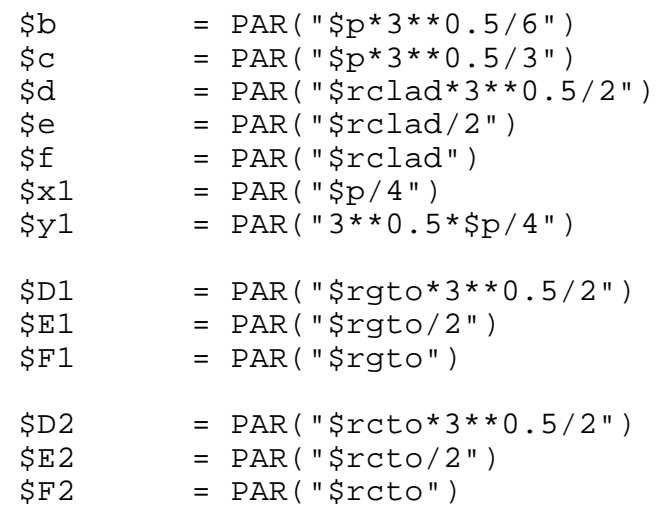




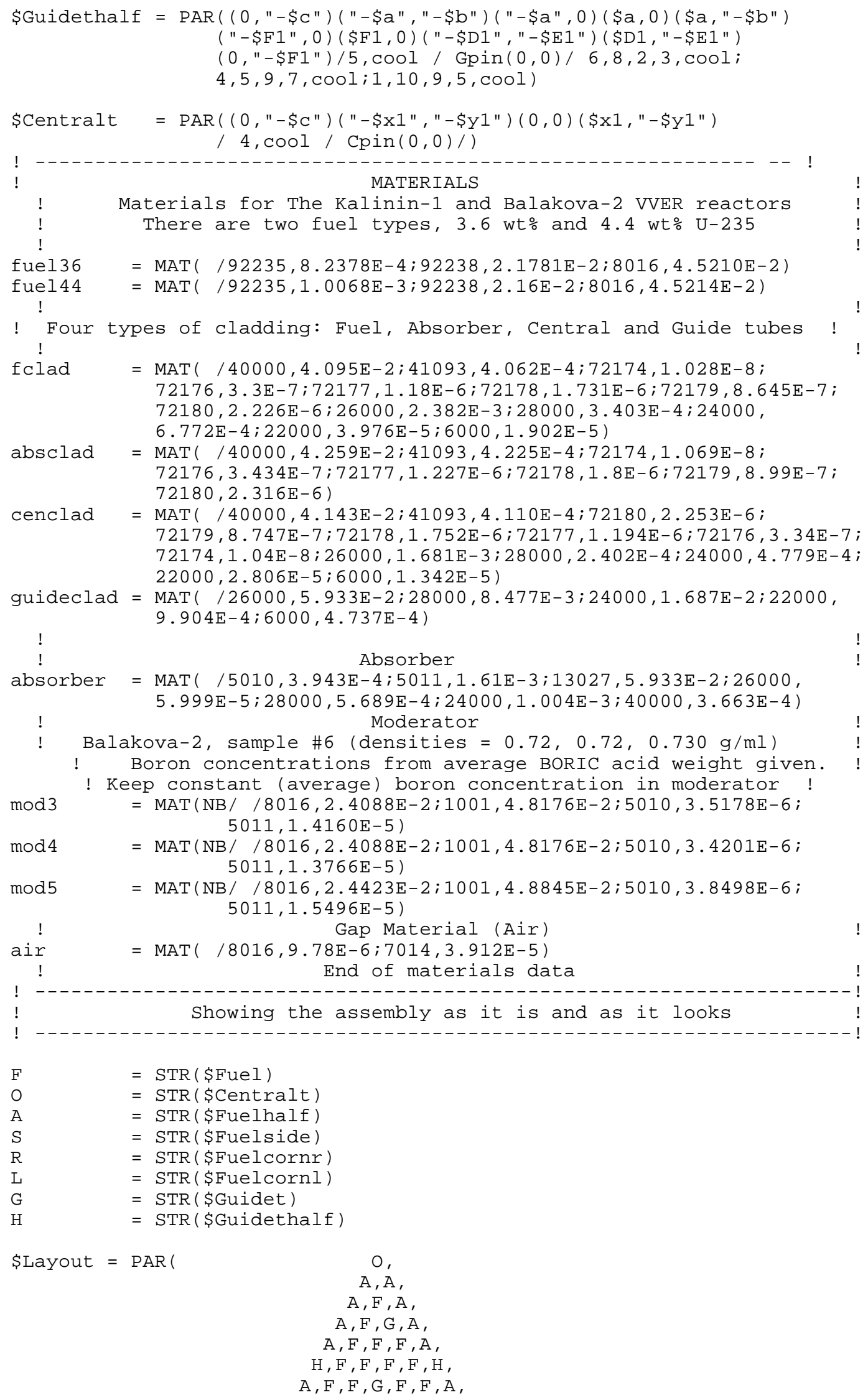




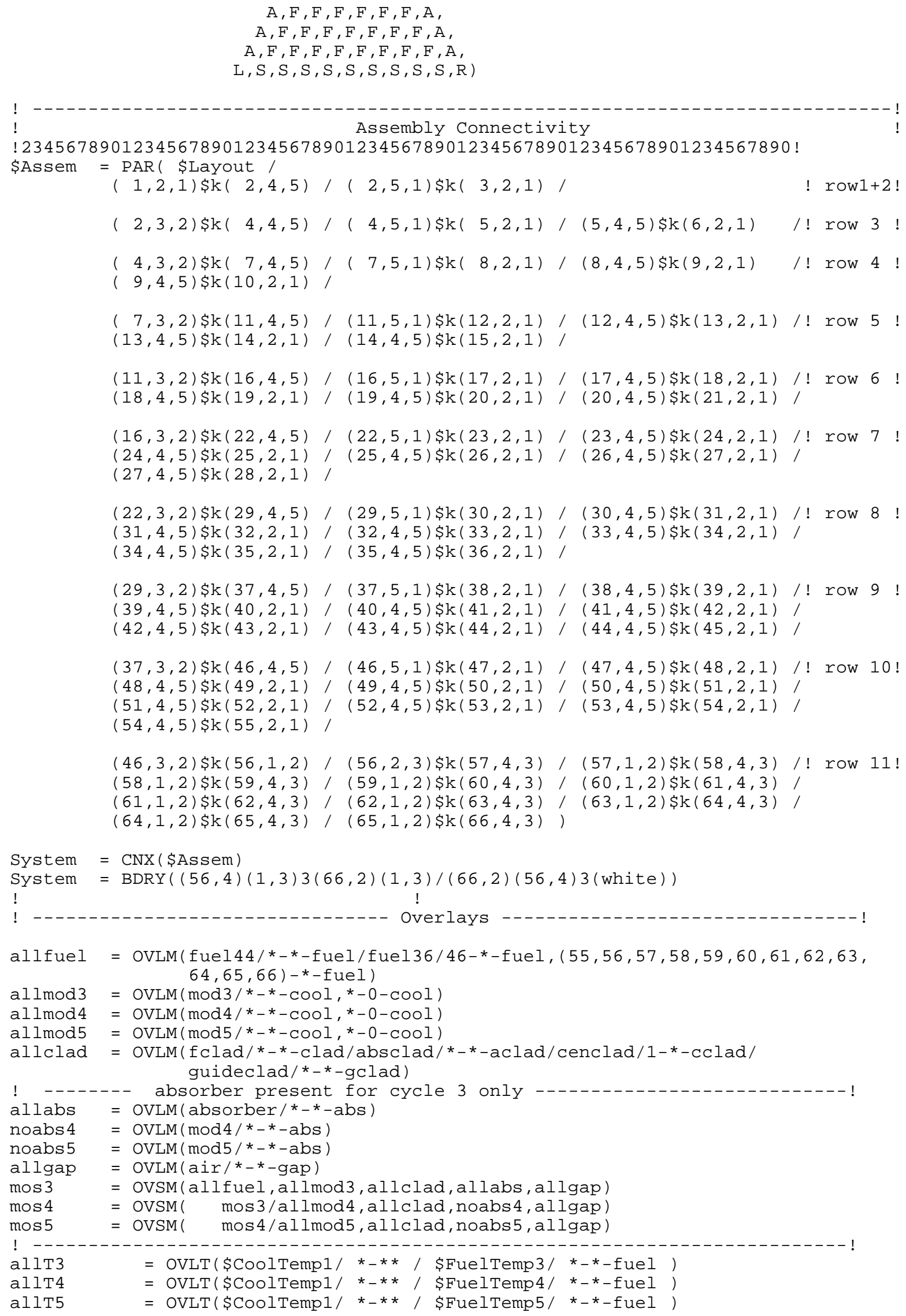




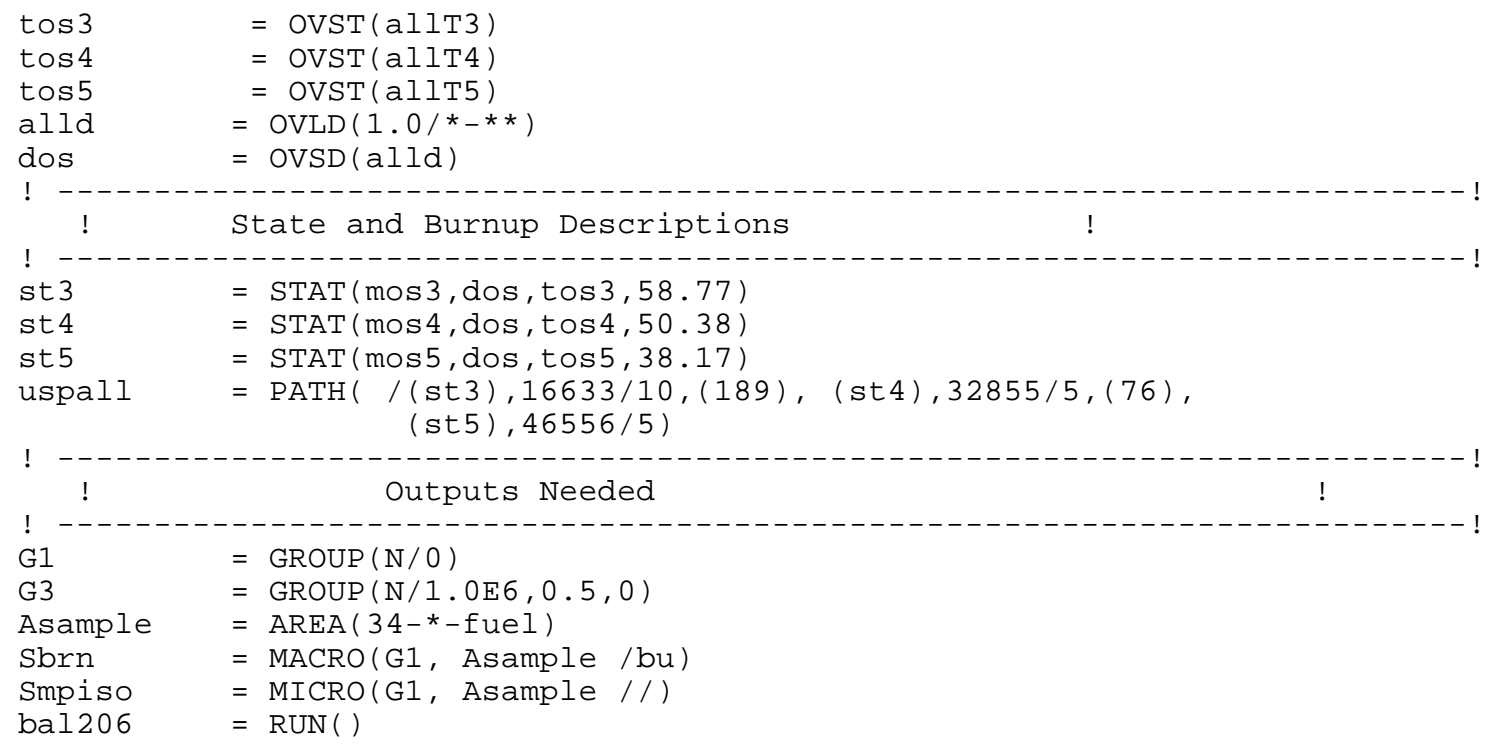


LISTING NO. 4; THE HELIOS INPUT FOR SAMPLE 15 IN BALAKOVO-2:

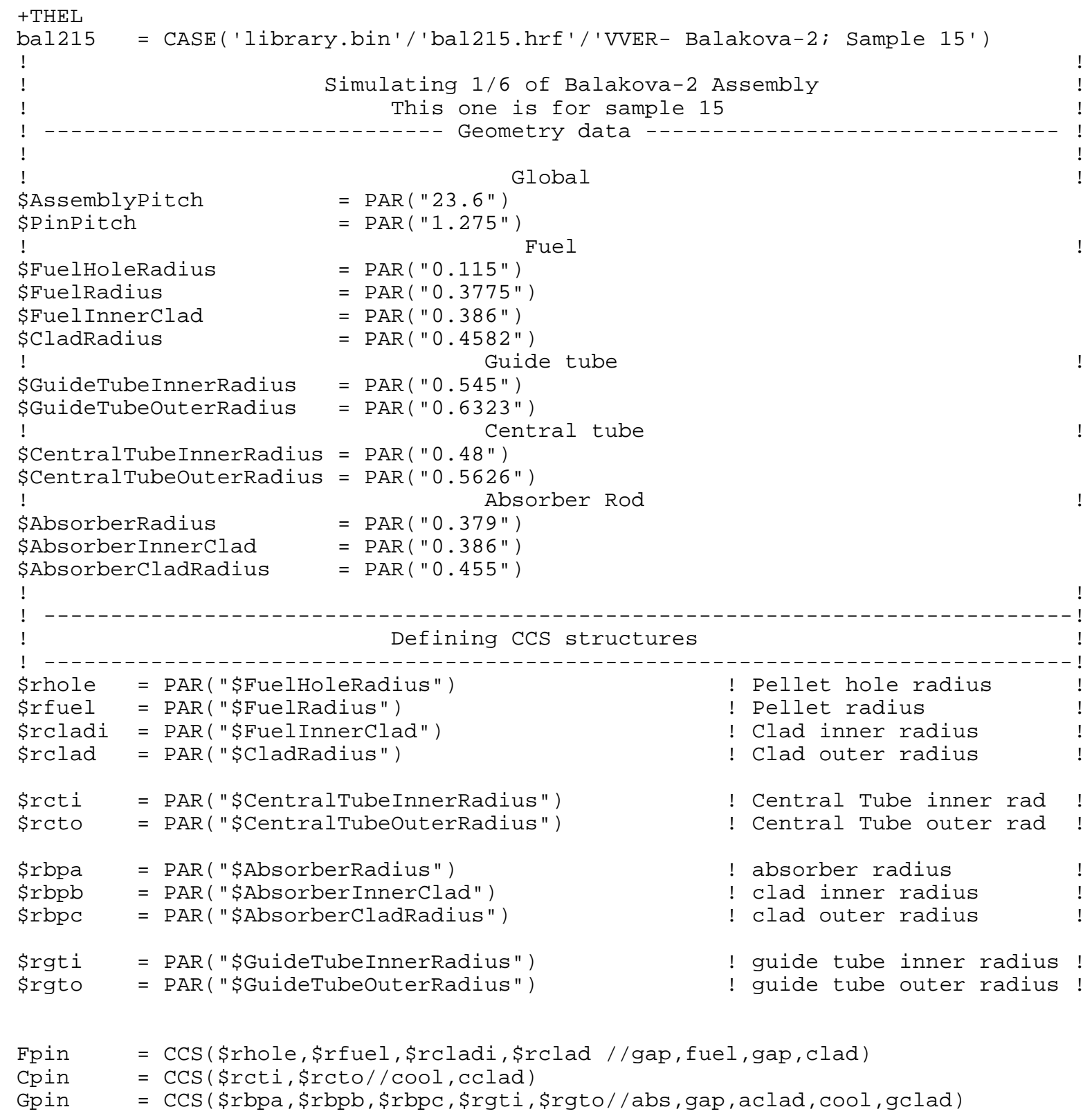




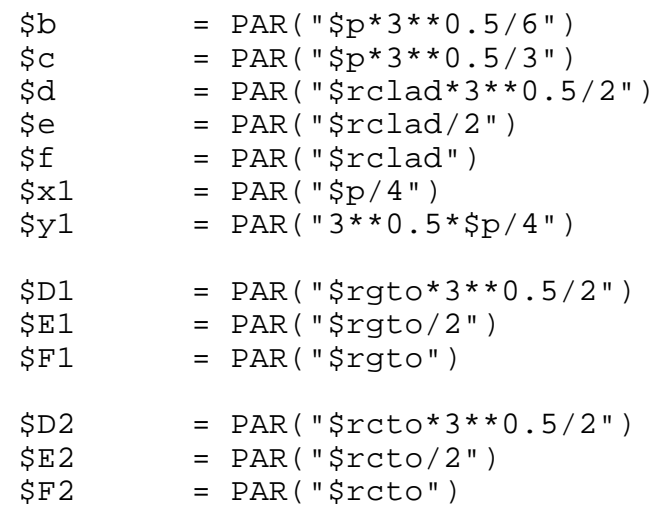




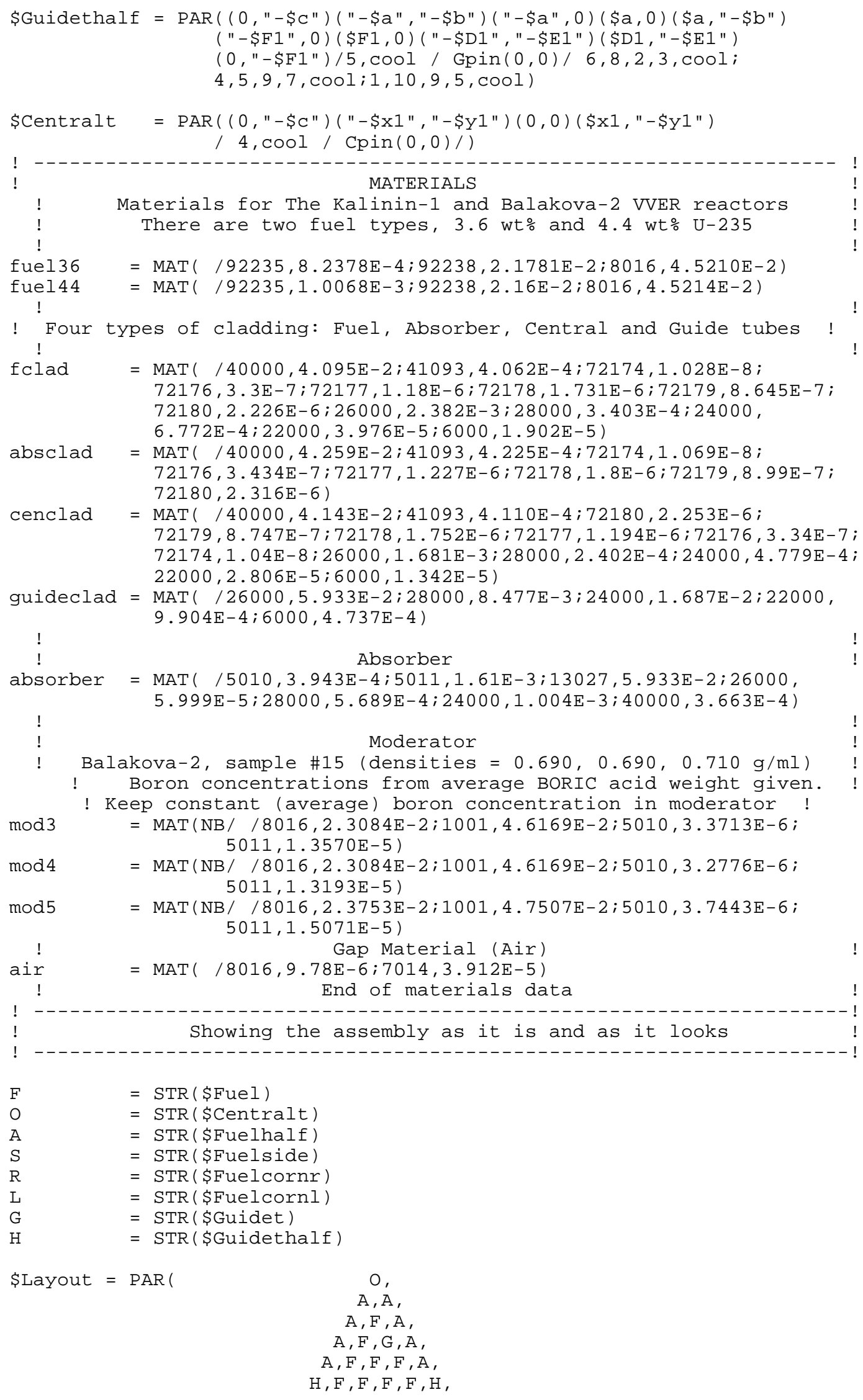




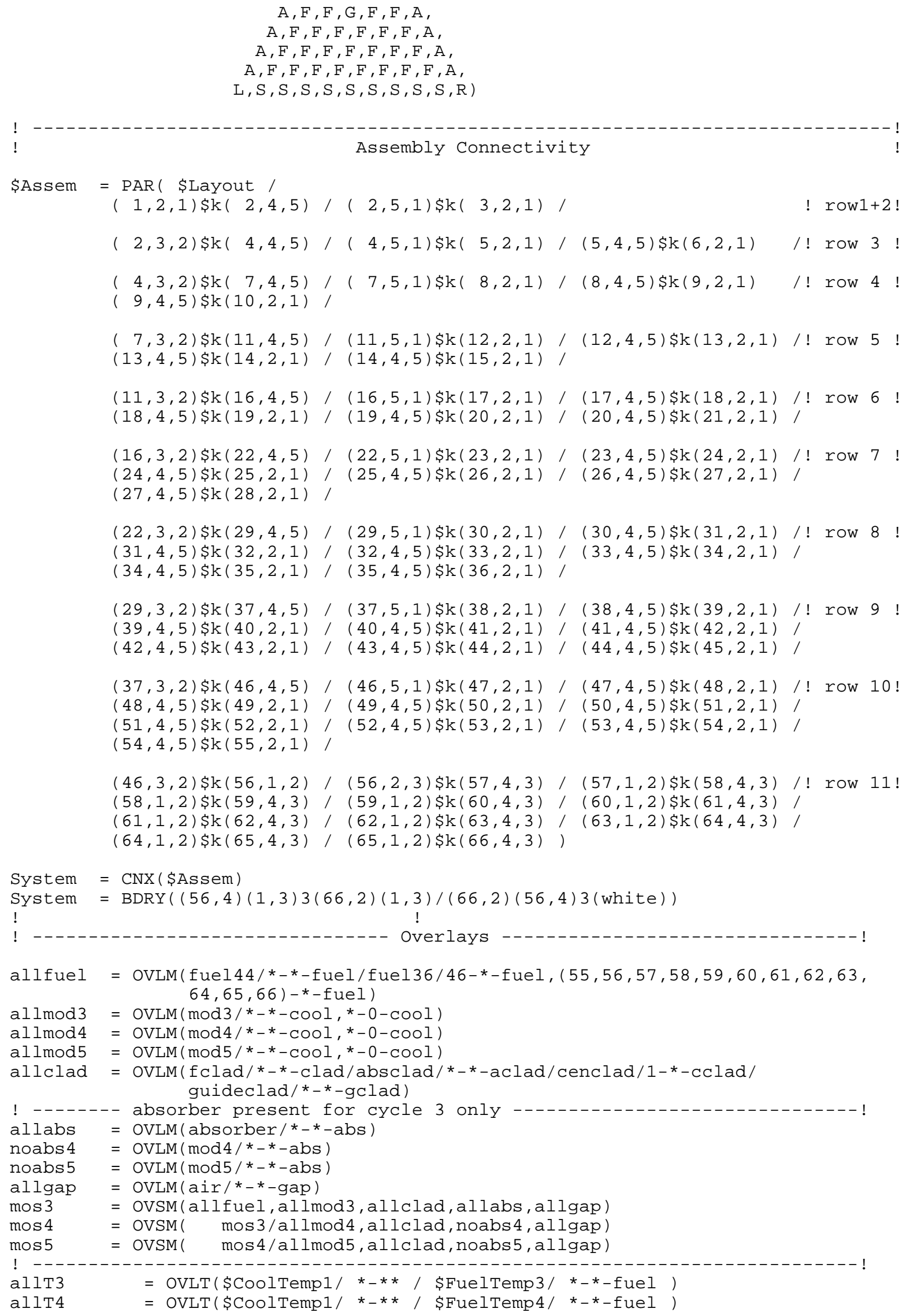




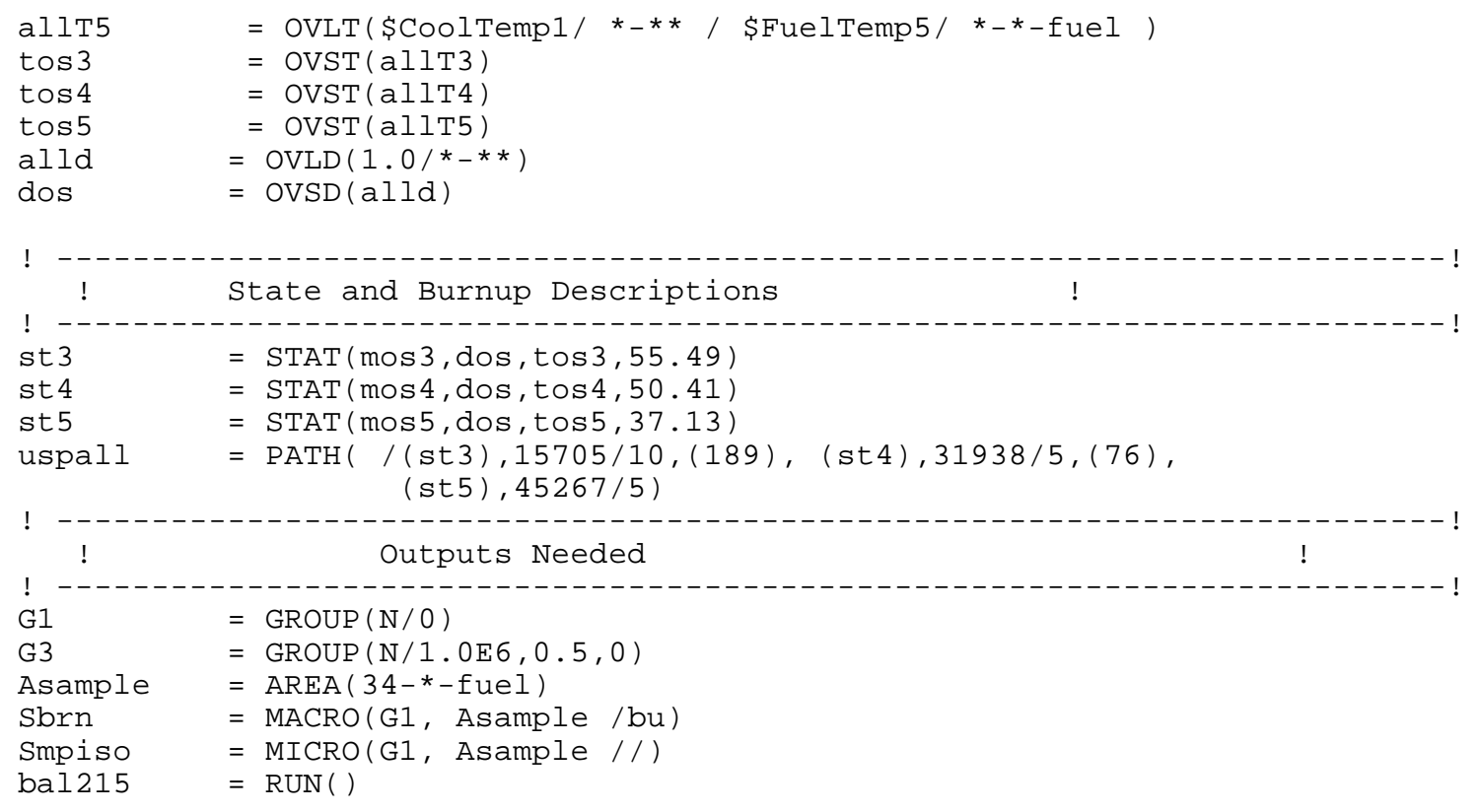


LISTING NO. 5; THE HELIOS INPUT FOR SAMPLE 912 IN BALAKOVO-3:

+ THEL

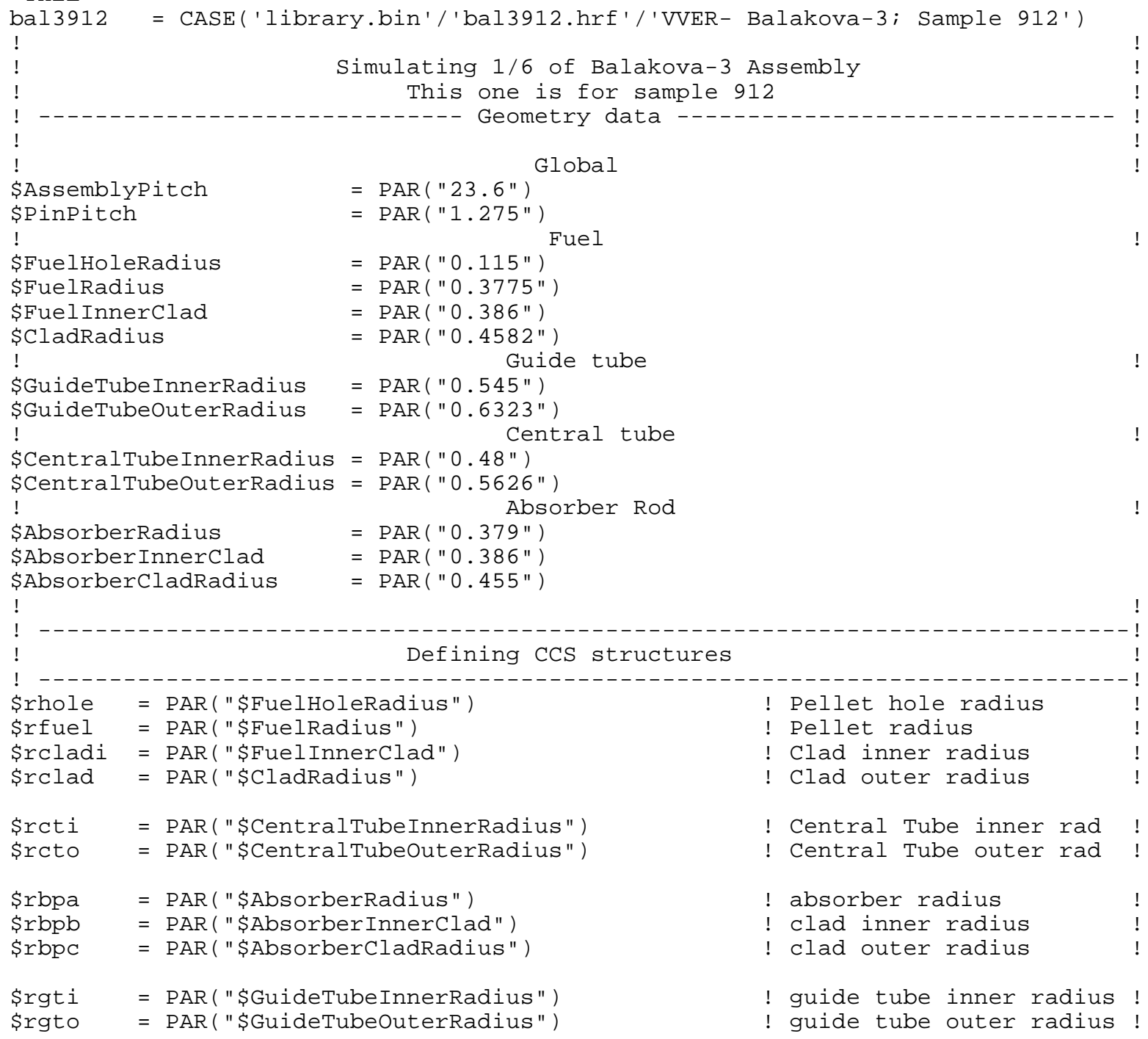

Fpin = CCS (\$rhole, \$rfuel, \$rcladi, \$rclad //gap, fuel, gap, clad)

Cpin= CCS (\$rcti, \$rcto//cool, cclad)

Gpin $=\operatorname{CCS}(\$ r b p a, \$ r b p b, \$ r b p c, \$ r g t i, \$ r g t o / / a b s, g a p, a c l a d, c o o l, g c l a d)$

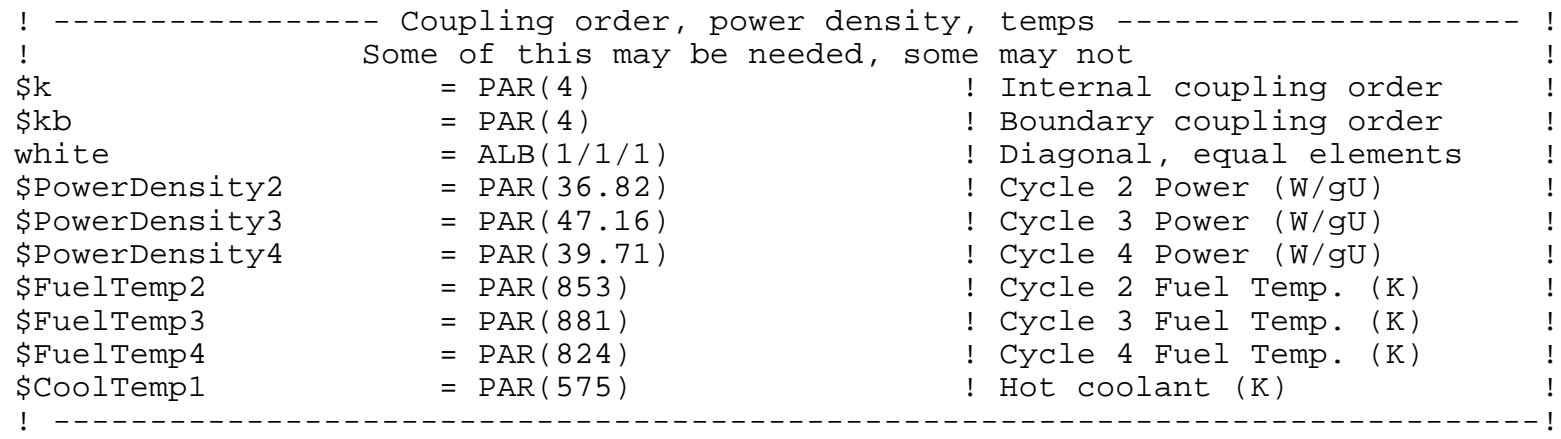

$\begin{array}{ll}\$ \mathrm{p} & =\operatorname{PAR}(" \$ P i n P i t c h ") \\ \$ \mathrm{a} & =\operatorname{PAR}(" \$ \mathrm{p} / 2 ")\end{array}$




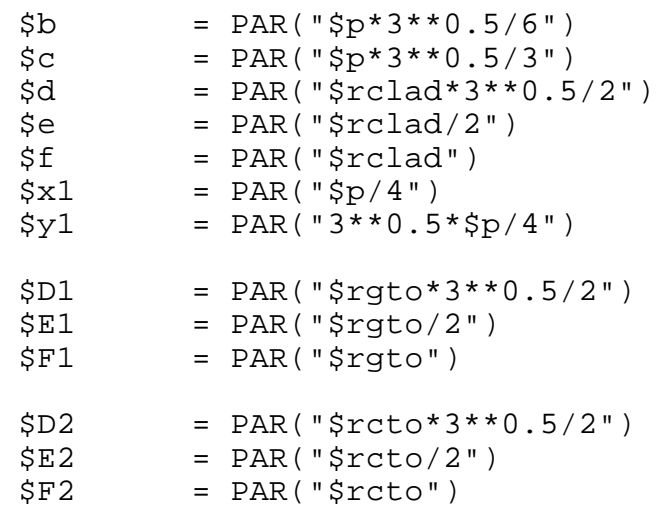




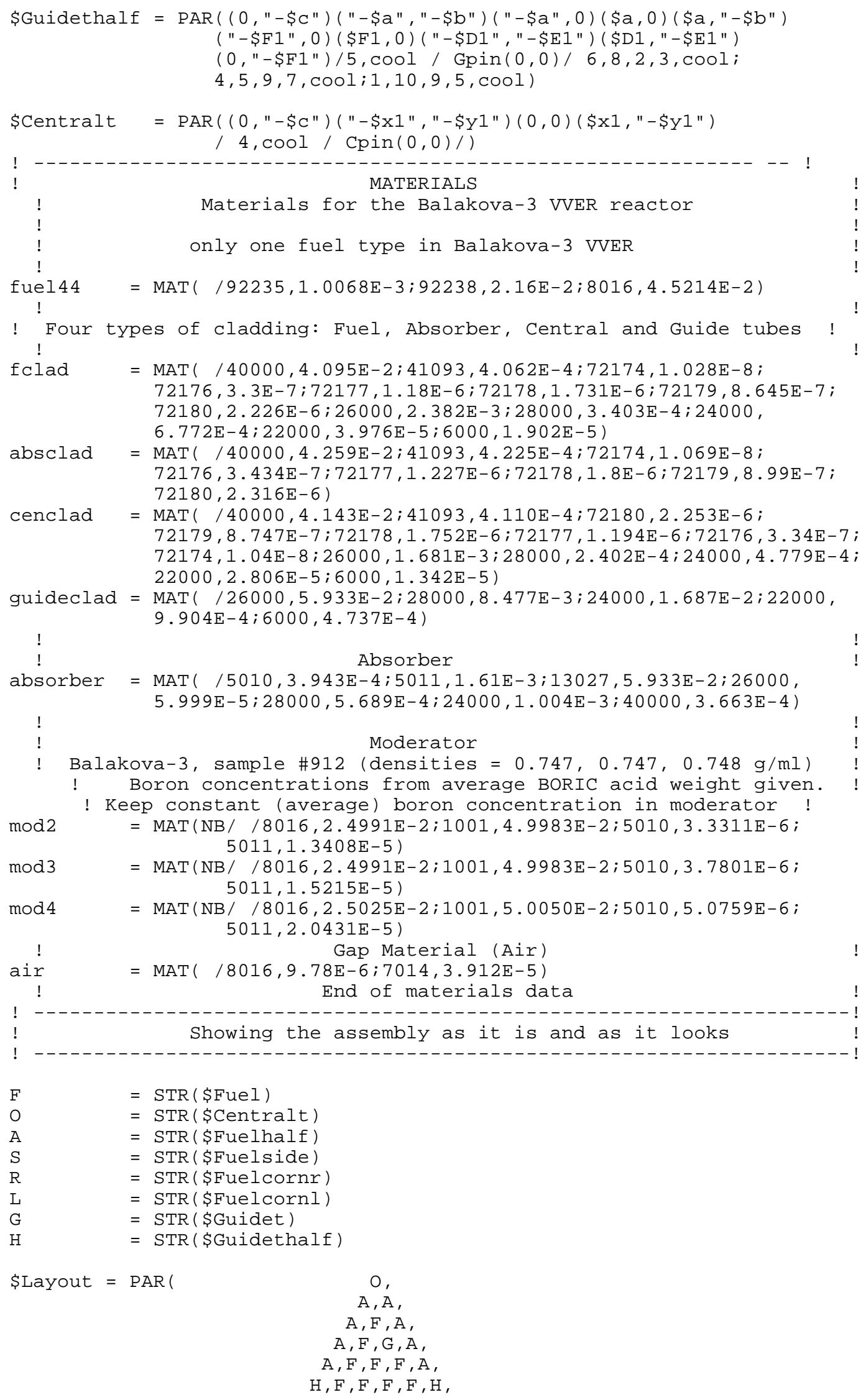




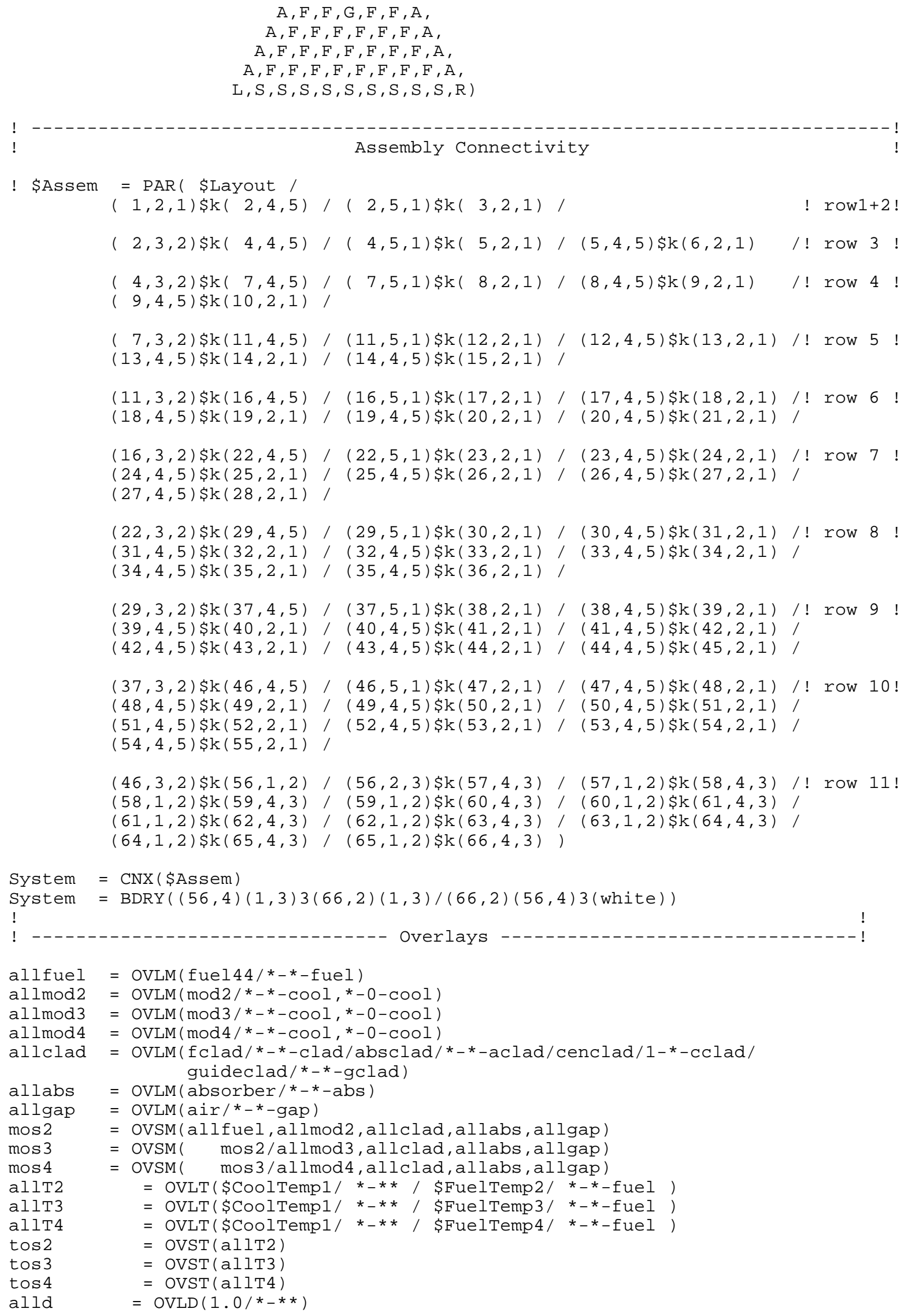




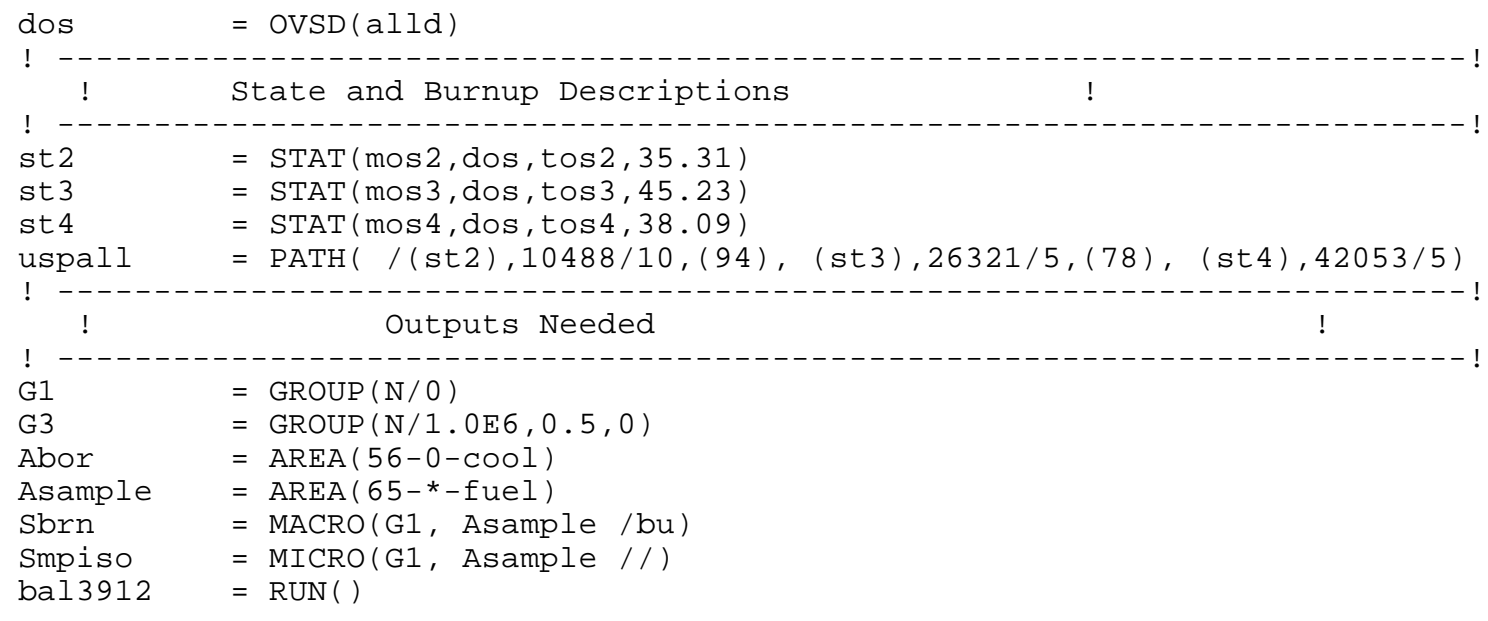


LISTING No. 6; THE HELIOS INPUT FOR SAMPLE 581 IN BALAKOVO-3:

+ THEL

bal3581 = CASE('library.bin'/'bal3581.hrf'/'VVER- Balakova-3; Sample 581')

!

!

\$AssemblyPitch

Simulating $1 / 6$ of Balakova-3 Assembly

This one is for sample 581

\$PinPitch

!

\$FuelHoleRadius

\$FuelRadius

\$FuelInnerClad

$\$ C l a d R a d i u s$

\$GuideTubeInnerRadius

\$GuideTubeOuterRadius

\$CentralTubeInnerRadius
\$CentralTubeOuterRadius

\$AbsorberRadius $\quad=\operatorname{PAR}(" 0.379 ")$

$=\operatorname{PAR}(" 23.6 ")$

Global

$=\operatorname{PAR}(" 1.275 ")$

$=\operatorname{PAR}(" 0.115 ")$

$=\operatorname{PAR}(" 0.3775 ")$

$=\operatorname{PAR}(" 0.386 ")$

$=\operatorname{PAR}(" 0.4582 ")$

$=\operatorname{PAR}(" 0.545 ")$

Guide tube

$=\operatorname{PAR}(" 0.6323 ")$

$=\operatorname{PAR}(" 0.48 ")$

Central tube

SAbsorberInnerClad $\quad=\operatorname{PAR}(" 0.386 ")$

\$AbsorberCladRadius $\quad=\operatorname{PAR}(" 0.455 ")$

\$rhole = PAR ("\$FuelHoleRadius")

Defining CCS structures

\$rfuel = PAR ("\$FuelRadius")

\$rcladi = PAR ("\$FuelInnerClad")

\$rclad = PAR ("\$CladRadius")

\$rcti = PAR ("\$CentralTubeInnerRadius")

\$rcto = PAR ("\$CentralTubeOuterRadius")

\$rbpa = PAR ("\$AbsorberRadius")

\$rbpb= PAR ("\$AbsorberInnerClad")

\$rbpc = PAR ("\$AbsorberCladRadius")

\$rgti = PAR ("\$GuideTubeInnerRadius")

\$rgto = PAR ("\$GuideTubeOuterRadius")

! Pellet hole radius

! Pellet radius

! Clad inner radius

! Clad outer radius

! Central Tube inner rad !

! Central Tube outer rad

! absorber radius

! clad inner radius

! clad outer radius

! guide tube inner radius !

! guide tube outer radius !

Fpin = CCS (\$rhole, \$rfuel, \$rcladi, \$rclad //gap, fuel, gap, clad)

Cpin = CCS (\$rcti, \$rcto//cool, cclad)

Gpin = CCS (\$rbpa, \$rbpb, \$rbpc, \$rgti, \$rgto//abs, gap, aclad, cool, gclad)

! -------------- Coupling order, power density, temps ------------------ ! ! Some of this may be needed, some may not

$\$ \mathrm{k} \quad=\operatorname{PAR}(4) \quad$ ! Internal coupling order

$\$ \mathrm{~kb} \quad \quad=\operatorname{PAR}(4)$

white $\quad=\operatorname{ALB}(1 / 1 / 1)$

\$PowerDensity2 $\quad=\operatorname{PAR}(40.460)$

\$PowerDensity3 = PAR $(41.929)$

\$PowerDensity $4 \quad=\operatorname{PAR}(37.149)$

\$FuelTemp2 $\quad=\operatorname{PAR}(891)$

\$FuelTemp3 $\quad=\operatorname{PAR}(892)$

\$FuelTemp $4 \quad=\operatorname{PAR}(822)$

\$CoolTemp1 $=\operatorname{PAR}(575)$

! Boundary coupling order

! Diagonal, equal elements

! Cycle 2 Power (W/gu)

! Cycle 3 Power ( $\mathrm{W} / \mathrm{gU})$

! Cycle 4 Power (W/gu)

! Cycle 2 Fuel Temp. (K)

! Cycle 3 Fuel Temp. (K)

! Cycle 4 Fuel Temp. (K)

! Hot coolant (K)

$\$ \mathrm{p} \quad=\operatorname{PAR}(" \$ P i n P i t c h ")$

! pin pitch

$\$ a$

$=\operatorname{PAR}(" \$ p / 2 ")$ 


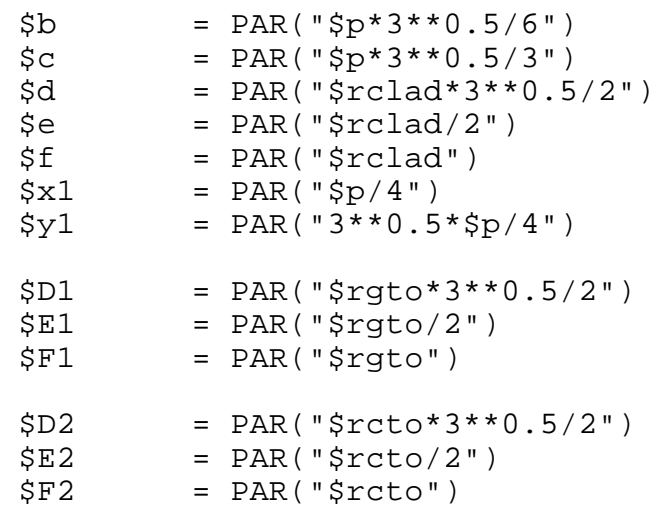




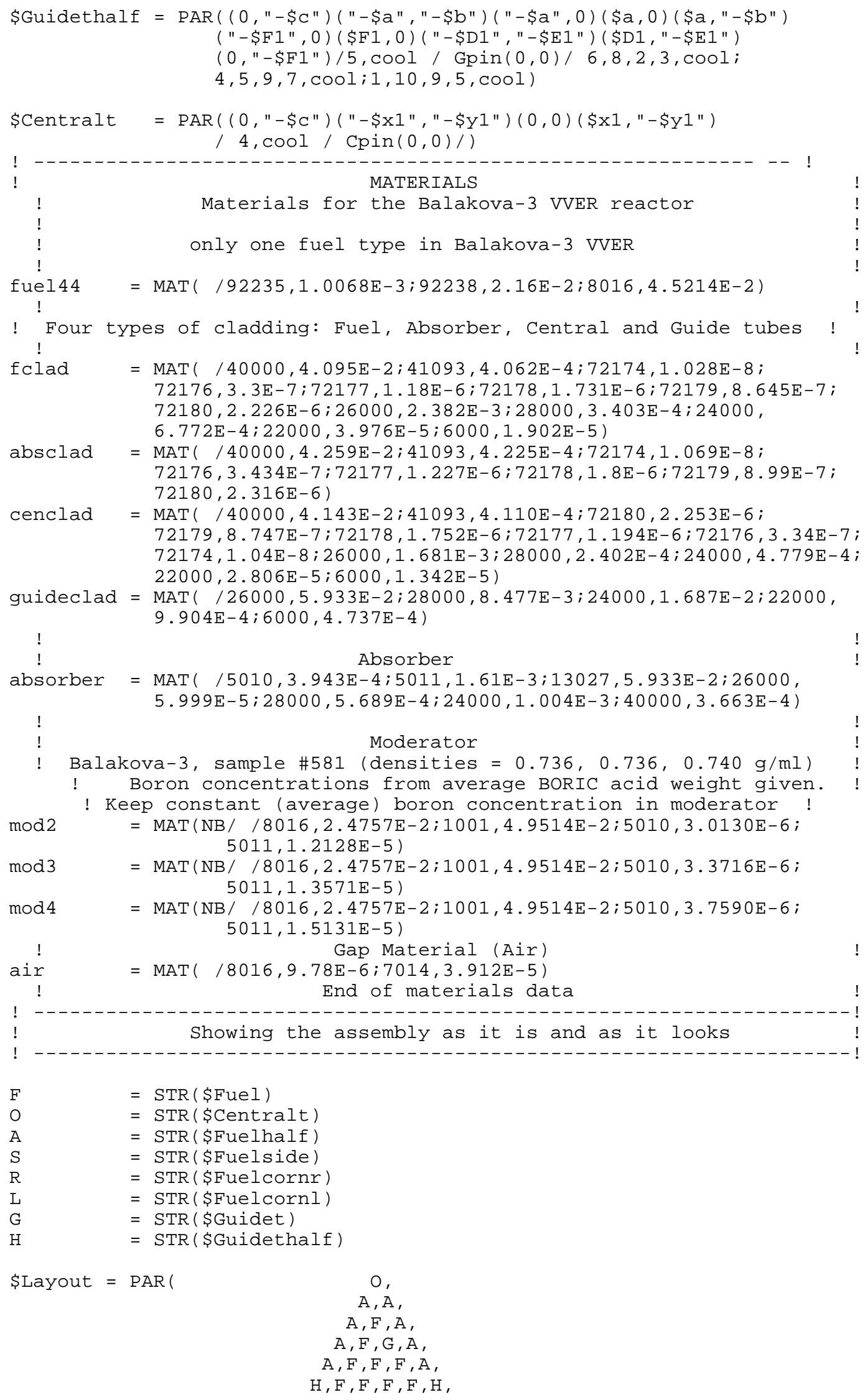




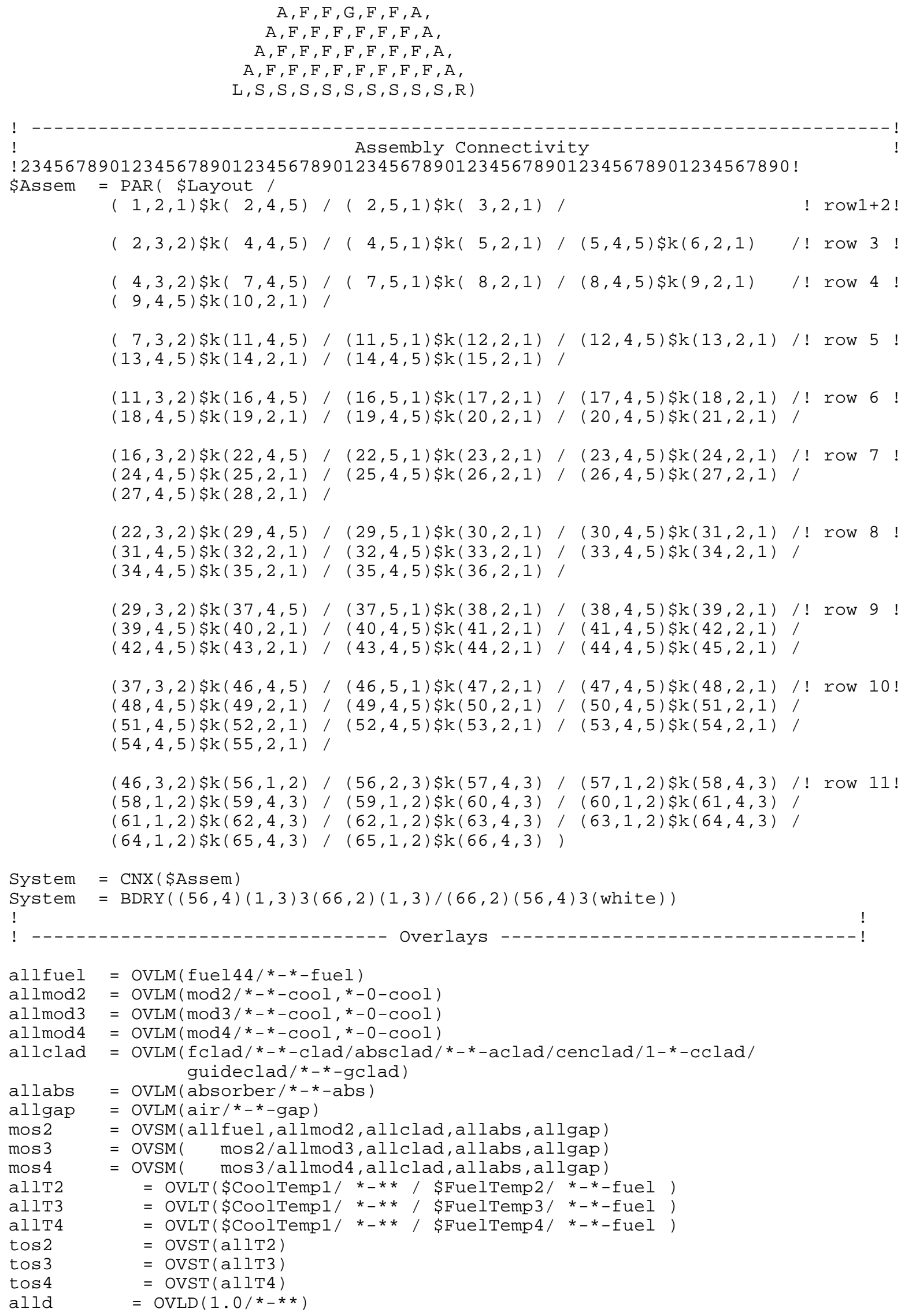




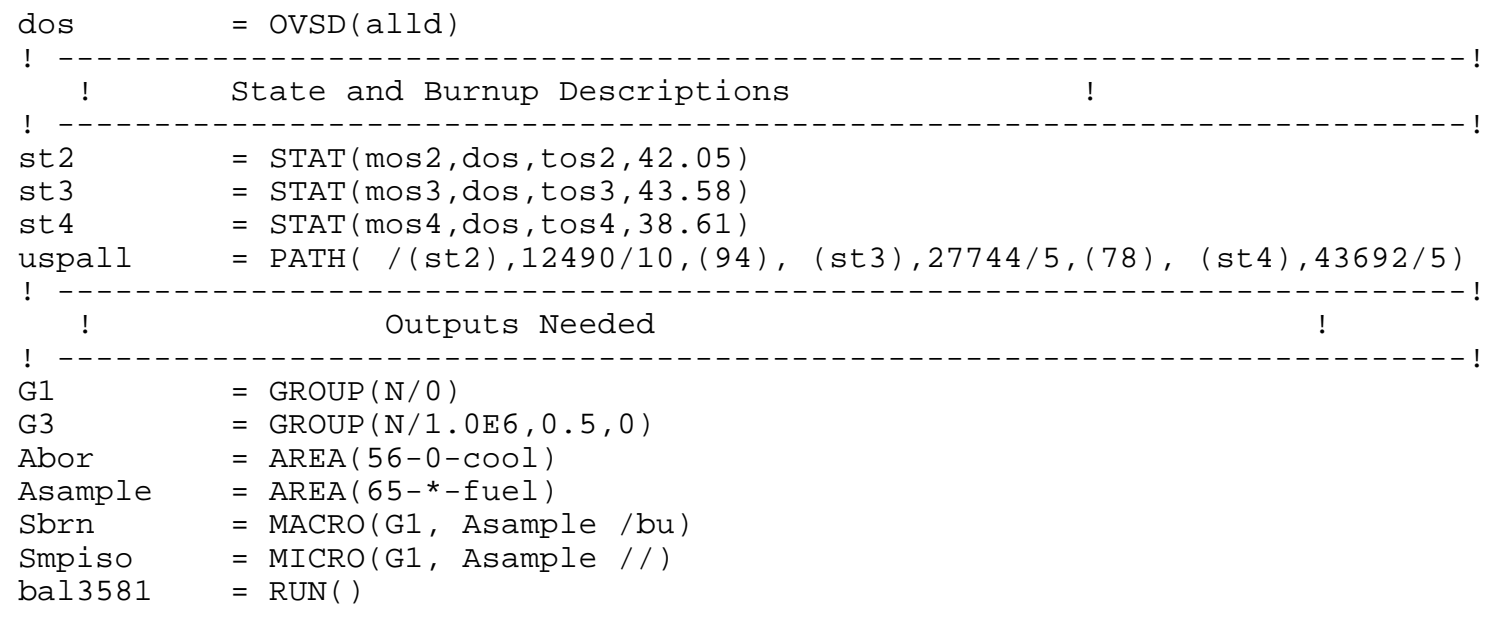




\section{INTERNAL DISTRIBUTION}

1. B. B. Bevard

2. B. L. Broadhead

3. J. J. Carbajo

4B8. W. C. Carter

9. E. D. Collins

10. B. S. Cowell

11. M. D. DeHart

12. F. C. Difilippo

13. R. J. Ellis

14. M. B. Emmett

15. J. C. Gehin

16. S. R. Greene

17. R. Holdaway

18. T. W. Horning
19. S. B. Ludwig

20. M. A. Kuliasha

21. G. E. Michaels

22B26. B. D. Murphy

27. D. L. Moses

28B32. C. V. Parks

33. L. M. Petrie

34B38. R. T. Primm III

39. W. J. Reich

40. C. H. Shappert

41. D. J. Spellman

42. R. M. Westfall

43. Central Research Library

44B45. ORNL Laboratory Records (OSTI)

46. ORNL Laboratory Records-RC

\section{EXTERNAL DISTRIBUTION}

47. M. L. Adams, Department of Nuclear Engineering, Texas A\&M University, Zachry 129, College Station, TX 77843

48. D. Alberstein, Los Alamos National Laboratory, MS-E502, P.O. Box 1663, Los Alamos, NM 87545

49. J. Baker, Office of Fissile Materials Disposition, U.S. Department of Energy, MD-3, 1000 Independence Avenue SW, Washington, DC 20585

50. J. B. Briggs, Idaho National Environmental and Engineering Laboratory, P.O. Box 16253855, Idaho Falls, ID 83415-3855

51. M. S. Chatterton, Office of Nuclear Reactor Regulation, U.S. Nuclear Regulatory Commission, MS O10 B3, Washington, DC 20555-0001

52B56. A. Chetverikov, State Scientific Center Research Institute of Atomic Reactors, 433510, Dimitvovgrad -10, Ulyanovsk region, Russia

57. K. Chidester, Los Alamos National Laboratory, MS-E502, P.O. Box 1663, Los Alamos, NM 87545

58. R. H. Clark, Duke Cogema Stone \& Webster, 400 South Tryon Street, WC-32G, P.O. Box 1004, Charlotte, NC 28202

59. W. Danker, U.S. Department of Energy, MD-3, 1000 Independence Avenue SW, Washington, DC 20585

60. D. Dziadosz, Innsbruck Technical Center, 5000 Dominion Blvd., Glen Allen, VA 23060

61. N. Fletcher, Office of Fissile Materials Disposition, U.S. Department of Energy, MD-3, 1000 Independence Avenue SW, Washington, DC 20585 
62. L. Holgate, Office of Fissile Materials Disposition, U.S. Department of Energy, MD-1/2, 1000 Independence Avenue SW, Washington, DC 20585

63. L. Jardine, Lawrence Livermore National Laboratory, P.O. Box 808, MS-L166, Livermore, CA 94551

64B68. A. Kalashnikov, Institute of Physics and Power Engineering, 1 Bondarenko Square, Obninsk, Kaluga Region, Russia 249020

69B73. J. Kravchenko, Russian Research Center "Kurchatov Institute," Institute of Nuclear Reactors VVER Division, VVER Physics Department, 123182, Kurchatov Square, 1, Moscow, Russia

74B79. A. Lazarenko, Russian Research Center "Kurchatov Institute," Institute of Nuclear Reactors VVER Division, VVER Physics Department, 123182, Kurchatov Square, 1, Moscow, Russia

80. S. Nesbit, Duke Cogema Stone \& Webster, 400 South Tryon Street, WC-32G, P.O. Box 1004, Charlotte, NC 28202

81. J. O. Nulton, Office of Fissile Materials Disposition, U.S. Department of Energy, MD-3, 1000 Independence Avenue SW, Washington, DC 20585

82. S. L. Passman, Sandia National Laboratories, Suite 110, 950 L'Enfant Plaza S.W., Washington, DC 20024-2123

83B87. A. Pavlovitchev, Russian Research Center "Kurchatov Institute," Institute of Nuclear Reactors VVER Division, VVER Physics Department, 123182, Kurchatov Square, 1, Moscow, Russia

88. K. L. Peddicord, Associate Vice Chancellor, Texas A\&M University, 120 Zachry, College Station, TX 77843-3133

89. U. Shoop, Office of Nuclear Reactor Regulation, U.S. Regulatory Commission, Washington, MS O10 B3, DC 20555-0001

90B94. V. Sidorenko, Russian Research Center "Kurchatov Institute," Institute of Nuclear Reactors VVER Division, VVER Physics Department, 123182, Kurchatov Square, 1, Moscow, Russia 